\title{
Anachronistic Space and an Architecture of Allegory,
}

By

Grant Oikawa, B.A.S.

\author{
A Thesis Submitted to the \\ Faculty of Graduate Studies and Research \\ in partial fulfillment of \\ the requirements for the degree of
}

Master of Architecture

Carleton University

Ottawa, Ontario

09-09-05

(C) Copyright 2005, Grant Oikawa 


\begin{abstract}
This thesis is a weaving of architectural threads that addresses the current stasis of our gaze, and the implications of that gaze on the loss of the art of architecture. By directly engaging an 'architecture of desire', the interested viewer's subjective participation is encouraged in the construction of the architectural project, in order to make associative links between the work and their own memories and experiences. Through the interactive exchange between the viewer and the mode of representation, the viewer is able to project their own inter-subjectivity and 'dwell' in the space of the virtual taken as the embodied speculative projection through the plane of representation. This interactive exchange of the virtual allows the architect to express greater depth, understanding, and ideas in his work, but is only possible by engaging a 'contemplative image' which does not rely on mediation. This is what will return the art to architectural representation.
\end{abstract}


To my

Mother and Father

for their undying support

and

Michael Jemtrud

who taught me to

look awry 


\section{Table of contents}

Introduction 1

Part 1

Chapter 1: Pornography / Eroticism

Chapter 2: The Virtual

Chapter 3: Cyberspace

Part 2

Chapter 4: The Gap

Chapter 5: The Image

Part 3

Chapter 6: The Project

Conclusion

Bibliography

\section{Appendices}

A

B

C 


\section{List of Plates}

Plate 1 Narrative One and Context (Text, Photograph, and Site Map)

Plate 2 Narrative Two and Context (Text, Photograph, and Site Map)

Plate 3 Narrative Three and Context (Text and Photographs)

Plate 4 Narrative Four and Context (Text, Photograph)

Plate 5 Carceri d'Invenzione di. G. Battista Piranesi (Title page: Imaginary Prisons of G. Battista Piranesi [2 ${ }^{\text {nd }}$ state]) From: Luigi Ficacci, Giovanni Battista Piranesi, (New York: Tashen, 2001) 31.

Plate 6 [Carcere XI] (The Arch with a Shell Ornament [2nd state]) From: Ibid., 41.

Plate 7 [Carcere XII] (The Well [2 $2^{\text {nd }}$ state]) From: Ibid., 43.

Plate 8 [Carcere XIV] (The Gothic Arch [2 $2^{\text {nd }}$ state]) From: Ibid., 44.

Plate 9 [Carcere XV] (The Pier with a Lamp [2 $2^{\text {nd }}$ state]) From: $\underline{\text { Ibid., }} 45$

Plate 10 Narrative Five and Context (Text and Photographs)

Plate 11 [Oxygen House] (Ideogram) From: Douglas Darden, Condemned Building: an Architect's Pre-text, (New York: Princeton Architectural Press, 1993) 148.

Plate 12 [Oxygen House] (Project Title Page) From: Ibid., 141.

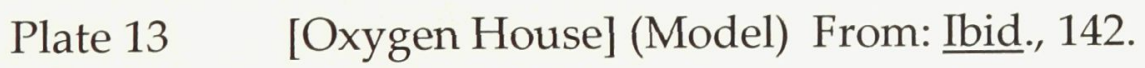

Plate 14 [Oxygen House] (Sub-text) From: Ibid., 143.

Plate 15 [Oxygen House] (Anatomical Section) From: $\underline{\text { Ibid., }} 149$. 
Plate 16 [Oxygen House] (Letter from Abraham) From: Ibid., 145.

Plate 17 Narrative Six and Context (Text and Photographs)

Plate 18 Adam Ironsides, the Steam Man (Original Promotional Posters) From: Andrew MacDonald, Lisa Di Valintino, and Norman Pinder, "Industrial Hamilton: A Trail to the Future - Adam Ironsides, the Steam Man" Adam Ironsides, the Steam Man, (Hamilton Public Library: December 8, 2005).

Plate 19 Horizontality (Collage and Line Drawing)

Plate 20 Verticality (Collage and Line Drawing)

Plate $21 \quad$ Repetition (Collage and Line Drawing)

Plate 22 Verticality - Model (Model)

Plate 23 Verticality - Model - Detail 1 (Model)

Plate $24 \quad$ Verticality - Model - Detail 2 (Model)

Plate $25 \quad$ Horizontality - Model (Model)

Plate $26 \quad$ Horizontality - Model - Detail 1 (Model)

Plate $27 \quad$ Horizontality - Model - Detail 2 (Model)

Plate 28 Repetition - Model (Model)

Plate 29 Repetition - Model - Detail 1 (Model)

Plate $30 \quad$ Repetition - Model - Detail 2 (Model)

Plate $31 \quad$ Planimetric Survey 1 (Photograph)

Plate 32 Planimetric Survey 2 (Photograph) 
Plate 33 Planimetric Survey 3 (Photograph)

Plate 34 Sectional Survey 1 (Photograph)

Plate 35 Sectional Survey 2 (Photograph)

Plate 36 Sectional Survey 3 (Photograph)

Plate 37 Elevational Survey 1 (Photograph)

Plate 38 Elevational Survey 2 (Photograph)

Plate 39 Elevational Survey 3 (Photograph)

Plate $40 \quad$ Section Collage

Plate 41 Drawing - Section

Plate $42 \quad$ Elevation Collage

Plate 43 Drawing - Elevation

Plate $44 \quad$ Plan Collage

Plate 45 Drawing - Plan

Plate 46 Computer Panel One - Curtain Wall

Plate 47 Computer Panel Two - Crane 


\section{List of appendices}

Appendix A Oxygen House From: Douglas Darden, Condemned Building: an Architect's Pre-text, (New York: Princeton Architectural Press, 1993) 141-56.

Appendix B

Drawing Details (Plan, Section, Elevation)

Appendix C Computer Panel Details (Curtain Wall, Crane) 


\section{Introduction}

In today's fast paced, information society, images are continually competing for the attention of our eye; so much so, that they have subverted the way in which we see the world. With the popularization of video camcorders and cameras there is hardly a moment that goes by without being documented. This incessant documentation is obliterating our subjective understanding of the world for objective recording, which in turn has removed our eye and replaced it with a lens. Thus we are reduced to scanning imagery and text in order to obtain its information without understanding or looking for any profound significance in its content. This is of particular importance to the jurisdiction of architecture as it exists specifically through representation, both in drawings and built form.

Architecture is a product of thought, rich with ideas, meanings and interpretations, which delineate it as an art form; however, with the shift to an 
objective being, architecture is losing its status as one of the arts, and is being reduced to how it looks on the high gloss pages of magazines and in books. Architects need to rediscover the importance of architectural representation and it's ability to inspire creativity and imagination. The major point of conflict in rediscovering architectural representation is the condition of the gaze itself; add to this the inherent contradiction between orthographic drawing and subjective interpretation, and it is almost inconceivable that architecture can be fated to anything other than that of the objectified image. Orthography, the primary representation technique in architecture, is used as documentation to map the past, present, or future construction of a building. However, the true architectural project does not exist solely in the construction of a building, but rather the process of ideation, representation, interpretation, and imagination. This creates the art of architecture and it is what we are losing.

This initiative is not new and can be traced through the work of Piranesi's Carceri (1761) or Douglas Darden's Condemned Buildings (1993), as well as the writings of Donald Kunze, Marco Frascari, and Robin Evans. These works have one major similarity, they are concerned with architecture as an art. Kunze states that "the rehabilitation of drawing in architecture has to do with a restoration of 
drawing as a direct correlate to the philosophical act of speculation"1 1 and that this act is unlikely to occur in the profession but only within an "artistic critical context." 2

In order to re-establish architecture and the architectural image within the realm of art, we must use the communicative properties of representation to better effect, and engage the subject directly through the framing of the content inscribed in the image. The weaving of a non-linear path through aspects that characterize the current status of representation and image, while at the same time building upon the existing traditions that define the paradigm of the "artistic-critical rehabilitation of drawing," ${ }^{3}$ will be the foundation upon which desire and the subjective are directly engaged to better effect in the architectural project.

This thesis is conceived in three parts, the first defines the terms that frame the thesis, the second articulates the process in which the art of architecture can be revitalized, and the third is the implementation of that process. The first part of this thesis consists of three chapters - "Pornography /

\footnotetext{
1 Donald Kunze, "Marks of the Abject Artifact," (Working paper, n.d.) 6.

2 Ibid.

${ }^{3}$ Ibid.
} 
Eroticsm," "The Virtual," and "Cyberspace" - that define the inter-subjective participation embedded in the act of viewing, and the projection of that subjectivity that allows the viewer to "dwell" in the space of representation. The second part consisting of two chapters - "The Gap" and "The Image" - uses that framework to posit a process in which the specific modes of representation will directly engage that inter-subjective projection. Thereby enticing the interested viewer to interpret the content of the image and therefore make associations to past experiences and memories. The third part of this thesis consists of the final chapter - "The Project" - that will then apply this process to a design project, specifically employing desire as a means to envelop the viewer in the embodied and speculative exchange between the representations and the subjective self.

Although this may be conceived as a distinct linear process, in actual execution, the intrinsic intertwining of these three parts contributes to the thesis as a whole. Making the document a series if interconnected elements, epitomizing the process of the project, and is further underscored by the insertion of the programmatic context as chapter dividers. This running narrative, separating the chapters, sets up the subjective interpretation which is an imperative step in constructing the architectural project and this document. 
I remember it well, the hollow echo of footsteps, the stale air mixed with hydraulic oil, an established voice deep from within inviting you inside. Its dark in there, as your eyes adjust, you can't help but feel out of place. There is little light, mostly concentrated from the window some thirty feet above you, the moonlight streaming in sets the aging rusted staircase aglow forcing your gaze upwards to the three and a half story semicircle of glass. The footsteps approach and there silhouetted in the moonlight is Cyrus C. Roe himself, descending from above he seems to have an angelic quality to his steps, not tall, Cyrus stands a humble five foot six inches, perhaps in his fifties, he has a youthful vigour to his build and as he nears it is reflected in his face, his clothes are worn, stained with the sweat and the grime from the days activities. Sensing your inquisitiveness, Cyrus points out that the staircase that he entered from was in fact removed from the Dere Marquette 18 (II), after it was laid up as a result of the Great Lakes Licensed Officers's strike and never sailed again, Cyrus had only stumbled upon it in after she was sold to the Luria Bros. of Chicago for scrapping. After trading his services, repairing a broken telegraph he was able to acquire it for himself.

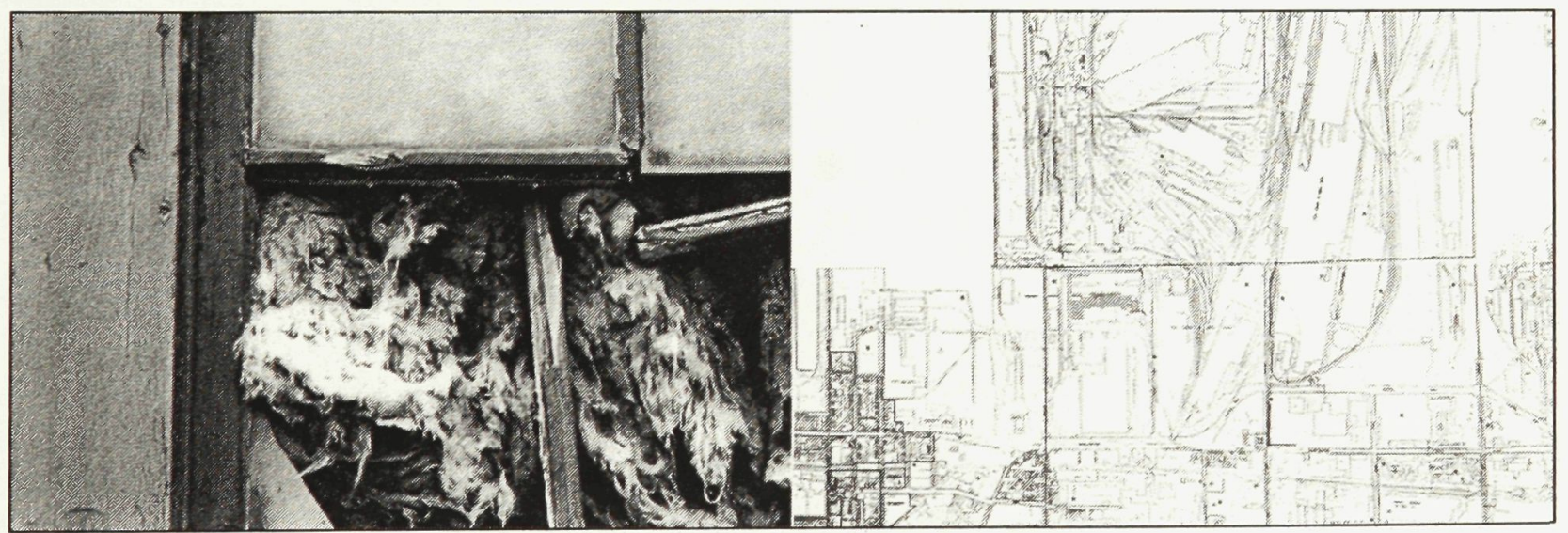

Plate 1 Narrative One and Context

Text, Photograph, Site Map 


\section{Pornography / Eroticism.}

In his writing to Federico Gonzaga in 1527, Aretino commented on the anticipated pleasures of a statue commissioned for the duke: "I understand that you the most rare Messer Jacopo Sansovino is about to embellish your bedchamber with a statue of Venus so true to life and so living that it will fill with lustful thoughts the mind of anyone who looks at it." ${ }^{4}$ For Aretino, all forms of representation carried an erotic potential. This potential lay not so much in the medium, as in the subject who could no longer contain his emotional reaction to the viewing of provocative imagery. Today, as Gilles Mayne elaborates in his introduction to Eroticism in Georges Bataille and Henry Miller:

If the adjective 'erotic' points to a quality, 'eroticism' seems to put into play a constellation of qualities whose unstoppable

${ }^{4}$ Gilles Mayné, Eroticism in Georges Bataille and Henry Miller, (Birmingham, Ala.: Summa Publications, 1993) 63. 
movement suddenly tears us away from the quiet ordering of our day-to-day reality. The erotic experience brutally confronts us with the following choice: either live such an experience fully, now, or altogether miss (the intensity of) such an experience."

In the erotic experience, the participants reach a point where society and societal values no longer hold the same significance to them. Eroticism has the distinction to be able to transgress the social order. ${ }^{6}$ this does not mean that it disregards social context but that the erotic experience comes from the tension between the impossibility of transgressing the social order and the impossibility of stopping the movement of transgression of the social order. In other words, it is only because the participants push against the possibility of transgressing a taboo that the possibility of transgressing this taboo becomes interesting. Through the force of the erotic we are driven from our daily experiences and come to enjoy to the highest degree violating our own rational selves and trying to sustain as long as possible this violation.

It is here important to distinguish between the erotic and the pornographic. In pornography we do not experience the urgency of choice (the

${ }^{5}$ Ibid., 1.

${ }^{6}$ The Social order is an idea used in sociology, history and other social sciences. It refers to a set of linked social structures, social institutions and social practices which conserve and maintain "normal" ways or relating and behaving in society. 
choice of submersion), since we have decided to rely on a medium that guarantees such specific excitement. The typical understanding of pornography is the genre supposed to "reveal all there is to reveal, 'to hide nothing', to register 'all' and offer it to our view."7 Slavoj Zizek indicates that pornography is intrinsically perverse and that this perversity is not only seen in the obvious fact that it "goes all the way and shows us all the dirty details;" ${ }^{8}$ it is perverse in that the spectator is forced to occupy a "perverse position." In order to understand this we must first acclimate ourselves to Lacan's 'eye and gaze'. The eye viewing the object is on the side of the subject, while the gaze is on the side of the object. In other words, when I look at an object, it is already gazing at me. The gaze marks the point from which the viewing subject is already gazed at. According to Lacan, "the gaze functions as a stain in the object, disturbing its transparent visibility and introducing an irreducible split in my relation to it." ${ }^{\prime 9}$ It is impossible to see the object from the point at which it is already gazing at me; since the gaze and the view are intrinsically dissymmetrical. The gaze is the mark

7 Slavoj Zizek, Looking Awry: An Introduction to Jacques Lacan Through Popular Culture, (Cambridge and London: The MIT Press, 1991) 109.

${ }^{8}$ Ibid., 110.

9 Elizabeth Wright, and Edmond Wright, The Zizek Reader, (Malden, Mass.: Blackwell Publishers Ltd., 1999) 15. 
(stain) that keeps me from looking at the object from a safe objective distance framing it as something belonging to my view. It is the point where the frame of my view is already inscribed in the content of the object. In pornography, instead of being on the side of the object, the gaze falls into the viewer, ourselves; there is no point at which the image from the screen gazes at us. It is only we, the spectator, which gazes unthinkingly at the image. It is the spectator who becomes objectified, not the actors on the screen as commonly believed; it is they who are the subjects, trying to provoke us sexually while we are reduced to the paralyzed object-gaze.

If pornography is generally considered to be the calculated arousal of desire, eroticism provokes us so much that the arousal of our desire seems to exist prior to and against our calculation. "Eroticism defies calculation and we sense that conversely, calculation might mark its very end." 10 In the erotic there is always an unknown, be it in the other person or in ourselves. This uncertainty is at the source of our growing desire: we can never tell what will happen next, and it is precisely this point that we get increasingly excited.

Eroticism is all around us; it is however, and all too often, that it is

10 Mayné, 1. 
overlooked. Belonging to the instantaneous, the erotic experience can only occur by fortune, a fortune that captures the participants entirely and one that they would not want to avoid. Our desire for the erotic has to do with our own subjective submersion with the object ${ }^{11}$; this unification of subject and object can be considered intimate, and therefore unstable, capable of "transforming both the viewer and the object of contemplation."12 Through this meshing of subject and object the participants surpass Lacan's interpretation of the real, transcending both time and space into a non-reality; a space of fantasy; a space based on our physical reality but at the same time suspended from it. In Lacanian theory, fantasy is the impossible relationship between the subject and the object-cause of its desire. This can be further demonstrated in Zeno's Paradoxes.

Zeno's first paradox: "As in a dream, the pursuer never succeeds in catching up with the fugitive whom he is after, and the fugitive likewise cannot ever clearly escape his pursuer; so Achilles that day did not succeed in attaining

\footnotetext{
11 The erotic experience has a direct correlation between an object and our interpretation and memory associated with a specific quality or characteristic of it. This correlation is an internalized or embodied connection, based upon the subjective understanding of our ontological condition.

12 Lynn Hunt, The Invention of Pornography: Obscenity and the Origins of Modernity 1500-1800 (New York: Zone Books, 1996) 63.
} 
Hector, and Hector was not able to escape him definitely."13 This is the example of the relation of the subject to the object as taken from the Iliad: the subject, faster than the object, comes closer and closer to the object, until the object is overtaken by it. The object can never be attained. The crucial feature of this distance of the object was properly indicated by Lacan when he emphasized the point that "Achilles could not overtake Hector (or the tortoise) since he is faster than Hector, he can easily leave him behind - but rather that he cannot attain him: Hector is always too fast or too slow." 14

Zeno's second paradox: the arrow that when fired, cannot move because at every point along its path it occupies a specific point in space. In the Odyssey, Heracles is continually shooting an arrow from his bow. He shoots it again and again but to no avail, the arrow does not move; it remains motionless. According to Zizek, the crucial factor of this scene is the location - "the infernal world in which Odysseus encounters a series of suffering figures - among them Tantalus and Sisyphus - condemned to repeat the same act indefinitely."15 Tantalus's torments clearly exemplify the Lacanian distinction between need, demand, and

\footnotetext{
13 Zizek, Looking Awry: An Introduction to Jacques Lacan Through Popular Culture, 4.

14 Ibid.

15 Ibid., 5.
} 
desire, the way that the goal of an everyday object is to satisfy some of our needs undergoes a kind of "transubstantiation"16 as soon as it is caught up in demand and ends up producing desire. The purpose for our demand of an object is not the need associated with that object rather the object becomes a network of intersubjective relations. This is better exemplified in the example of the mother giving milk to a child; the milk is no longer about nourishment, it becomes a token for her love. Freud uses the example of his daughter fantasizing about eating a strawberry cake. This is not a simple case of the "direct hallucinatory satisfaction of a desire." 17 His daughter did not simply want a cake, could not get it, and therefore fantasized about eating it. The important point here is that while she was voraciously eating a strawberry cake, she noticed how much her parents were enjoying watching her eat it. Her fantasy of eating the cake is about her attempt to form an identity that would satisfy her parents and make her the object of their desire.

Zeno's third paradox: we can never attain a certain distance $x$, because to do so we must first cover half its distance, and to do that we must cover one

\footnotetext{
16 Ibid.

17 Slavoj Zizek, The Plague of Fantasies, (London and New York: Verso, 1997) 9.
} 
quarter and so on to infinite. A goal, once reached, always retreats anew. In this third paradox, we can see the psychoanalytical notion of desire, or better yet Lacan's distinction between aim and goal. The goal is the final destination, while the aim is what we intend to do to get there. Lacan states that the real purpose of drive is not its goal, but rather its aim; the drive's ultimate aim is to reproduce itself as drive, to return to its circular path, and to continue on its path to and from the goal. The example of Sisyphus continuously pushing the stone up the hill only to have it roll back down makes this point; the real source of enjoyment is in the circularity of the path, "the repetitive movement of this closed circuit."18 When we look at the latter of Zeno's paradoxes and the Lacanian understanding of desire (aim and goal), we can make the link between the enjoyment of the repetitive movement within the closed circuit, and the repetition produced during the sexual act. What is perhaps of more interest is not this direct connection, but rather the underlying structure involved. Pornography is the production of certainty. For our initially fascinated eyes, "beautiful" bodies make "love" and we know that they are going to again. We begin to lose interest when we realize that they seemingly always do so according to some

18 Zizek, Looking Awry: An Introduction to Jacques Lacan Through Popular Culture, 5. 
predetermined formula. It is that predetermined formula that is the calculated arousal of desire. In Pornography as a genre, there is a reliance on mechanical reproduction, replication and repetition to establish, sustain and fulfill our desires.

What is most distinguishable between eroticism and pornography is our relationship and engagement with each. In the pornographic experience the goal is predetermined and its createdness is inherent in the genre. As such it relies almost entirely on the visual to convey the images used in the "fulfillment" of our desire. ${ }^{19}$ As stated earlier, the erotic experience involves our subjective submersion with the object; this is permitted to occur while the object is being experienced in its physicality. Our subjective submersion with the object is directly dependant with our embodied and speculative interaction with it. Since our subjective Being is built upon our memories, all past experiences are integral in the experience of any new object, in fact, it is those past experiences, (that form

19 The difference between the pornographic image and the erotic image is defined by their visual connection to the real. In the erotic image, there is a "film", or texture that is referenced from the real and placed into the image. This texture is what gives a particular tactile richness or quality to the erotic image. In the pornographic image, that texture is absent. The image is "clean", devoid of any grit, and because of this, the image lacks any visual indicators that begin to evoke the memory of the other senses. In this way the pornographic image only engages vision, where the erotic image begins to engage the other senses through synaesthesia. 
the subjective), combined with the new experiences relating specifically to the immediate objects that are integral to the erotic experience. As such the erotic experience differs from person to person depending on the specific level of engagement with the object. It is that intimate engagement with the object that enables the participant(s) to reach that heightened reality and allows them to transgress the social order. For them it is that transgression that heightens the formal understanding of the Real ${ }^{20}$.

20 Dino Felluga, "Modules on Lacan: On the Structure of the Psyche", Introductory Guide to Critical Theory. November 28, 2003, Purdue U, March 12, 2005, <http://www.purdue.edu/guidetotheory/ psychoanalysis/lacanstructure.html>. - Lacan sometimes represents this state of nature as a time of fullness that is subsequently lost through the entrance into language. The primordial animal need for copulation similarly corresponds to this state of nature. There is a need followed by a search for satisfaction. As far as humans are concerned, however, "the real is impossible," as Lacan was fond of saying. It is impossible in so far as we cannot express it in language because the very entrance into language marks our irrevocable separation from the real. Still, the real continues to exert its influence throughout our adult lives since it is the rock against which all our fantasies and linguistic structures ultimately fail. 
Creativity through understanding - that's what the sign beside the doors read, and it is only after several visits to his workshop do you realize, that this is not just a motto, it is how Cyrus works. As you exit the foyer to the left, passing under the sign, you now notice that the rusted stairs from the Pere Marquette 18 (II) were not the only thing in the room, in fact just to the left of the entrance, is another staircase, the first few steps are lit by the moon but soon trail off into darkness beneath the floor, chained off, the stairs seems cold and uninviting, as you pass by and look down into its abyss, the steps of Cyrus ahead of you are resonating below, creating low reverberations in the depths. Continuing on you enter into a large space littered with machinery, on first glance it looks like farming equipment, and a good portion of it is, but upon closer inspection you notice sewing machines, typewriters, pumps, and a myriad of other machinery and equipment, next to each of these is a table with various parts and pieces of the machinery as well as detailed drawings, sketches and notes done by Cyrus himself. Caught up in all of the quasi-scientific displays, you soon find your'self alone, meandering around, you can find Cyrus elbow deep in the engine compartment of a Westinghouse steam engine, or railway air brakes, depending on what he has in the shop that particular week, removing what looks like a one way check valve or pressure regulator, he examines it closely in his hand and frantically records it into the corresponding notebook.

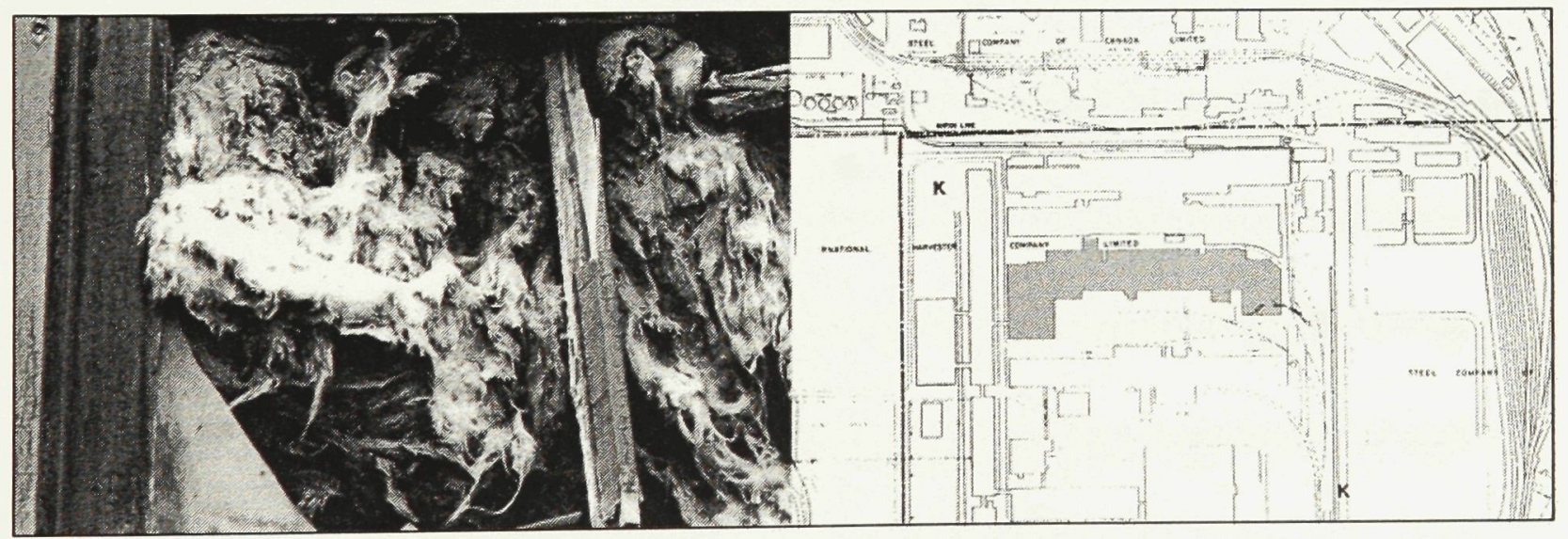

Plate 2 Narrative Two and Context

Text, Photograph, Site Map 


\section{The Virtual.}

The concept of virtuality has been with us for a remarkably long time. It is an idea that exists in Plato's writing, in which, both ideas and simulacra exist in a state of virtuality. The crucial feature of the virtual is that it requires direct engagement to understand and participate in it; where the pornographic experience reduces us unthinkingly to objective viewers, the virtual requires an interest view, this is obtained through the imagination. Coming from the root word 'image', imagination is not based on fantasy, but requires the mental construction of an object, an embodied speculative projection past the surface of the image. Unlike the current obsession of linking it to the use and invention of new technologies, we must realize that since there has been writing, there has been the idea of the virtual. This idea of the virtual exists as replication of reality, but since the very term 'virtual reality' dictates a phantasmatic extension of the 
Real, specifically the mind, will, and desire, beyond the body; this is a real that is not Real ${ }^{21}$. It is an apparent, rather than actual Real. Lacan refers to virtuality in terms of a mirror. "When a real object is reflected in a mirror image, the mirror contains behind its surface an object in a relation of inverted identity with the real object, existing in virtual space, the space behind the plane of the mirror."22 The mirror plane creates a "space" that reflects the real and duplicates qualities, and all of the visual characteristics of the object. Lacan specifies that we acquire an identity only through an encounter with the virtual, however that identity remains continually split, since we cannot perceive the difference between the real and the virtual "body", and that the space of virtuality is necessarily dependant on the real, inseparable from each other ${ }^{23}$. This is in fact not unlike the

\footnotetext{
${ }^{21}$ Based on the Cartesian tradition, Lacan states that "I am not my body, I have it" this is the possibility of virtual reality, in which, I can shift from one to another virtual body. This is further developed in Zizek's chapter entitled Memes, Memes Everywhere, from his Organs Without Bodies.

22 Elizabeth A. Grosz, Architecture from the Outside: Essays on Virtual and Real Space, (Cambridge, Mass.: MIT Press, 2001) 79-80.

${ }^{23}$ This comes directly from Lacan's definition of his mirror stage. In which the child, between six and eighteen months of age, first recognizes in the reflection of the mirror, his own image. The mirror stage corresponds to the demand of the child insomuch as the child misrecognizes in its own image, a stable coherent whole self, however, it does not actually correspond to the child. Called the "Ideal-I," the image is a fantasy constructed by the child to make up for the sense of loss. For Lacan the Imaginary continues to exert itself (in the form of role models) throughout our adult lives and does not simply mark the child's entrance into the symbolic; thus the imaginary is intertwined with the symbolic and in tension with the Real.
} 
erotic experience, the direct correlation between our subjective submersion with an object in the erotic experience and the inability to distinguish the split between the real body and the virtual "body", is at the core of both. The inconceivable split between virtual and real "bodies" is due to the embodied and speculative nature of the virtual. Therefore, our ability to understand or experience any virtual space is dependant on our distancing from the social order. This is the limit of the virtual, although it is distanced from the social order, it is still indebted to the real, not only in its contextual reality, but in the way that it is "inhabited". When referring to virtual reality or virtual worlds, the "mirror" (or the more advanced mirror, the computer screen) of the virtual will show us the double of the world while at the same time uncovering the very qualities of the Real that are perhaps hidden or unrecognized within the physical world, however with the virtual the boundary separating it from the real is not so black and white, the boundary is more of a grey formless mist. Let us look at a sci-fi novel by Robert Heinlein, The Unpleasant Profession of Jonathon Hoag, used by Zizek to describe the Lacanian Real.

"The action takes place in contemporary New York where a certain Jonathon Hoag hires the private investigator Randall to find out what happens to him after he enters his working premises on the (nonexistent) thirteenth floor of the Acme building - Hoag is 
totally unaware of his activity during this time. Next day, Randall follows Hoag on his way to work, but between the twelfth and fourteenth floors Hoag suddenly disappears and Randall is unable to locate the thirteenth floor. The same evening, a double of Randall appears to him in his bedroom mirror and tells Randall to follow him through the mirror where he is called by the committee. On the other side of the mirror, the double leads Randall to a great meeting hall where the president of the committee of twelve informs him that he is now on the thirteenth floor, to which he will be called from time to time for interrogation. During these subsequent interrogations, Randall learns that the members of this mysterious committee believe in a Great Bird supposed to breed small birds, her offspring, and to rule the universe together with them. The denouement of the story: Hoag finally becomes aware of his real identity and he invites Randall and his wife Cynthia to a picnic in the countryside where he relates to them the whole plot. He is, he tells them, an art critic - but of a peculiar kind. Our human universe is just one of the existing universes; the real masters of all worlds are mysterious beings, unknown to us, who create different worlds, different universes as works of art. Our universe was created by one of these universal artists. To control the artistic perfection of their productions, these artists from time to time send their creations one of their own kind, disguised as an inhabitant of the created universe (in Hoag's case disguised as a man), who acts as a sort of universal art critic. (With Hoag, there was a short circuit: he forgot who he really was and had to ask for the services of Randall.) The members of the mysterious committee interrogating Randall were only representatives of some evil lower divinity striving to interrupt the performance of the real "gods," the universal artists. Hoag then informs Randall and Cynthia that he has discovered in our universe some minor defects that will be quickly repaired in the next few hours. They will never even notice, if they simply make sure that when they drive back to New York, they do not - under any circumstances and despite what they might see - open the window of their car. Thereafter Hoag leaves; still excited, Randall and Cynthia start to drive home. Things proceed 
without mishap as they follow the prohibition. But then they witness an accident, a child is run over by a car. At first the couple remain calm and continue to drive, but after seeing a patrolman, their sense of duty prevails and they stop the car to inform him of the accident. Randall asks Cynthia to lower the side window a little: She complied, then gave a sharp intake of breath and swallowed a little scream. He did not scream, but he wanted to.

Outside the window was no sunlight, no cops, no kids nothing. Nothing but a grey and formless mist, pulsing slowly as if with inchoate life. They could see nothing of the city through it, not because it was to dense but because it was - empty. No sound came out of it; no movement showed in it.

It merged with the frame of the window and began to drift inside. Randall shouted, "Roll up the window!" She tried to obey, but her hands were nerveless; he reached across her and cranked it up himself, jamming it hard into its seat.

The sunny scene was restored; through the glass they saw the patrolman, the boisterous game, the sidewalk, and the city beyond. Cynthia put a hand on his arm. "Drive on Teddy!"

"Wait a minute," he said tensely, and turned to the window beside him. Very cautiously he rolled it down - just a crack, less than an inch. It was enough. The formless grey flux was out there, too; through the glass; city traffic and sunny street were plain, through the opening - nothing." 24

Zizek uses this story to exemplify the Lacanian real as the grey formless mist, which is encroaching on the space of the car. He illustrates that the crucial aspect here is the place where the real is manifested, the windowpane, separating the inside from the outside, constitutes the discontinuity and disproportion between

${ }^{24}$ Zizek, Looking Awry: An Introduction to Jacques Lacan Through Popular Culture, 13-14. 
the two realities. “To those sitting inside a car, outside reality appears slightly distant, the other side of a barrier or screen materialized by the glass. We perceive external reality, the world outside the car, as 'another reality,' another mode of reality, not immediately continuous with the reality inside the car." ${ }^{25} \mathrm{As}$ Zizek illustrates, the outside appears as a sort of cinematic projection on the screen of the window and that the phenomenological experience of the barrier is that it is ultimately fictional. The distinguishing feature shared between the screen of the window and the screen of the mirror is the space presented on the other side of the plane, in the case of the mirror separating the object from its "double", and in the case of the window separating two distinct realities. In either case this screen is present in the split. This is the split of the virtual, which is irreducible to either side of the screen. It is the moment that produces the virtual in the real and the real within the virtual. This is the case with all forms of virtuality, be it art, literature, cinema, or digital technologies; all forms of media have embedded in them this irreducible split between the real world, and its virtual double.

What is perhaps of most interest to us in the story presented by Heinlein is

25 Ibid., 15. 
that the perception between reality and virtuality has been distorted in a way that (when clarified later) undermines the typical understanding of what is real, and what is virtual. The direct connection to our current status of digital technologies is transparently evident, through the self-projection as universal artists, we can envision the process involved in the creation of these universes. However, through the image of reality that is painted in his work, Heinlein sets up the possibility in the reader's mind that his or her own (security) blanket of reality can be ripped away at any time; thus further underscoring the inability to render the split tangible.

We must be clear not to assume that by referring to the virtual, we are specifically dealing with digital technologies, when in fact they are of a particular sort. For now, we must consider this argument in terms of the Platonic idea of virtuality, whether it is text, image, video, or any combination of the three. Inherent in each of the Platonic examples is the screen of the virtual, or to use Kunze's term, "the plane of representation"26. This plane is significant to architecture since it is basis on which architecture is composed. The plane of representation, the paper on which an image is presented is sterile; that is, until it

26 Kunze, "Marks of the Abject Artifact", 3. 
becomes abjected or marked. "White paper, 'unmarked,' is virginal. Marks abject it, mark it as something, seal its fate." ${ }^{27}$ It is clear here that the paper does not physically disappear; but that we no longer see it as a screen, rather as representation, as image. By abjecting the paper, we cast it off as the screen of the virtual, which cannot be fully seen since it is now an integral part of the image, imbedded in the representation; it is through this abjection that we are unable to render the split visible. Through abjection, the corporality of the paper dissolves which in turn, assists our free embodied projection through the plane of representation and allows our subjectivity to dwell in the space on the other side of split.

By focusing on those Platonic modes of virtuality, we can specifically understand that our projection into the virtual is in fact an embodied experience, similar to that of the erotic. In both cases, the embodied experience is based on

$\underline{\text { Ibid. }}$ - Abjection is a term that is typically used to describe the casting off of unwanted items, and is achieved by marks. "Marks beget abjection, and abjection begets marks." Kunze suggests that for architecture the importance of abjection is based on the fact that distance is necessary because it is the frame that distinguishes us from what we want to avoid. Through the abjection of the plane of representation (the marking of the paper) the zero state of meaning is created. The zero state of meaning is eloquently described in Kunze's notes on the zero degree: "In architecture, the zero degree is often created through the absence of some element [the plane of representation] that is then defined - by its absence - as a mark, although it may not have existed as such before." 
the real, but at the same time suspended from it. This embodied experience occurs within cyberspace as it is a form of virtuality, but with cyberspace this projection into cyberspace comes with the physical mediation of the interface. Cyberspace exists as a series of interconnected nodes, and for the first time, the space of virtuality is not presented to us in the same way as a story or image is presented on a page, but requires a mediated interaction in order to reveal the information concealed within. There is a direct physical interaction that is made between the user the screen and the virtual. Because of this direct connection, cyberspace can be used to explain the exchange that occurs within the split of the virtual. The mediation occurring when engaging cyberspace, gives an outward expression to the act of transgressing the split between the real world and the space of virtuality. Therefore allowing us the means in which to understand our inherent subjective projection into the space of the virtual. 
Shortly after he is finished, Cyrus explains what he does here, dismantling various machines in order to learn from them, he performs these operations with the purpose of understanding their creation and the specific way in which they work or how newer generations of machines have evolved from the previous. He has been at this for many years, the stains left from spilt oil, the rust marks from weathered iron, the worn floor engraved from the heavy machines, all are indications of the history in this room, the depth of knowledge Cyrus has recorded. Every minute part gets recorded and logged into his notebooks, and it is with great pleasure that Cyrus will walk you through each of them, some detail the inner workings and mechanism of a pocket watch, others the complexities found within the internal combustion engine, or the intricacies of a transistor radio. He has thousands of books each with hundreds of diagrams dating back to the first day when he started his work, in fact as far back as he can remember, Cyrus has been captivated by all things mechanical, the first object that he disassembled was his mother's White Vo sewing machine, similar' to the one that now lies in the corner of his shop behind the pile of salvaged electric lighting fixtures saved from the James street theatre.

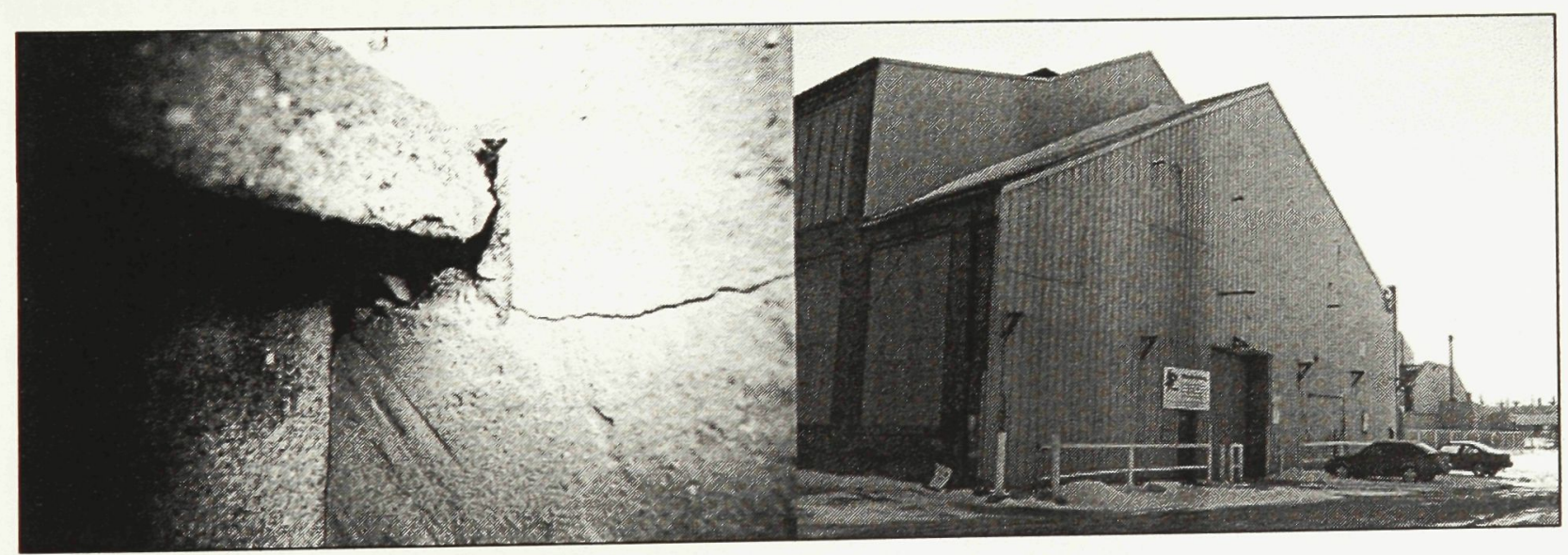

Plate 3 Narrative Three and Context Text, Photographs 


\section{Cyberspace.}

Cyberspace has been typically considered a parallel universe to our own generated and sustained by global communications networks and computers linking many different physical spaces and individuals through a shared "virtual" space, the space of linked, networked computers and their users. The (inter)net forges a link between the local, physical and material space of our 'reality' and the dislocated, 'virtual', "immaterial" space of the information sphere. This immaterial space of the internet is still predicated on the real, and the link that is made between the real and the virtual is a perceived not physical link. As in the previous examples of virtuality, the self projection into this space is still an embodied speculative projection. Where the virtuality of cyberspace differs from the virtuality of other mediums is the immediacy inscribed in its content, and the "connection" to other users. The net is made up of "islands of 
non locality", from one "location" to another, not travelling along a continuous line as the "information super-highway" metaphor eludes. With the net, the structures of non-locality that were first brought about by the telephone and television become amplified, intensifying with continual expansion. For the first time dislocation and non-locality, allow communication beyond the local horizon. Up to now of course, the viewer and the image were on the same local horizon. Even in an interactive computer installation, the viewer and the image were in the same space at the same time. Interactive net art makes it possible for the image and the viewer to be "at" any place at any time. Here, images and texts are not tied to specific localities, to the viewers' locality. "This interaction is not unidirectional, monosensory and irreversible, as was previously the case." ${ }^{28}$ Even in computer installations, the viewer's movements triggered a response in the digital image. The movements made within virtual space had no effects on our physical space. In computer based net installations, the relation between the image and the viewer is reversible, it takes place in two directions: information moves from the viewer to the image, then back from the image to the viewer;

28 Peter Weibel and Timothy Druckrey, Net Condition: Art and Global Media, (Cambridge/London: The MIT Press, 2001) 14. 
from the real to the virtual back to the real. Actions in virtual space influence the sequence of events in physical space and the events in physical space influence the sequence of events in virtual space. "Interactivity which is reversible and which dislocates is the new characteristic of net-based computer installations." 29

There are three distinct and separate levels of cyberspace that are of any importance to us: the technological, the psychological, and the ontological; which can be translated into mechanization, simulation, and interpassivity. These three levels of interaction in cyberspace are directly based on the technologies conceived within the information sphere.

\section{( I-Mechanization)}

In the level of mechanization, technology is seamlessly integrated into our corporal lives. Found specifically in the mechanical systems of everyday spaces, these systems are designed to create healthy and comfortable living and working environments. With them everything from climate and lighting to security and even irrigation is controlled through the use of complex lighting, heating/cooling, air and moisture sensors. What is of particular importance with these systems is the loss of immediate control and connection to our physical reality. This level of

29 Ibid., 14-15. 
cyberspace renders the direct physical exchange between the real and the virtual visible, the physical conditions of the real world affect the information in the virtual which in turn re-adjust those same physical conditions. These systems require a distancing from external reality (that being outside of the building envelope) to create an isolated, sterilized, "ideal" space free from external particulates and volatile, natural and social phenomena. What these spaces bring to the subject is a sense of safety, of being suspended from the influence of the other, as well as an "enhanced" way of life, through the autonomic functions of the banal everyday living.

\section{( II - Simulation)}

This possibility of simulation could be considered a surplus in that we are creating a world parallel to our own, one that is the limitless possibility at the heart of virtuality. In it, the physical attributes from our current reality are the basis of the simulation, however they can be suspended and altered at will, with no consequence; since this space is not navigable with a physical body; we are instead what Zizek calls 'organs without bodies', and as such we could leave our own physicality and inhabit these new spaces free of physical restraints; 
ultimately able to opt out of our current world for the digital one $\mathrm{e}^{30}$. With the God-like choice of simulation, "we have passed over the extreme of technology, into technology as an extreme phenomenon." ${ }^{31}$ Beyond this there is no longer any reversibility in the world. With it, there is a transformation that Baudrillard describes where the world is becoming a brain, and the brain is becoming a world. This possibility of simulation in its ultimate form comes from the desire of integration between the physical and the virtual, one where each are dependent on the other to endure, and as such can never be separated back into their distinct and original forms. This specific desire sees the integration of a physical and digital presence into one entity that transforms the relationships of society, community, physicality, location, sexuality, personal intimacy, and shared workspace; not just in the digital, but in the Real as well. This desire to transform our reality into an 'objective reality' brings with it a loss of immediacy and physical presence. Perhaps what is simultaneously admired and feared is the ability for these technologies to supplant and replace those previous technologies

\footnotetext{
30 This choice is only possible since for Zizek, there are two deaths, the first is a biological death, in which our bodies fail, and eventually decompose, this is the death in the Real. The second is a symbolic death, not involving the destruction of our actual bodies, but rather the symbolic order, and our subject states.

${ }^{31}$ Jean Baudrillard, "The Perfect Crime", (London Verso 1996) 33.
} 
that have already been accepted into everyday use.

$$
\text { ( III - Interpassivity) }
$$

Zizek offers that the engagement with cyberspace, through its distancing from the symbolic order ${ }^{32}$, can allow particular structures of fantasy to surface. “This distancing from actual experience most commonly takes the form of 'interpassivity', because the surfer is active with the intention of rendering the 'anonymous "big other"' passive, so that he or she can reach the security of a narcissistic identification, and therefore be inscribed in the symbolic." ${ }^{\prime 33}$ On the opposite side of the spectrum Zizek invests the term interactivity with a contrary effect; the subject is passive while another actively performs its task. What Zizek determines is that the two terms are not mutually exclusive; in fact, they are interdependent since society can provide active form to give an inward passive feeling an outward expression, and therefore open the gap between the inner and the outer, between reality and appearance. This gap offers three possibilities: the gap allows the false display of a ritual, conversely the ritual can provoke genuine

\footnotetext{
32 Felluga, "Modules on Lacan: On the Structure of the Psyche", Introductory Guide to Critical Theory. - The symbolic, through language, is the pact which links subjects together in one action. The human action par excellence is originally founded on the existence of the world of the symbol, namely on laws and contracts. Whereas the Real concerns need, the symbolic is about desire. Once we enter into language, our desire is forever bound up with the play of language.

33 Wright, 102.
} 
feelings of someone going through the motions, and the gap can stretch between the ritual itself and the feelings that they are trying to avoid. Zizek uses Tamagochi, a Japanese toy from the 1990's to illustrate this gap between inner and outer, (feeling and expression). The toy reduces the other to an entirely virtual existence on a screen that requires acting as if there is a living being behind the screen. The notable feature of this toy is that through the use of beeps and flashing lights, the being (usually some kind of pet, a dog or cat) demands nurturing attention from the child who then responds - through a sequence of buttons - with food or water; the Tamagochi can even demand that the child play with it, if it is bad, it needs to be disciplined, again through the proper functioning of the buttons. If the demands of the object are not met it "dies" and only has one more life; if it dies again it simply stops working and needs to be replaced. "Since this ultimate 'death' has caused numerous nervous breakdowns and deep traumas in the children who owned them, recent versions of Tamagochi contain endless possibilities of resuscitation - that is, after the pet-object dies, the game is simply over, and one can start again." ${ }^{34}$ This obviously obscures what was so intriguing and traumatic about the original, that its death was final. What

34 Ibid., 106. 
is of particular interest is that we are dealing with a mechanized toy, one that ultimately provides satisfaction by acting as a rambunctious child demanding our attention. Our satisfaction is met by our being compelled to care for and nurture the object at any time it wants. This is what Zizek calls the "ultimate exemplification of the obsessional's object, in so far as the obsessional's object of desire is the other's demand." 35 Thus the other has been reduced to an entirely virtual presence, no longer a true intersubjective other, rather simply a screen, a stand-in for the non-existent pet that just signals the pets demands. Thus we have pure signals with no influence, the "game has been reduced to the symbolic order, to the exchange of signals, with no referent beyond it." 36 What is interesting is that the Tamagochi doesn't mean to replace a child's pet through realistic, life-like imitation; it reduces it to the symbolic level. This allows the Tamagochi to be functionally active unlike a doll, which is passive, the Tamagochi takes the active initiative which is the crucial feature of the toy. What this means is that cyberspace is not a limitless space of simulation, or the mechanization of systematic control, but rather inscribed in the symbolic order, and is therefore an

\footnotetext{
${ }^{35}$ Ibid., 107.

36 Ibid.
} 
uncontainable field in which we are already and always participating. The Tamagochi does not offer the possibility of artificial intelligence or thinking machines, rather it allows us to satisfy our ontological need to nurture and care for the other. The Tamagochi allows us to fulfill our desire to care for humanity, but it perverts the interaction converting it to a necessary "idiosyncratic pathology which should be satisfied in private, without bothering your fellow human beings." ${ }^{37}$ Thus, Tamagochi represents the idea that we have no need for the other in that we can fulfill all of our ontological needs through these "(inter)active objects" on the symbolic level. The Tamagochi is structured on the same principles as our engagement with virtuality, the only difference is that the interaction between the subject and space of the virtual is given an outward expression, it is made physical. The same structures occur in all modes of virtuality; with cyberspace that exchange is given a tactile nature.

In all three levels of cyberspace, and all virtual mediums for that matter, the dialogue between the real and the virtual space is the exchange of the virtual, and consists of the movement from the virtual to the real back to the virtual or vice versa. With the example of mechanization, a pragmatic and technical

37 Ibid., 109. 
exchange occurs, that is the inverse of the example of simulation; with it, the movement of exchange occurs from the virtual to the real back to the virtual, where the example of simulation moves from the real to the virtual back to the real.

In either case, within this exchange, there is a gap that opens up. It is that gap that permits our subjective to "enter" the space of the virtual. This gap is of particular significance to the realm of architecture, as it is an art that specifically deals with virtuality in its creation and representation. The gap created allows the architecture to exist on paper, since our interactive exchange with the virtual permits us to enter the space of the representation. Given that the space of virtuality is predicated on the real and is in fact inseparable from it, our experience of the design presented is analogous to the subjective submersion that we aspire to in the erotic experience. 
If you are lucky enough to be with Cyrus on the day of a new shipment, or better yet if you are there when it arrives, then you have the chance to experience the electricity that fills the air on that sacred day, his face lights up like a child's on Christmas, eager to see what has been delivered. Very rarely does Cyrus ever turn anything away, in fact, this is the day that he makes room in his shop for the new arrivald, after categorizing the parts, he will load them onto the crane and lower them into what can only be described as a crypt for the dismembered machines, the platform for the crane is as large as a room, about nine by twelve, and is controlled from a place somewhere over the main floor. As the crane lowers into the crypt, and the light pours in through the opening of the floor, this is your first chance to see into the deep cavernous space beneath your feet, looking down and to the left, the space seems to go on uninterrupted forever, the light never reaching the bottom, you can begin to see some of the larger relics from past dissections, the hydraulic piston from a front end loader still caked with mud from its days spent forging new roads, or the bruised hull of the city's first harbour patrol boat, this is where everything gets stored, to be called back at a later date, for whatever purpose Cyrus sees fit. Down and to the right of the crane supports, wrapping around the north side of the building is multileveled storage where the majority of the parts end up. Here the boxes from his shop are coded with dates and brief descriptions of the object and stored on the many shelves and tables until they are needed again.

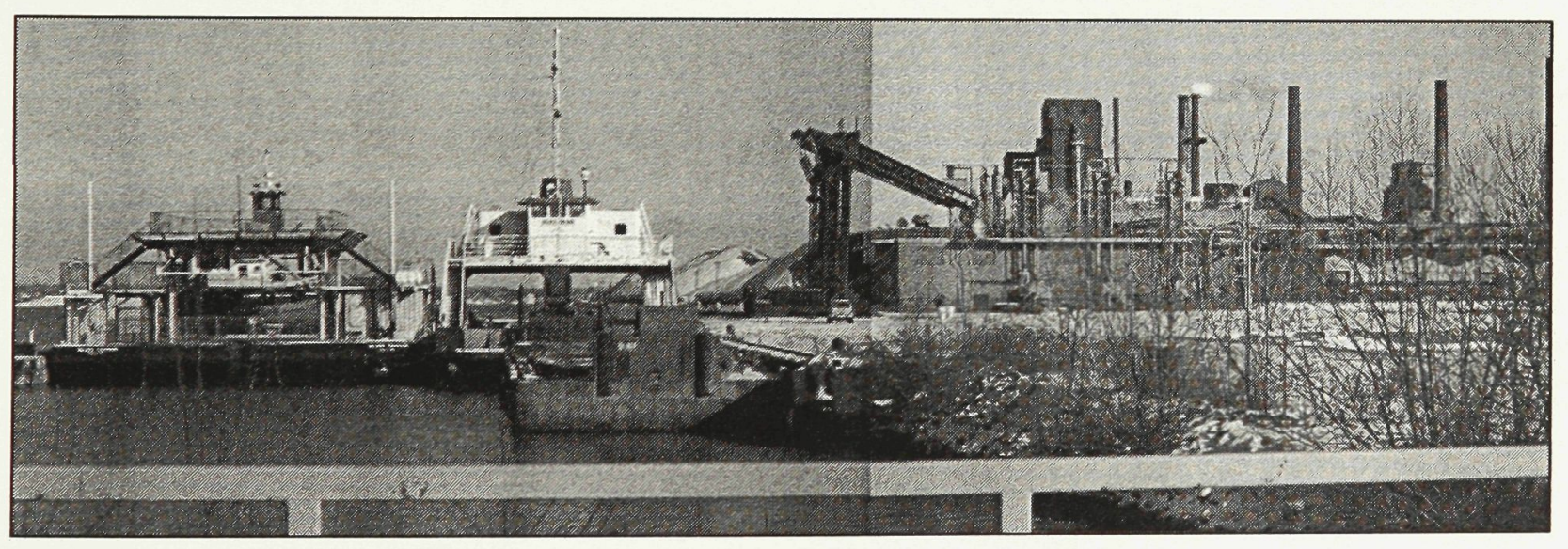

Plate 4

Narrative Four and Context

Text, Photograph 


\section{The Gap.}

The gap created through the exchange of the virtual resides on the side of imagination, "our habits of fitting out time in the costumery of space, and casting time into roles decided by those costumes comes from our need to measure and control time." 38 This is the basis of the 'gap'. There are two orders of time according to Kunze; there is first the order of experience, and the second, the order of memory. The order of experience is based on the subjective, while the order of memory is not a collective memory as such, however it resides in the way that an object is assessed and reassembled. They are what Kunze calls "the alternative orders", which are capable of overthrowing what the object first appeared to be. In both orders, memory and experience, the "time" that exists is

38 Donald, Kunze, "Evil Enchantment: The Anacoluthic Structure of Architectural Composition", (Working paper, n.d.) 1. 
not a linear time, rather it is a vertical or anacoluthic time. ${ }^{39}$ This anacoluthic time is in opposition to the main linear progression of the creation of architecture, and it is by this gap created, through which the exchange between the real and the virtual takes place, that the architect finds his expression. When an architectural idea is in the act of conception, the architect is already beginning to transgress the gap, and therefore must be fluent in both experiential and memorial orders of time. To expand on this, we must first understand the goal of the architect, and that of Architecture.

The goal of the architect is not to create space, or even beautiful space; these guises are superficially inserted to give an easily understandable description for the role of the architect. The fundamental goal of the architect is to create experience, and it is the implications of space, materiality, structure, detail, and colour (essentially tectonics), combined with subjective interpretation

39 In his unpublished manuscript, Evil Enchantment, Donald Kunze hypothesizes on the anacoluthic structure of architectural composition. In it, he stresses that there are two orders of time, that of experience (controlled in performance and reading, but open to chance in painting sculpture and architecture), and that of memory (where parts of the work are assessed and reassembled, capable of overthrowing the original understanding that the work first seem to be.) Kunze stresses that architecture follows these concealed models of space and time found within art and literature. This time is not a continual lateral time, rather, " a-spatial medium of many facets, capable of inversions, contaminations, and visitations." It is this idea of time, and that as architects we must share the role of creator, that puts the viewer in the place of the maker. 
and memory, that the architect uses in order to create that experience. This experience is not necessarily a phenomenological experience; the architect as artist is primarily concerned with representation, in conveying ideas, inspiring creativity, and ultimately bringing a built work into being. The experience created is in fact an embodied speculative experience, in which the viewer experiences the architectural project in a state of virtuality, through the page of the paper. We can observe that if experience is paramount to Architecture, and that experience is ultimately mediated by and through a subjective process, the architect must actively engage the subjective in order to transgress the gap between representation (the only tool of the architect) and the represented (the architectural project).

According to Kunze, our modern view has evolved out of a need for control, and the language of control is space. Space, unlike time, can be controlled or manipulated since it is "an invisible container that conditions what it holds yet seems to stay neutral." 40 This idea had remained constant until it was challenged by both mathematicians and painters, with the concept of the "fourth dimension". This was not specifically time, but as Kunze refers to it, a space that

${ }^{40}$ Ibid., 2. 
can escape time. This fourth dimension has been embedded in poetry, theatre and fiction for quite a while, however it was simply too subtle to observe; the ability for these narrative modes to "warp", or bend time was just accepted as a necessity required to present a story, either on stage or in a book. Time has long been considered measurable and perhaps scientific, that is, until we realize it as a construct of the mind; it is then that we may consider time as an artificial, warped entity. Kunze is clear to point out that we are not to assume that time is a fiction of the imagination, but that its "form and definition are applied by human experience, and that there are as many ways of living time as there are aspects of the human condition." 41

It is the malleability of this time/space construct that renders the gap an autonomous subjective split between representation and the represented. Robin Evans, in his Translations from Drawing to Building, indicates that he was struck by "what seemed at the time the peculiar disadvantage under which architects labour, never working directly with the object of their thought, always working at it through some intervening medium." ${ }^{42}$ This indirectness or displacement

41 Ibid.

42 Robin Evans, Translations from Drawing to Building, (Cambridge: MIT Press, 1997) 4. - Evans 
within contemporary architecture is the most distinguishing feature from the other visual arts, and is what makes it comparable to the Tamagochi. Just as the Tamagoch i is inscribed in the symbolic, so to is the architectural drawing, given that the drawings are marked as signs, limited to the symbolic exchange. Where painters and sculptors work primarily (the exception being preliminary sketches or maquettes,) with the object at hand, architects work at their object through a transubstantiated process. By using representation to present the architectural project, the architect is reproducing the same effects as the Tamagochi by directly engaging the subjective other through the medium. According to Evans, this leaves Architecture with two options: we choose to join it to the other visual arts by definitively stating that the work of the architect is only that which he manipulates by his own hands, or that the use of the "transmissive, communicative properties of the representation be used to better effect." 43

is referring to the gap between drawing and the work of architecture in its physicality, where the drawings are less concerned with what they represent, and more concerned with their own constitution. For our purposes, we are isolating the drawings specific relation to the architectural project itself, and the process in which we take to realize the building.

${ }^{43}$ Ibid., 5. 
The first requires a divorce from the symbolic order; in this case architecture would exist separately from the political and social order. Evans indicates that this is what has occurred in the schools; for him, particularly architectural drawing has gone through a rediscovery. This rediscovery has "made drawings more consumable, but this consumability has most often been achieved by redefining their representational role as similar to that of early twentieth-century paintings, in the sense of being less concerned with their relation to what they represent than their own constitution. And so the drawings themselves have become the repositories of effects and the focus of attention." 44 Evans refers specifically to architectural drawing in his text, however for our purposes we shall expand this to all architectural representation; whether it be drawing, modeling, or the digital. What is occurring is the same within each of the mediums; they are becoming more and more consumable as objects in themselves.

The 'thing-ness' composing contemporary architectural representation is directly opposed to the idea of subjectivity and anacoluthic time being proposed as the 'gap' in which the architect finds his expression. If the constitution of these

\footnotetext{
44 Ibid.
} 
"representations" is leaning more to the side of art (painting and sculpture), then what we are losing is the very essence of the representation itself. The art(full)ness of architectural representation is not in question here, as all representations have an artistic quality to them, rather we are questioning the loss of representational properties of the work in itself. With this loss comes objective understanding, not the subjective experiential qualities that were inherent in the representations. It is here perhaps important to distinguish architectural representation not for its communicative objective role, as construction documents but at the fundamental level of architectural thought and idea. It is this facet of representation that we are addressing; in it, we must be critically precise with, and within each of the mediums used in order to investigate, explore, and articulate any architectural idea.

Currently, with drawing, in order to engage experiential representation, the common attitude is to discard orthography altogether (the "objective" vantage point) for perspective, consequently displacing the viewer into the same space as the image. The idea is to frame a 'realistic' image from the inhabitants standpoint, (that being the same as the viewer), and present it to him. This reduction to life-like representation reduces the image to a "flat" reading, into a 
one to one relationship; what I see in the image is what it is, there is no depth beyond this reading, no deeper interpretation to the image. This flat reading has been evident for quite some time. Looking back to the etchings of Piranesi, his work in the mid-eighteenth century was a critical inquiry into this reality. Trained as an architect, Piranesi had numerous skills in a variety of technical fields as well as the arts. "A master draftsman of both imaginary and real subjects, as well as of architecture and stage design, Piranesi was also expert in the theory and practice of engineering and geometry. In addition, he was an extraordinary etcher." 45 The Carceri series (c.1761), Composed as 15 plates plus the title "Carceri d'Invenzione di G. Battista Piranesi" (Imaginary Prisons of G. Battista Piranesi), (Plate 5) is perhaps his most notable work, and of particular significance to the art of architecture. Often challenging Alberti's laws of perspective ${ }^{46}$ through ocular devices, Piranesi fathered a new idea in representation, the veduta (architectural vignette). While employing perspective in his etchings, Piranesi critiqued the very role of perspective in representation.

\footnotetext{
${ }^{45}$ Luigi Ficacci, Giovanni Battista Piranesi, (New York: Taschen, 2001) 7-8.

${ }^{46}$ In the early $15^{\text {th }}$ Century Leon Battista Alberti, formulated a method of constructing perspectives. In his system, a grid is placed between the viewer and the subject which then becomes the screen in which the painted world can be seen. The orthogonal projection of parallel lines represent the visual rays that connect the viewer's eye to a spot in the distance. The spot where these lines converge marks the vanishing point for the perspective.
} 
On first glance, the Carceri Etchings (Plates 5-9) seem to be typical perspective images, but by interposing subtle but multiple perspectives Piranesi sets up the contradiction that forces the viewer to actively contemplate the image. In Carceri XIV "The Gothic Arch", (Plate 8) there are several key instances where different horizon lines merge together to create the one (dis)continuous perspective. These instances are best described by Ulya Vokt-Göknil:

The open staircase to the left ascends, bends towards the right at a right angle, at the base of the pier, to form a bridge whose width completely fills the space between the two piers. The bridge finishes upon the central pier. When we give an upward glance at the arch which joins the central pier to that on the left, it makes us dizzy because at the bottom the distance between the two piers is barely that of a flight of stairs. At the level of the base, in front of the staircase going to the right, we suddenly notice that the branch does not at all remain between the two piers, since it ends in a platform situated just in front of the pier itself. The second part rising steeply to the right, begins at the edge of the pier. If we follow the joinings of the two pairs higher up, we become more disoriented than ever: we suddenly realize that this vast interior only has two naves, rather than three. The two piers that we had viewed from the bottom as parts of two parallel arcades, observed from above belong to the same group. The space that the flight of stairs going to the right occupies, in reality, does not exist. ${ }^{47}$

Each of these moments brings together the collapse of space, the discontinuity ${ }^{47}$ Manfredo Tafuri, The Sphere and the Labyrinth
Footnote written by Ulya Vogt-Göknil in Giovanni Battista Piranesi pp 34-35. 


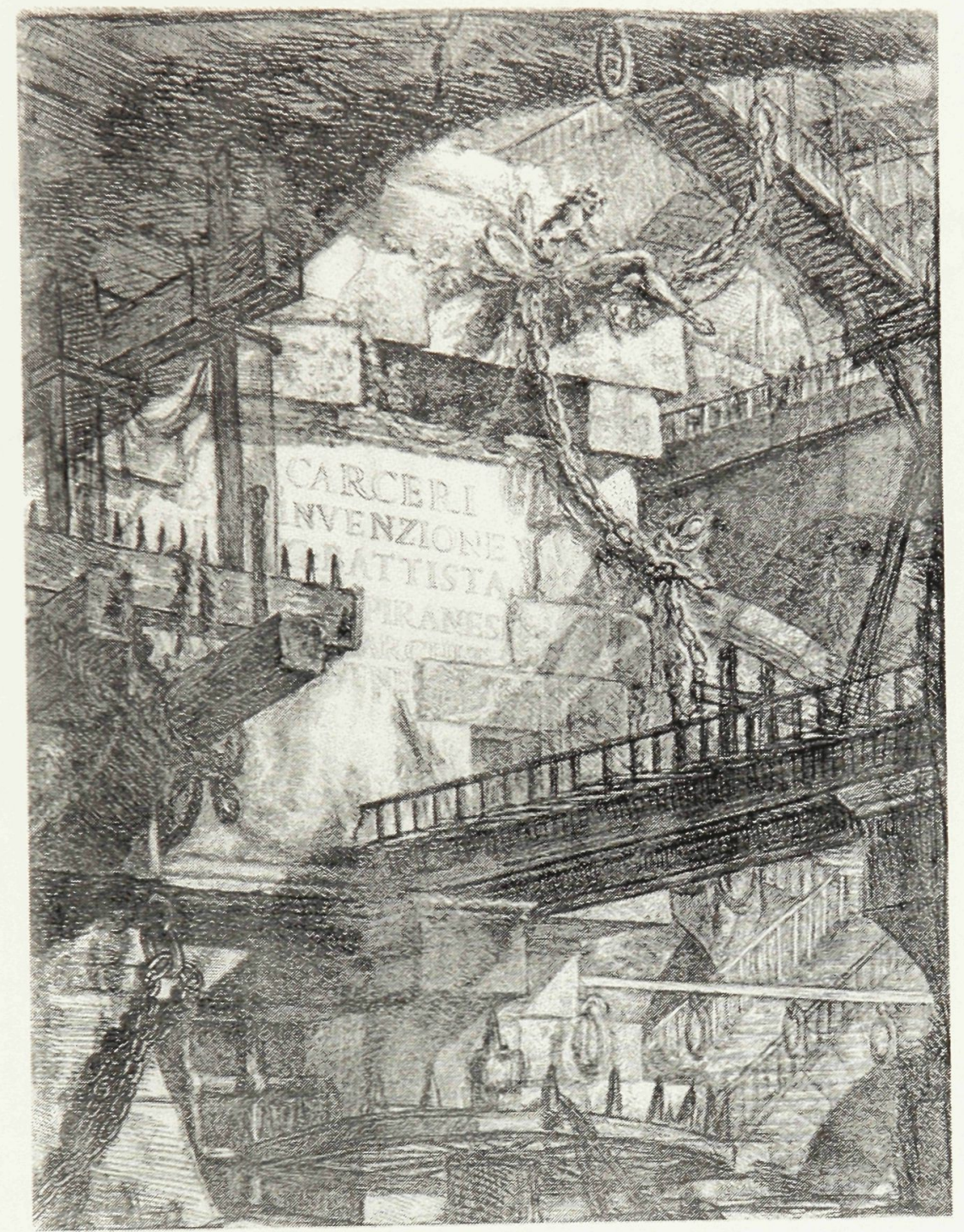

Plate 5

Carceri d'Invenzione di G. Battista Piranesi $545 \times 410 \mathrm{~mm}$ Title page: Imaginary Prisons of G. Battista Piranesi (2nd state)

From: Luigi Ficacci, Giovanni Battista Piranesi, (New York: Taschen, 2001) 31. 


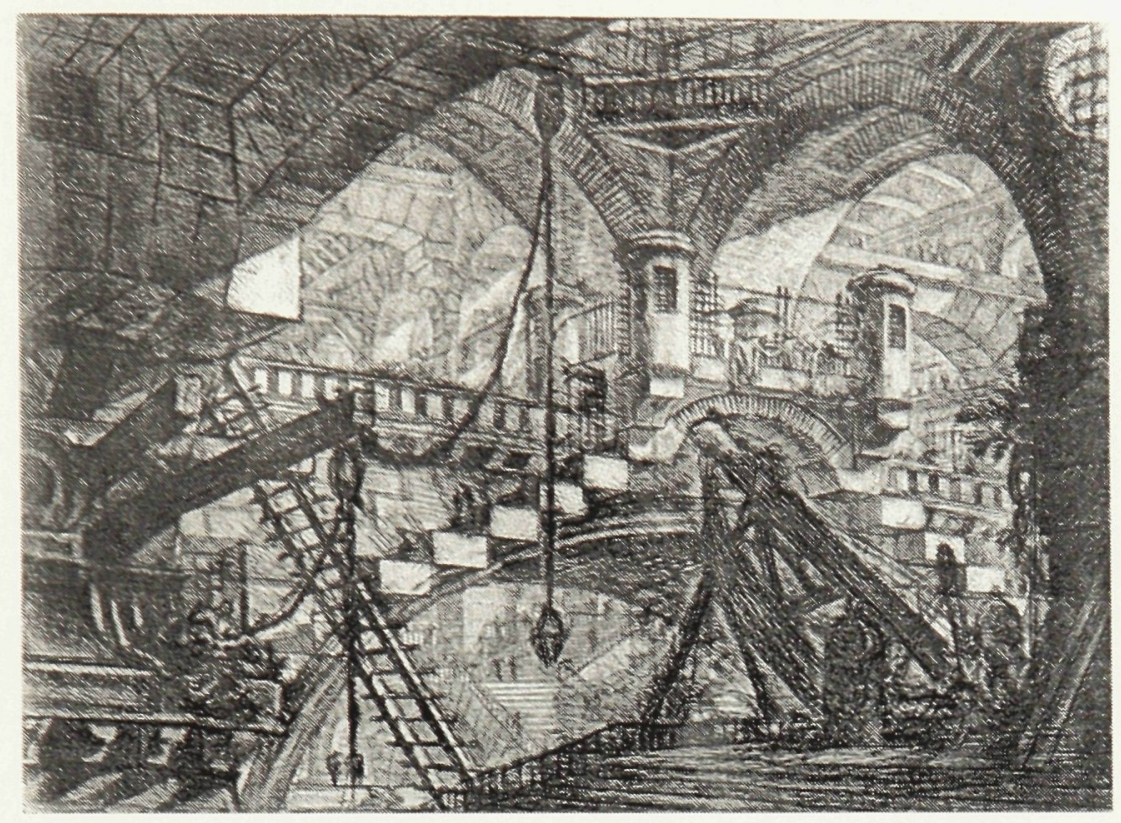

Plate 6

[Carcere XI] $405 \times 545 \mathrm{~mm}$

The Arch with a Shell Ornament (2nd state)

From: Luigi Ficacci, Giovanni Battista Piranesi, (New York: Taschen, 2001) 41. 


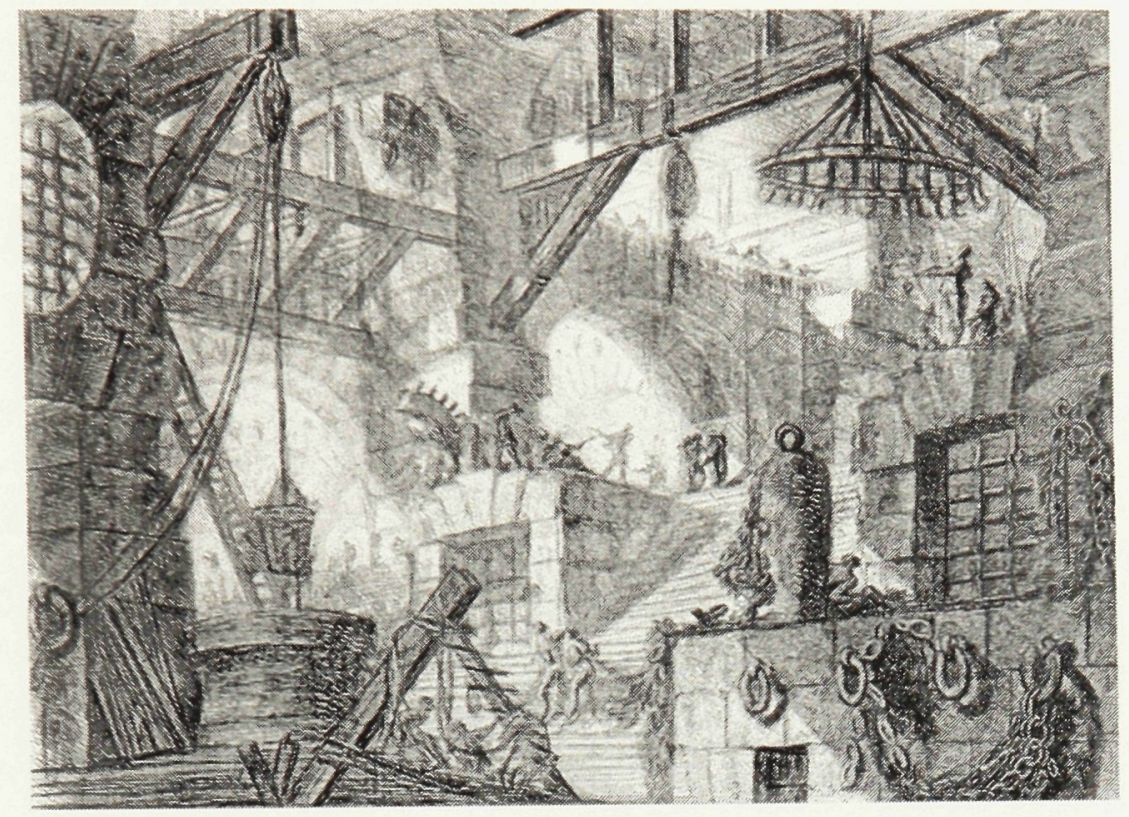

Plate 7

[Carcere XIII]

$400 \times 545 \mathrm{~mm}$

The Well (2nd state)

From: Luigi Ficacci, Giovanni Battista Piranesi,

(New York: Taschen, 2001) 43. 


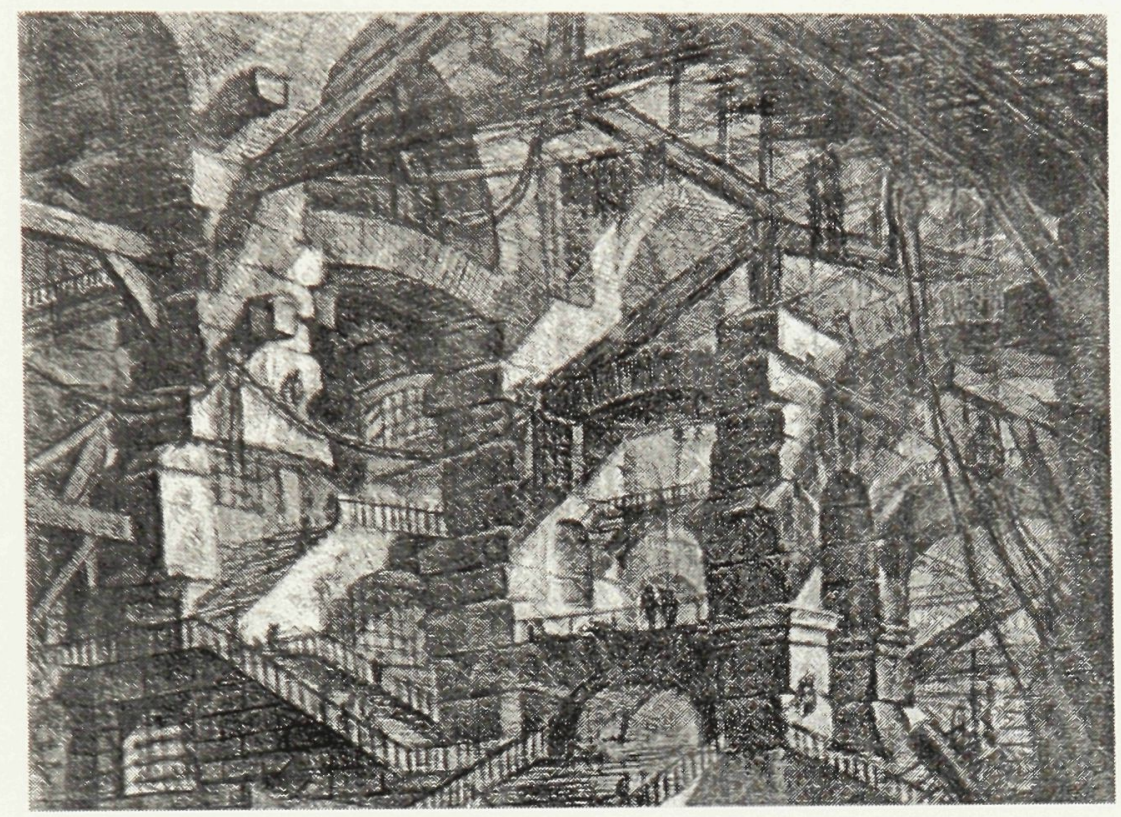

Plate 8

[Carcere XIV] $410 \times 535 \mathrm{~mm}$

The Gothic Arch (2nd state)

From: Luigi Ficacci, Giovanni Battista Piranesi, (New York: Taschen, 2001) 44. 


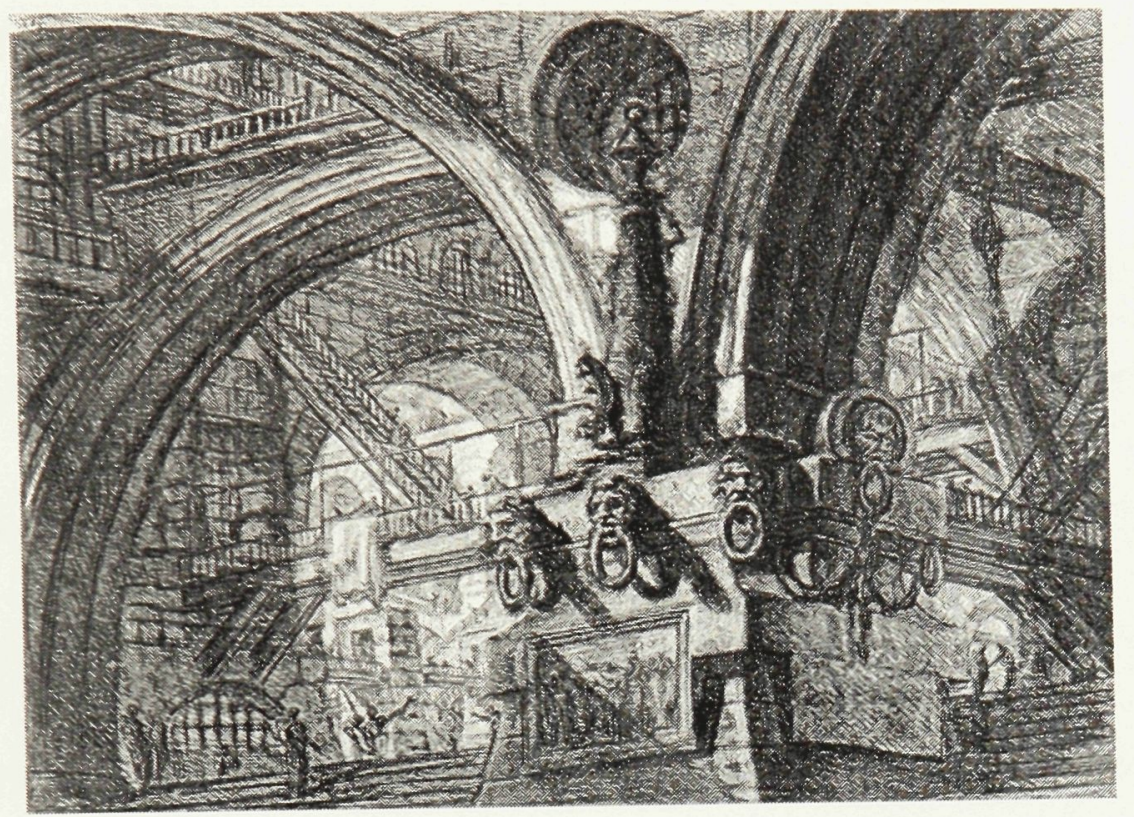

Plate 9

[Carcere XV] $405 \times 550 \mathrm{~mm}$

The Pier with a Lamp (2nd state)

From: Luigi Ficacci, Giovanni Battista Piranesi, (New York: Taschen, 2001) 45. 
between overall perspective, and the architectural fragments that make the scene. Piranesi undermines Alberti's laws with the implication that the composition is a false perspective, and because of the layering of multiple, but subtle perspectives, he convincingly demonstrates that it is only upon a contemplated view that the perspective begins to fall apart. Since he was a master draftsman, Piranesi was skilled in representation and because of this realized that in order to achieve greater depth and meaning in his work he had to obliterate the typical perspective. His veduta not only question the typical representation techniques of the time, but also critically use that same technique as it is an integral part of the content of the image. The inherent folding of space within the veduta creates a continuous, looping path that the eye traces through the image; the individual fragments of space flow freely into one another, making the direct association to the viewers inhabitation of the space to the labyrinth of the torturous prisons of which one will never escape.

Piranesi was the first architect to critically inscribe the content (the prison scene) of the image with the context (the representation). When traditional orthography is engaged in drawing, whether it is plan, section, or elevation, even at the outset, there is already an explicit deeper understanding of the image, 
since it is already part of the context of that particular medium; therefore, the content of the image must either conform or challenge the context in which it is rooted. In orthogonal representations, the tension between the content and the context is where the gap lies. Working within this gap the architect must be aware of the intricacies of each specific mode of representation and address those while at the same time articulating his own design in it. By directly dealing with, and being critically specific with the choice and implementation of the medium, the architect has the ability to entice the interested viewer to find the multifaceted complexities within the image, to understand the image, not simply look at it. 
Walking back through the foyer and past the entrance, you enter into a room divided by a row of columns, and lit from above and to the east by a wall of windows, the floor is worn but in far better shape than the disassembly room, in fact when you first enter this room the air doesn't even seem as dense, the windows let the moonlight stream in, lighting up what at first glance seems similar to the other spaces that you have visited, on closer inspection these machines are different, in fact, none of them are recognizable as objects, silhouetted in the moonlight, the parts seem to merge together at random. Cyrus has disappeared again, you stand there trying to make sense of the place when the generator kicks in and the lights buzz to their full intensity, Cyrus is in the corner by the fuse panel walking back towards the doorway. He explains that this is his real work, these are his creations. The room is full with them, they are various shapes and sizes, from his Random type generator, a cross between several microphone receivers an electric typewriter and the engine block from a 37 ' Ford flathead, used for the sole purpose of creating a continuous string of random numbers, or his lumiscope, a little contraption no bigger than breadbox, made from the parts of a telescope, the flash bulbs from a camera and a thermostat, when placed over a heat source would flash incessantly and send beams of light across his workshop. Most of his contraptions had either a very specific function, or no function at all, Cyrus would spend as much time as possible on all of his inventions working all night into the early hour's of the morning.

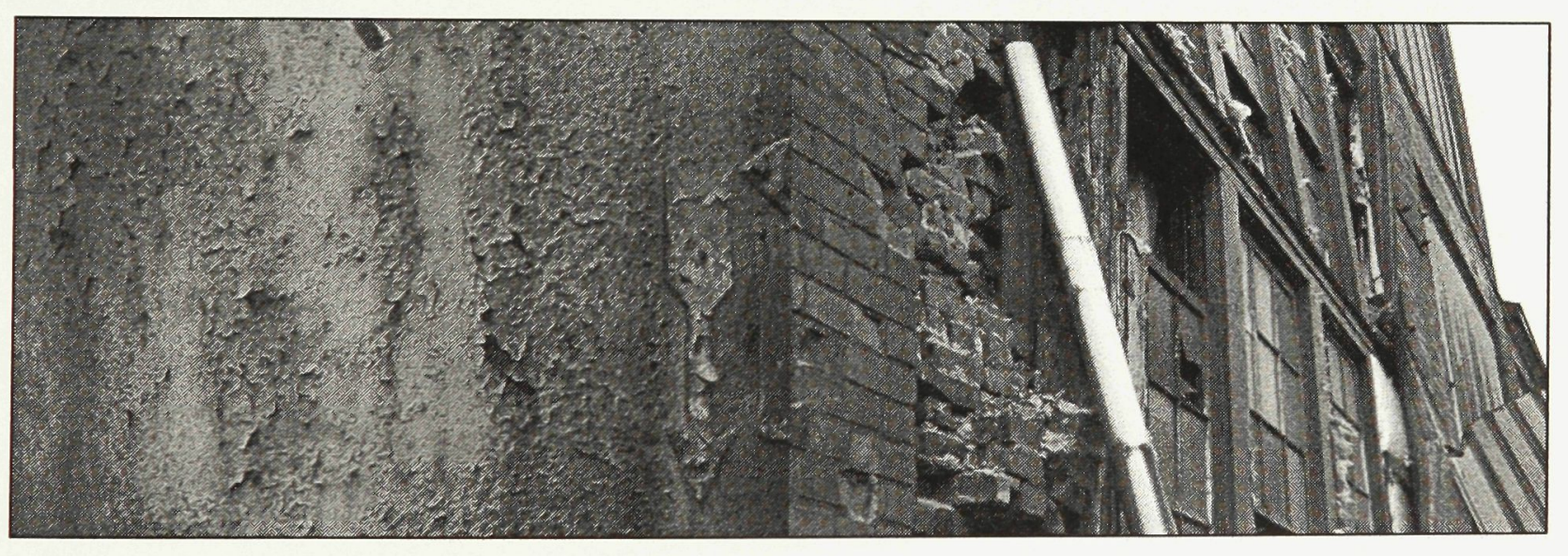

Plate 10 Narrative Five and Context Text, Photographs 
The Image.

Ivan Illich has described our present stasis as the fourth and current regime of the gaze. Here orthography is given precedence over perspective; it is the "age of diagrammatics" 48 , or what Illich calls "the age of show, during which the eye becomes dependant on the interface rather than imagination." ${ }^{49}$ With the Renaissance perspective the viewer is forced to acknowledge where he stands, to accept the frame of the image as his own. Illich illustrates that the space in which the viewer stands and the space in which the object is shown are homogenous. Even in photography the viewer can tell what angle the shot was taken from. This homogenous space between the subject (viewer) and the object (image) is the basis for understanding the Renaissance image. The transition into 'the age of

48 Ivan Illich, "Guarding the Eye in the Age of Show", (November 31, 2000) 9.

49 Ibid., 9. 
show' removed the viewer from the homogeneity of space between himself and the image, and the common ground shared between them. This was the birth of orthography, the scientific, objective, view from infinity. Displacing perspective, the orthographic drawing required a re-education of the viewer as he no longer had any direct physical relation to the image. Illich suggests that "the new naturalists want the object to be shown as it is in itself; they want a blueprint of the object that can be used by an artisan who has to reconstruct it as a threedimensional model." ${ }^{50}$ As stated earlier, Illich describes the age of show as the eye being seduced by the mediation, not the image itself. With the popularization of not only cameras, but camcorders, he expresses the gaze as being understood and sensed through a digital process, and that this recording "becomes a filter that dulls the light in the other's eyes and removes me from his fleshy presence." 51 Since the eye is being perceived as a lens, it is becoming an integral part in the age of show to the extent that it is further mediating past epochs such as the 'Renaissance perspective'. As our eyes become fused with the mediation, perspective becomes experienced as show, here we are reduced, through image

\footnotetext{
50 Ibid., 20.

51 Ibid.
} 
to the pornographic object gaze. Illich suggests that the evolution from pictures to show came with the switch from perspective to orthography, but maintains that much like walking is still around with the monopoly of the car, so to is the renaissance idea of gaze in the age of show.

The ability to take advantage of an understanding or contemplated view is directly related to my willingness to engage in it. When perspective was abolished for orthographic drawing, as used in scientific documentation, orthography was clearly the objective method of recording, ${ }^{52}$ however in architectural drawing specifically, orthography can be used to investigate the building with regards to the typical (objective) means of denoting scaled measured drawings, while at the same time used for its connotative (subjective) abilities in establishing a vibrant architectural discourse.

It is with loose footing that a subjective framework is used in architectural representation since the common practice is to present the project as convincingly and realistic as possible, it is based on this very idea of hyperrealism that the computer is finding its way into architecture schools and offices.

\footnotetext{
52 In the early nineteenth century, anatomists attempted to replace perspective with orthography. Trying to eliminate the perspectival distortion, the implications of objectivity would be the foundation that they could map every little bone and organ. This documentation replaces the views of perspective with measured drawings of isometry.
} 
Through its screen, the computer more often than not is used to create life-like perspectival imagery that is more on the side of show than the side of image. It is important to be clear that the seductive qualities of the image whether traditional or digital, are not at fault, as that seduction is what calls you to contemplate the image in the first place. Rather it is the reliance on show that is preventing any further understanding past the superficial quality of the image and the medium. In order to restore a contemplated view, we need to employ a method of representation that directly engages both the content of the image as well as the mediation of it, thus providing the viewer the opportunity to dwell in the image, to understand it.

This is where we must turn to the erotic experience, the unstoppable movement that suddenly tears us away from the quiet ordering of our day-today reality and deposits us in the virtual space of the image. In fact to inhabit space in an orthographic drawing requires distancing from our physical reality which is inherent in the abstraction of the drawings themselves. This distancing can be brought about through desire by employing the erotic experience of the image; this is where subjectivity can play an important role in understanding and inhabiting the image. At first, it seems with great apprehension that the role of 
subjectivity be used for greater effect in architectural representation, however upon closer inspection, it is important to note that (as Aretino suggests) subjectivity plays a crucial role in distinguishing all forms of representation; as such, it is only natural to express representations that directly utilize subjectivity in order to assist in the understanding and articulation of the architect's intentions and ideas. This can be achieved by composing the specific drawings and modes of representation in order to 'construe' the project thereby allowing the viewer to interpret and construct the spaces that have intentionally been represented in this way. In his only published work, Condemned Building, Douglas Darden approaches his projects in a very precise, regimented way. To follow the complexity and the construing of his projects, we will focus on his Oxygen House, subtitled: A Near Triptych on the Act of Breathing.

Oxygen House is perched on a depressed flood plain northnorthwest of Frenchman's Bend, Mississippi. The structure is designed for Burnden Abraham, an ex-train signalman, who must now live in an oxygen tent.

In the early spring of 1979, after torrential rains, the railroad tracks on which Abraham worked were flooded. They were never fully repaired. That following summer during a routine operation, Abraham suffered a collapsed lung when a train jumped the track and sent metal debris puncturing his right lung.

Three years later the railroad company put the property up for sale. Abraham purchased the plot where he had once worked. He requested that his house be built over the scene of his near-fatal 
accident. Abraham also requested that he finally be entombed in the house. ${ }^{53}$

Darden's "dis/continuous" genealogies, which he terms ideograms, are the foundation for each of his architectural explorations; existing as a set of superimposed images, each carries its own unique meanings and memories. The ideogram works in much the same way as Piranesi's Carceri; the formation of one image collapses the spaces and meanings of several individual images, allowing the imagination to discover multiple meanings that are not at first evident in them. For his Oxygen House, Darden superimposes ink drawings of four distinct images, an American Civil War Engraving, Caboose Water Cooler and Basin, Westinghouse Train Brake, and the Hindenburg Zepplin, each coming together to comprise his resulting ideogram. (Plate 11) These four images, drawn individually, are then combined and rendered as the ideogram. Each of the specific drawings has innate formal qualities and ideas, that when combined result in a number of complex associations that seem to form the initial basis for his project.

In fact, the project is presented in a discontinuous series of image and text

53 Douglas Darden, Condemned Building: an Architect's Pre-text, (New York: Princeton Architectural Press, 1993) 143. 
arranged in order to provoke our engagement with the representations and the project. ${ }^{54}$ The project consists of ideograms; a title page including the title, subtitle, and location for the project, as well as the architectural canon and its "reversa"; (Plate 12) models, built photographed then destroyed; (Plate 13) texts, and sub-texts providing glimpses into the context that the project was developed around; (Plate 14) plans, sections, elevations and details showing the specific functions and hierarchy of the project; (Plate 15) and letters, written to Darden from his client Abraham. (Plate 16) These facets of the project are woven together in the same way that the individual images make up the ideogram.

In his project, Darden cleverly positions each of the artefacts in a way that does not completely represent his architecture; it is only through the associations, ideas, memory and experience of the architectural fragments that the viewer is able to understand the complexity and the richness of his project. The specific rendering technique as well as the drawings that Darden incorporates into the project assists in conveying his ideas to the viewer. If we take for example his two sections, "Anatomical section", and "Post-mortem section", and make the

\footnotetext{
${ }_{54}$ See appendix A for a complete presentation of Darden's Oxygen House.
} 

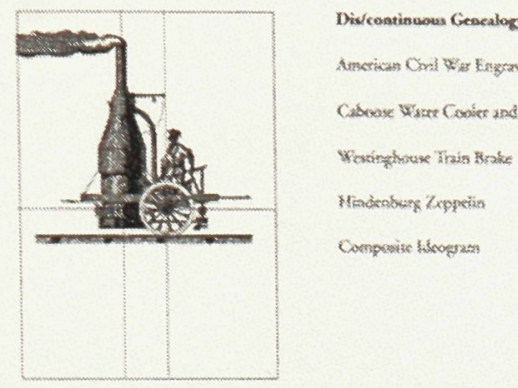

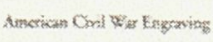

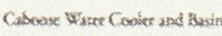

Wearinghroux Trais Froker

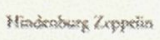

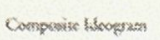
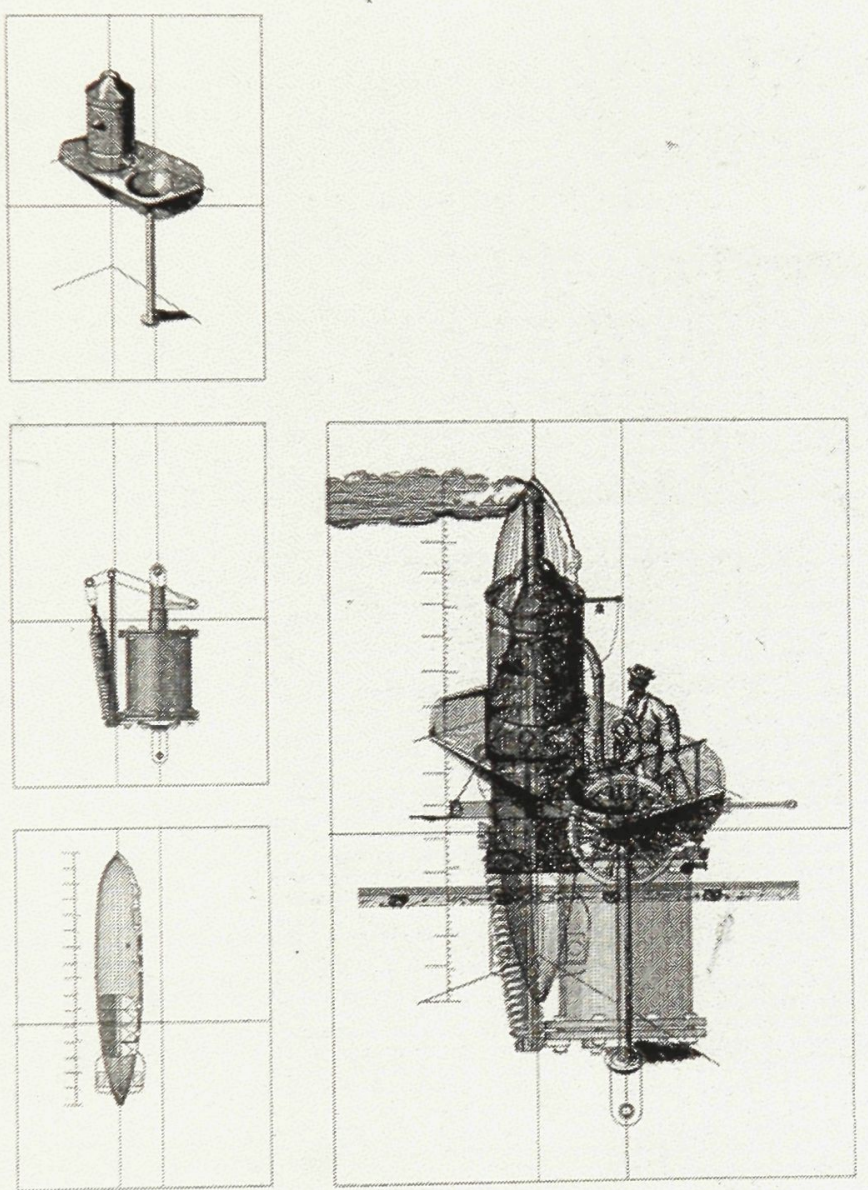

Plate 11

[Oxygen House] Ideogram

From: Douglas Darden, Condemned Building: an Architect's Pre-text, (New York: Princeton Architectural Press, 1993) 148. 
Oxygen House

A NEAR TRIPTYCH ON THE ACT OF BREATHENC:

FRENCHMAN'S BEND, MESSISSIPRI

From: Douglas Darden, Condemned Building: an Architect's Pre-text, (New York: Princeton Architectural Press, 1993) 141. 


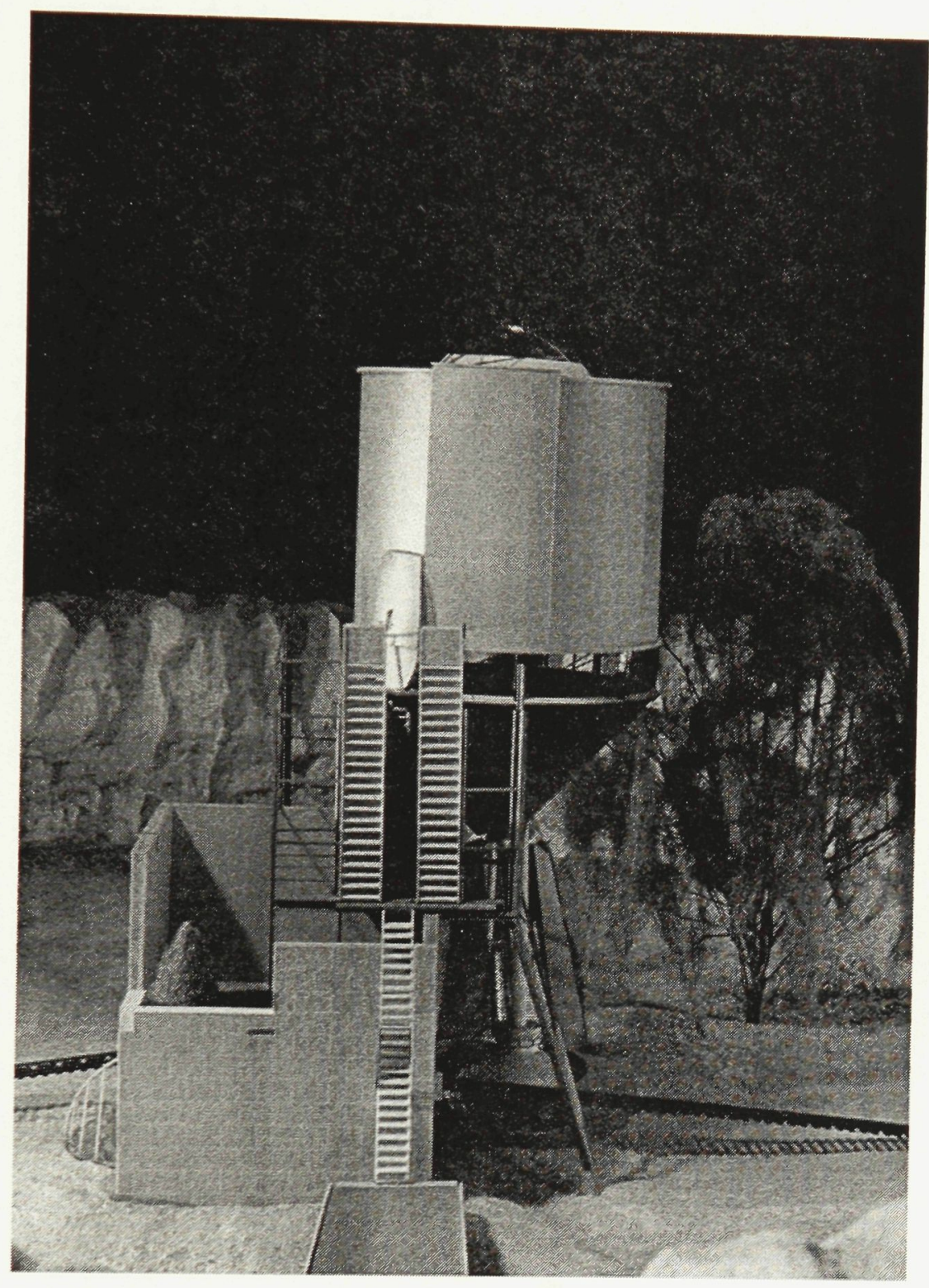

Plate 13

[Oxygen House] Model

From: Douglas Darden, Condemned Building: an Architect's Pre-text, (New York: Princeton Architectural Press, 1993) 142. 
OXYGEN House is perched on a depressed flood plain norch-northwest of Frenchman's Bend, Mississippi. The structure is designed for Burnden Abraham, an ex-train signalman, who must live in an oxygen tent.

In the early spring of 1979 , after torrential rains, the railroad tracks on which Abraham worked were flooded. They were never fully repaired. That following summer during a routine operation, Abraham suffered a collapsed lung when a train jumped the track and sent meral debris puncturing his right lung.

Three years later the railroad company pus the property up for sale. Abraham purchased the plor where he had once worked. He requested thar his house be built over the scene of his near-facal accident. Abraham also requested that he finally be entombed in the house.

Plate 14

[Oxygen House]

Sub-text

From: Douglas Darden, Condemned Building: an Architect's Pre-text, (New York: Princeton Architectural Press, 1993) 143. 


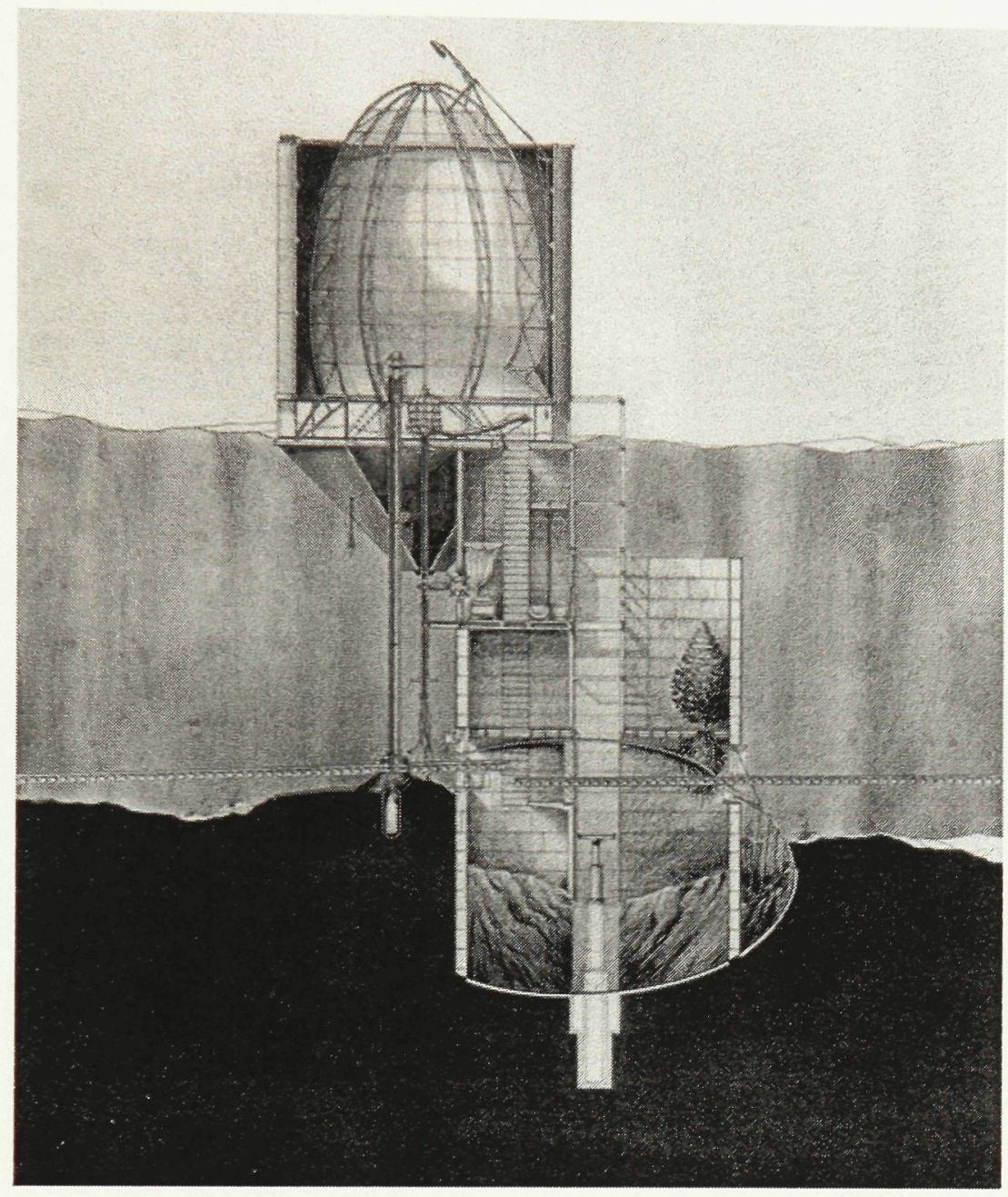

Plate 15

[Oxygen House] Anatomical Section

From: Douglas Darden, Condemned Building: an Architect's Pre-text, (New York: Princeton Architectural Press, 1993) 149. 
The following letter was writen by the client to the architecr from the client's hos. pital room in Byhalia, Mississippi. The client died shorkly after the fooxings of the house were poured. The construction of the house was never finished.

\section{6 ) wiy 1979}

Dear Mir. Darden:

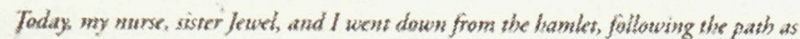
- good as she could push me and my rolling drain. It was my thivd visit to the piace where I wes alunost killed three years ago. inyone wathing us from the bluffis could bave seen Jewed's straw-colored hatr blowing more than a full head abowe my awn in the dust.

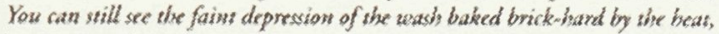
which wstermined she tracker. The syacks run straigigt as a plambline, crossed by she trash, I san now look calonly at the break in the line. My diest no longer goes cinusk chack. I am doing the right thing so parshase this plat for my bouse.

Close so the break, in the center of the plain, is an old blockhouse. A path nows cir. rios she house at four soft right angles and gocs on acous the plain again. The block

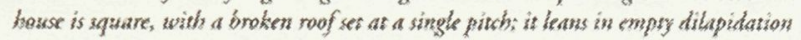
in she sunkight wibls a single broad window in ruco opposite wall giving onto the ap proaches of the macks. You shonid have seen Jewei step shrough the wiondow in a singie stride while $I$ took in the shimmering willow bronow.

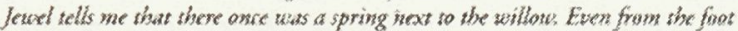

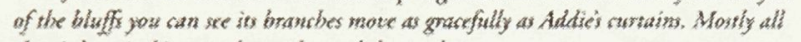
that is bere is this tree, the tracks, and ine sand.

You bave asked me to thare with you my thoughts about death. Nose is not the sine for this. I hase lived for too many wonths shinking in a fury that l bad onity a few days-sametimes anly a fere boun-do live I was a bublik.

l can onty say that death no longer threaters me. It mons bite soff gold beturen the dhadow spaces, a diagonal wein passing though my life. Euen though I hardhy ear onserge from my toms, this win gives me an ouduing sense of sound movement, of andzement, and privilege, Let's go an and brald athe bouse.

Yours sincerely,

Burnden diónabam

From: Douglas Darden, Condemned Building: an Architect's Pre-text, (New York: Princeton Architectural Press, 1993) 145. 
connection to the content of each image, the text, and to the client, we can see the subtle intricacies that Darden uses to further underscore the relationship to the canon of architecture: "A house is for living," and Darden's reverse: "A house is for dying." In the first, the "Anatomical section," Darden depicts the 'living' condition of the house, that is, the structure, assemblage, and details, in its entirety (its body); in the second, the "Post-mortem section", Darden depicts the decomposition of the former house; the fragments that formerly comprised the house are now situated within the site as monuments. This specific reading is made possible only through the mediation of the "Operations" and the juxtaposition of those "During Life" with those "After Death"; the former belonging to the operations that the visitor performs when visiting Abraham, and the latter to the operations performed on his house after Abraham is deceased. In this description, we cannot help but notice the constant assimilation of medical terminology to their architectural counterpart; and the linking of it back to Abraham's dependence on a perpetually medicated state, that of being confined to his oxygen tent. Darden's appropriation of medical language is just one of his many subtle insertions that construe his ideas to the viewer. There are many instances in the work that reference something outside of the project. In 
fact, it is only upon closer inspection of his allegory that we realize the conditions for the project (the site and Abraham) are fictional. It is only when the viewer notices the similarities between Burnden Abraham's letter and William Faulkner's As I Lay Dying, the tale of Addie Bundren's death and the story of her subsequent burial; or that the site for the project, Fisherman's Bend, Mississippi, comes from the map of Faulkner's Yoknapatawpha County; that we realize our participation in Darden's representations involves the viewers embodied assemblage of the parts into the whole.

In "Monsters of Architecture", Frascari validates Darden's process by specifically referring to the symbolic images embodied in the materials of architeture:

...[I]n architecture, fantasy [desire] and memory [subjectivity] are the guiding faculties of imagination; expressive details are thus endowed by the mind. This hermeneutical process liberates the symbolic images embodied in the materials of architecture. Viconian terminology would characterize the properties, functions, and attributes of the architectonic artifacts as emerging from the technological point of view: the union of construction, the Viconian factum [signified], with construing, the Viconian verum [signifier]. ${ }^{55}$

The process of the union between signifier [construing] and signified

\footnotetext{
55 Marco Frascari, Monsters of Architecture: Anthropomorhism in Architectural Theory, (Maryland: Rowman \& Littlefield Publishers, INC., 1991) 12.
} 
[constructing] are at the core of desire in the architectural project. Construing is essentially the act of the architect, the creation of signs that exist in a state of virtuality but are continually referencing the symbolic; constructing involves the participation of the viewer, the interpretation and assemblage of parts referenced in the drawing, done (subjectively) as an imaginative exercise. The architectural project exists as the process of ideation, representation, interpretation, and imagination; when construing (ideation and representation), the architect creates the signs that allows the viewer access to his ideas through the images, by constructing (interpretation and imagination), the viewer assembles the project and therefore subjectively understands and relates to it in the same way as the erotic experience.

When we understand the architectural project to be the interpretations of the architectural representations, it is clear to see that the architect must be precise and critical when not only choosing the content of the image (the symbols and signs) but also, the medium in which he uses to convey that content; if the architect chooses to objectify the building in his selection of representation, then the expression of the fundamental idea or concept that was inherent in the creation of the project is lost. We are left with a building represented in such a 
way that leaves no wonder or further understanding of it, it is simply a map that denotes precisely what is to be built. To further clarify the distinction of the image as instrumental to the architectural project we must consider the image as object; in doing this, we have removed the denotative structure of the image and are now regarding it as an edifice that like all edifices requires contemplation to be understood. When considering the image as object, inherent in our task is the realization that the drawing is not self-referential, there is something that exists outside of it; this is the corporeality that is inscribed in its content, the symbolic. In his chapter on Demonstrations Frascari summarizes the philosopher Antonio Gramsci, further underscoring the act of construing the architectural project as the art of architecture; "In this piece [Quaderni dal Carcere], the Italian Marxist philosopher [Gramsci] suggests that the work of art of the architect is in the project, not in the building, just as the work of art of the writer is in the manuscript, not in the printed book." ${ }^{26}$ Frascari suggests that the inversion of the relationship between the drawing and the building has occurred because today many preservation drawings are done right on the existing working drawings, and not on a survey of the building. When consideration is placed on a survey as

${ }^{56}$ Ibid., 93. 
part of the architectural project, there is a much more intimate, and thoughtful consideration of the existing building, and its specific qualities, and gives deeper understanding and begins to set up the specific associations that will construe the architectural project.

Construing is the only act of the architect, and involves the weaving together of architectural texts. This is not a cursive endeavour, but a discursive one. "Indeed classical Roman rhetoricians selected the Latin verb texo, texin, textum, texere (to weave) to indicate both the acts of composing a literary work or an architectural piece." Thus the architectural project may be conceived as a textile made by weaving threads between the architectural fragments, moments, and ideas, essentially, the architectural (con)texts. 
As the sun starts to rise, filling the large skylights with the reddish glow of morning, and the city is just coming alive, Cyrus begins to close the heavy iron doors of his shop, and will soon retire to his residence above the assembly room. From the exterior of the building, both spaces are closed off and seem impenetrable, in fact Cyrus does not bring anyone into either of these two areas, for him they are the most intimate and private of all the spaces in the building. The large doors close with a thunderous clang, as the lock swings closed, the latch echoes through the entire building. The overhead doors are lowered and the room becomes dark with the flip of the breaker. Back through the lobby into the disassembly room, Cyrus first locks the safety catch on the hoist, then attends to the lights, the room goes dark however the shapes are still recognizable as the sun continues to climb in the sky. As you exit the building, Cyrus invites you to return anytime you like, whether it is to help him document the machines, to get advice on mechanical problem, or simply to see what is in his shop on that particular day. The doors close behind you and Cyrus disappears up into his residence.

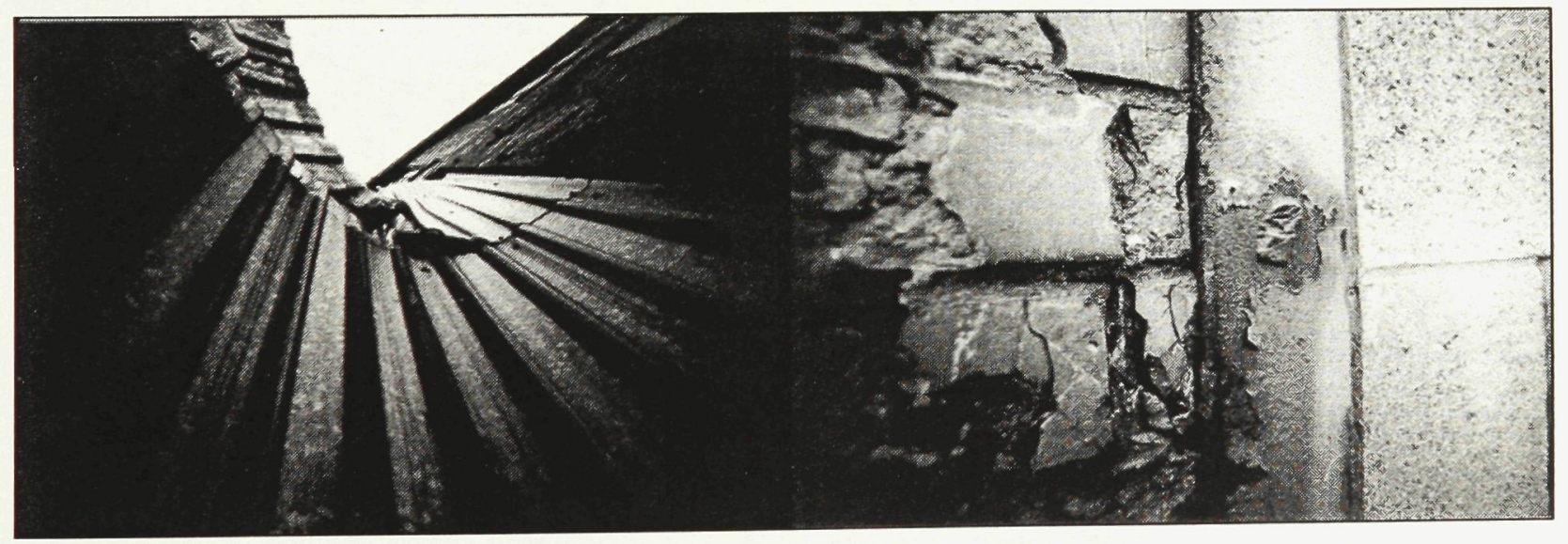

Plate 17

Narrative Six and Context

Text, Photographs 
The Project

This project begins at the site, 350 Sherman Ave, Pier 15, Hamilton, Ontario, Canada. Situated on the western most end of Lake Ontario, the Hamilton Harbour is approximately 500 square kilometres in surface area, and $75 \mathrm{ft}$ at its deepest. In 1823, a canal was cut through the beach strip which opened the harbour to mercantile shipping. The canal played an important role in the economic and industrial development of the area. In 1846, all of the sites on the harbour were deeded to the City of Hamilton through the Deeds of Incorporation, which incorporated the City of Hamilton and defined its boundaries. During the same year, the canal was widened to allow larger commercial vessels to enter Hamilton's port. When the railway terminus on the harbour front was developed, commercial traffic increased significantly, along with the local industries that were beginning to establish their companies on the 
shore. The convenient access to water for industrial processes as well as easy access to shipping created the ideal climate to foster the industrial expansion of the waterfront.

Positioned in the centre of the industrial area, 350 Sherman was developed in 1902 by Alexander Dunn. Dunn convinced the Deering company of Chicago that Hamilton would be the ideal site for their Canadian location. After constructing a few buildings, the Deering company amalgamated with several other farming companies: McCormick Harvesting Machine Company, Plano Harvester Company, Warder, Bushnell and Glessner Company, and Milwaukee Harvester Company. These 5 companies became the International Harvester Company. Over its first 16 years, the company gradually expanded its production from harvesting machines, seeding machines, tillage implements, and threshers in 1903 to include cultivators, harrows, land rollers, and plows in 1919. The next major development occurred in the fifties when International Harvester introduced its advanced engineering and product engineering building that did research into new agricultural machines. The 1950's also saw the addition of hay balers and the expansion of production, that divided the plant into three operations: the Hamilton Works, which designed and produced farming 
equipment; the Hamilton Heavy-duty Equipment Works, which produced diesel transport trucks and construction equipment; and the Hamilton Tractor Works, which created the first crawler tractors made in Canada.

The 1980's did not fare well for International Harvester; the \$53.4 million drop in profits coupled with a weak dollar and high interest rates saw the first financial loss in nearly 50 years. To combat this the engineering division, construction division and truck service centres were closed, but International Harvester still reported a \$39.5 million dollar loss. In 1984 International Harvester sold off the farm equipment operations to Tenneco Incorporated, which was then run by the J.I. Case Company.

Case proceeded to continuously cut back and restructure the plant, selling off land and demolishing buildings until it finally closed in $1999 .{ }^{57}$ Currently the site is being used for seasonal storage. The last remaining building and surrounding land has become the site for this architectural project.

The title for the project is The Residence of Cyrus C. Roe, and the Home of Fallen Machines. The program is the Residence and workshop for Cyrus C. Roe.

\footnotetext{
57 Andrew MacDonald, Lisa Di Valintino, and Norman Pinder, "Industrial Hamilton: A Trail to the Future International Harvester Company of Canada, Limit" History of industry in Hamilton, (Hamilton Public Library: December 8, 2005).
} 
Cyrus was listed in city directories as a machinist and showman, while in fact he was an inventor and innovator in Hamilton; with a shop on Wentworth St N. his many inventions include Adams Ironsides, The Steam Walking Man, a life sized (5'6" tall) steam man, a naturally walking "man" that can travel at a speed of four to ten miles per hour, by applying steam pressure to his joints. (Plate 18) The site context coupled with Cyrus himself is the thread that weaves the project together. From the very outset, the site has played a crucial role in the development of the text, the initial investigations, as well as all of the representations that make up the project.

When visiting the site, there is an overwhelming feeling of intrusion, partly because of the scale of the buildings, and partly because you are detained by the Port Authority. The first noticeable feature of the site is the rudimentary nature of the site itself; everything has a specific purpose, and there is not much focus put on anything else. Raw unfinished materials make up most of the façades, the foundations of the previously demolished buildings are still in the ground, and the marks are still evident from previous additions that are now removed. This was the first interesting feature of the site: the rawness of its characteristics, and the physical reminders of its past greatness. The initial visit 
to the site led to the investigation of forms, materials and textures, and ultimately the arrangement of three proto-collages, and subsequent line drawings. (Plates 19-21) The collage and drawing sets formalize the characteristics of the site as well as its materiality.

There were three fundamental themes that were investigated in the sets: horizontality, the tabla rasa of the site; verticality, the condition of the buildings set against the horizontality of the site; and repetition, in both the structure and forms found within the site. These were closely associated with the pornographic experience, in that they were revealed in entirety. Although the structure and form of the building reduces us to the unthinking spectator, the function (program) and the sublime, erotic, tactile conditions of the building, were what made the building desirable to begin with.

Three models were then created from the collages, embodying the ideas of horizontality, verticality, and repetition. (Plates 25, 22, 28) These models combine the construction techniques found on the site while at the same time investigating the erotic tactility of its materials. These models help to formulate an understanding of site while at the same time existing as 'objects of desire' in themselves. The models were constructed by the two primary materials found on 
the site, steel and concrete and come together in a very straightforward, minimalist way. This allows Kunze's two orders of time to occur. First, with the insertion of other materials, the objects become "sites" for additional models which allows for the possibility of Kunze's memorial time, in that the models are continually reassessed and reassembled. Where the models first existed as object, they now exist as site. The second is the order of experience, that resides in the way that the models are interpreted and "made sense of". By not articulating any specific space, but rather a sort of universally defined space, combined with qualities of light that play upon the materials, results in the models themselves becoming part of the imaginative, embodied projection in the viewers mind. Because of their scaleless quality, the series of lit and photographed model images assists the viewer to imagine the spaces and experiences of the model and reconstruct them. This can also occur by simply isolating certain aspects of the model; (Plates 22-30) in doing so there are certain associations made between the objects, and the viewers own memory and subjective experience.

The first attempt at design was approached by starting with typical plans sections and elevations of the existing building. These objective drawings did not engage an attitude towards site context, and did not fit with the initial idea of 
desire and eroticism that was so evident from the site visits. By turning to the revisited idea of site from the models, a new understanding of site was formed. A subjective survey was taken that involved discovering the site for the proposal. This was no longer 350 Sherman Ave, but rather an assembly of those aspects of the existing building that were desirable. A photographic architectural survey of the building was taken specifically through the lenses of: plan, conceived as orientation or uncovering; section, the precision of the cut and arrangement of parts; and elevation, the layering and flattening of surface. (Plates 31-39) Primarily dwelling in the north façade (as the interior of the building was restricted and inaccessible), the building was expressed as a collection of subjective images that embodied desire.

As a way to understand and directly engage desire in the new proposal these images were then collaged into the new "site" for the building, and the proposal was developed from this site as well as the historical context in which it exists. These collaged images were eventually transformed into plan, section, and elevation for the new architectural project, by "drawing out the desire in the building".

Starting from the site collage, the sectional lines were extended from the 
image and transformed into floors, walls and roof section cuts. (Plate 40) These lines evolved while constantly being tested against the program of the building and the spaces needed by Cyrus to inhabit it. (Plate 41) The process for the elevation involved the additional step of transferring the image directly onto the paper, (where the section was developed right on the collage); this further emphasized the flattening of image and the stain left by the process. This flattening was a crucial step for discovering the building through the lens of the elevation. When creating the collage for the elevation, (Plate 42) the most consideration went into the layering of images and flattening of time that was inherent in the façades; however, this was achieved while constantly checking that it "worked" with the section. (Plate 43) The plan was conceived in a similar way as the elevation, however the collage dealt specifically with orienting oneself within the site. These photos are precisely the ones that mediate placement and relation to the building. These images collaged became the texture for organizing the plan, program, and Cyrus' functions within the building. (Plate 44) By uncovering the collage within the plan, (Plate 45) the more public areas of the plan are distinguished from the areas which are private to Cyrus. This technique was developed in both the plan and the elevation, and was used to 
show the texture of the building in the spaces that are accessible to the visitor.

This achieved two effects, first, it focused the attention to Cyrus's outward persona, while still maintaining the mystique that makes him an object of desire; and second, it leaves a space for desire in the representations of the new building. By selectively revealing the building in the representations, the viewer is still able to protect their own constructed image of Cyrus, and the intimate spaces of his residence and workshop, thus giving them a space to project their own desire.

The computer panels (Plates 46,47 ) were created in a similar way to the drawings. Again, the site became the starting point for the digital; by using Shape Capture, a photogrametry software, the initial photographs of the existing building are loaded, and translated into three dimensional models. This process involves precisely shooting the subject at convergent angles, loading them into the software and picking common points in all of the images. The software then uses a sophisticated algorithm to calibrate the points, and the distortion of the lens. Once this is achieved, the points are then grouped into sets that compose the planes of the resulting vrml model.

There is an inherent abstraction in the production of the three-dimensional 
models that is mediated by the process itself. The abstracted details were then superimposed onto each other and this became the base site used for the computer models. The subsequent models were then constructed to demonstrate the fundamental architectonic components that comprise areas found in the drawings, the first runs vertically with the stair in the lobby, and the second, with the crane that passes through the roof, the disassembly area, and the storage beneath. In trying to avoid showing all of the details, (Illich's definition of show) rather weaving together the universal qualities and fragments into one image, (similar to the multiple perspectives found in Piranesi's Carceri) the computer panals can be considered the combination of experience and memory of the space. These images need to be understood, disassembled and reassembled. In doing so, the architectural fragments that comprise the image are evaluated not as objects but in their relationship to each other. 


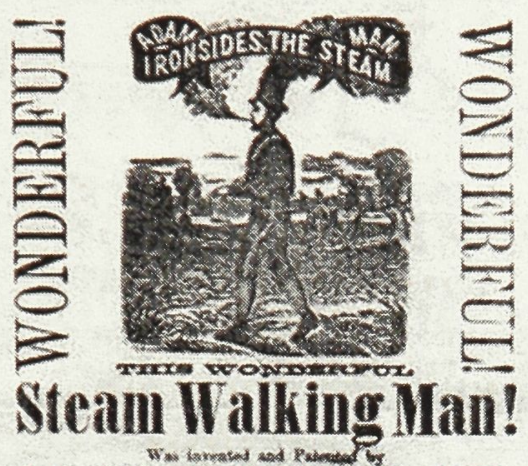

c. c. RoE, of IIAMITrov, oNx. in steam Walking Machines,

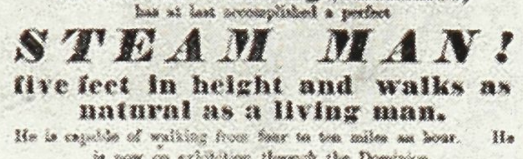

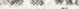

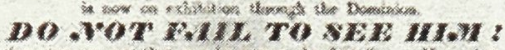

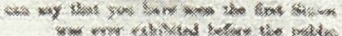

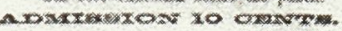

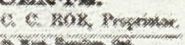

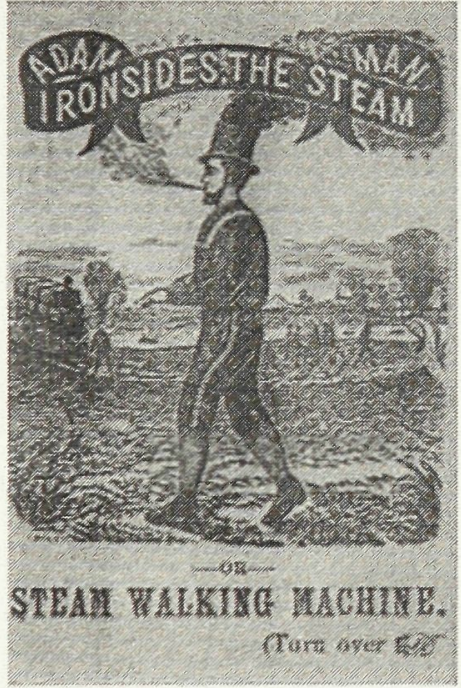

Thix waras?

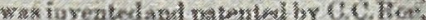
of Hazuilcon, Ont. after synesding thou. swas is of dollars and sexeral years oxkcrimenting in Stram Walking, Wrehx

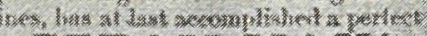

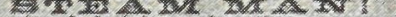
द⿱ as a living mon He ix canable of Wralkisis from foror to sen nsiles an bora

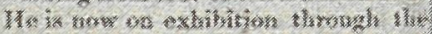

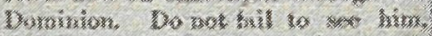

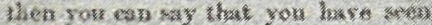

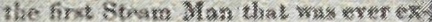

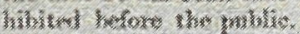
The proprationt asters as

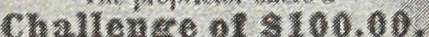

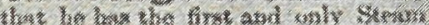
1)

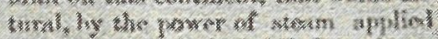

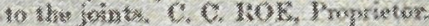

Plate 18

Adam Ironsides, the Steam Man Origianl Promotional Posters

From: Andrew MacDonald, Lisa Di Valintino, and Norman Pinder, "Industrial Hamilton: A Trail to the Future - Adam Ironsides, the Steam Man" Adam Ironsides, the Steam Man, (Hamilton Public Library: December 8, 2005). 

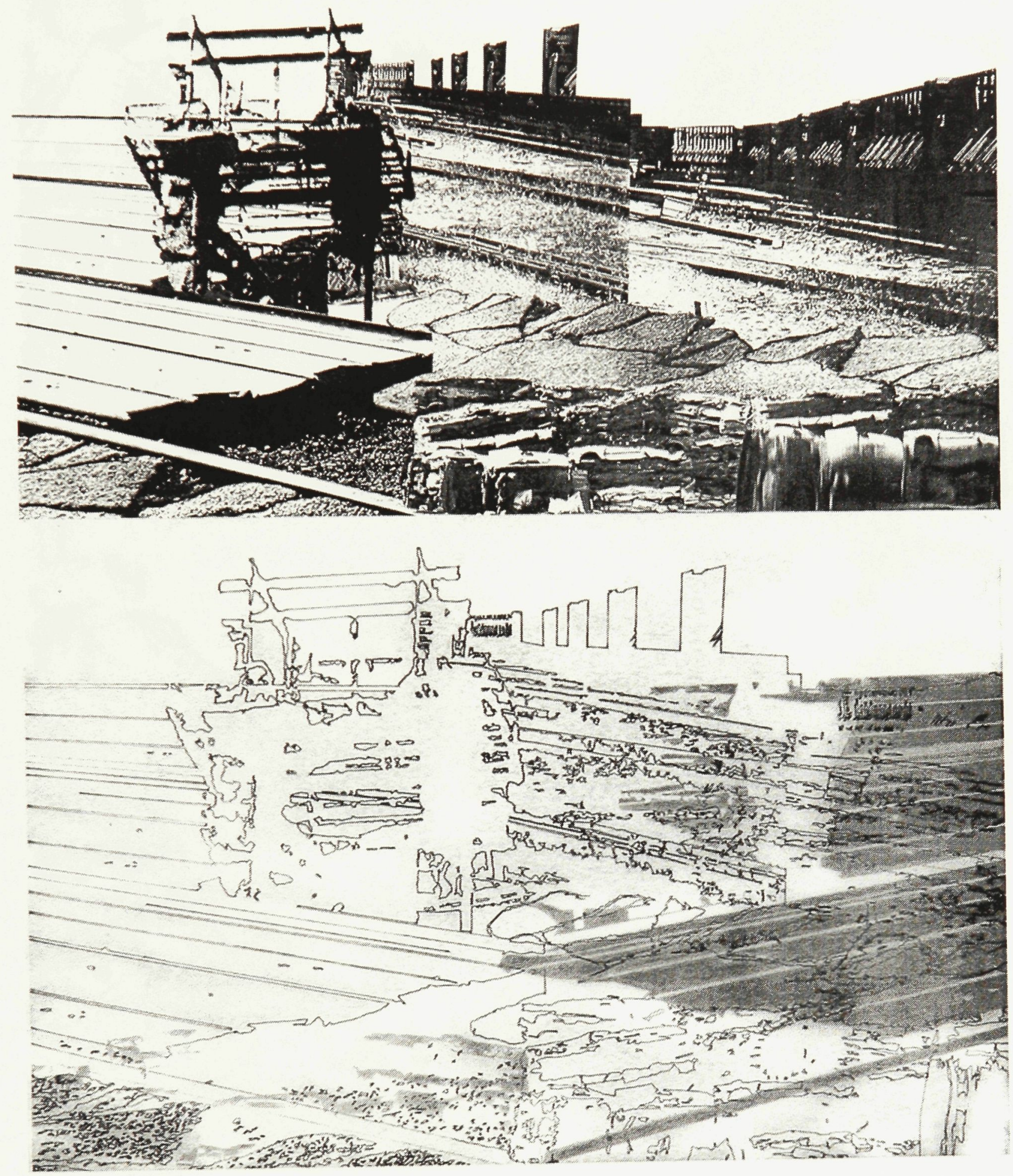

Plate 19

Horizontality

Collage and Line Drawing Ink on Mylar 


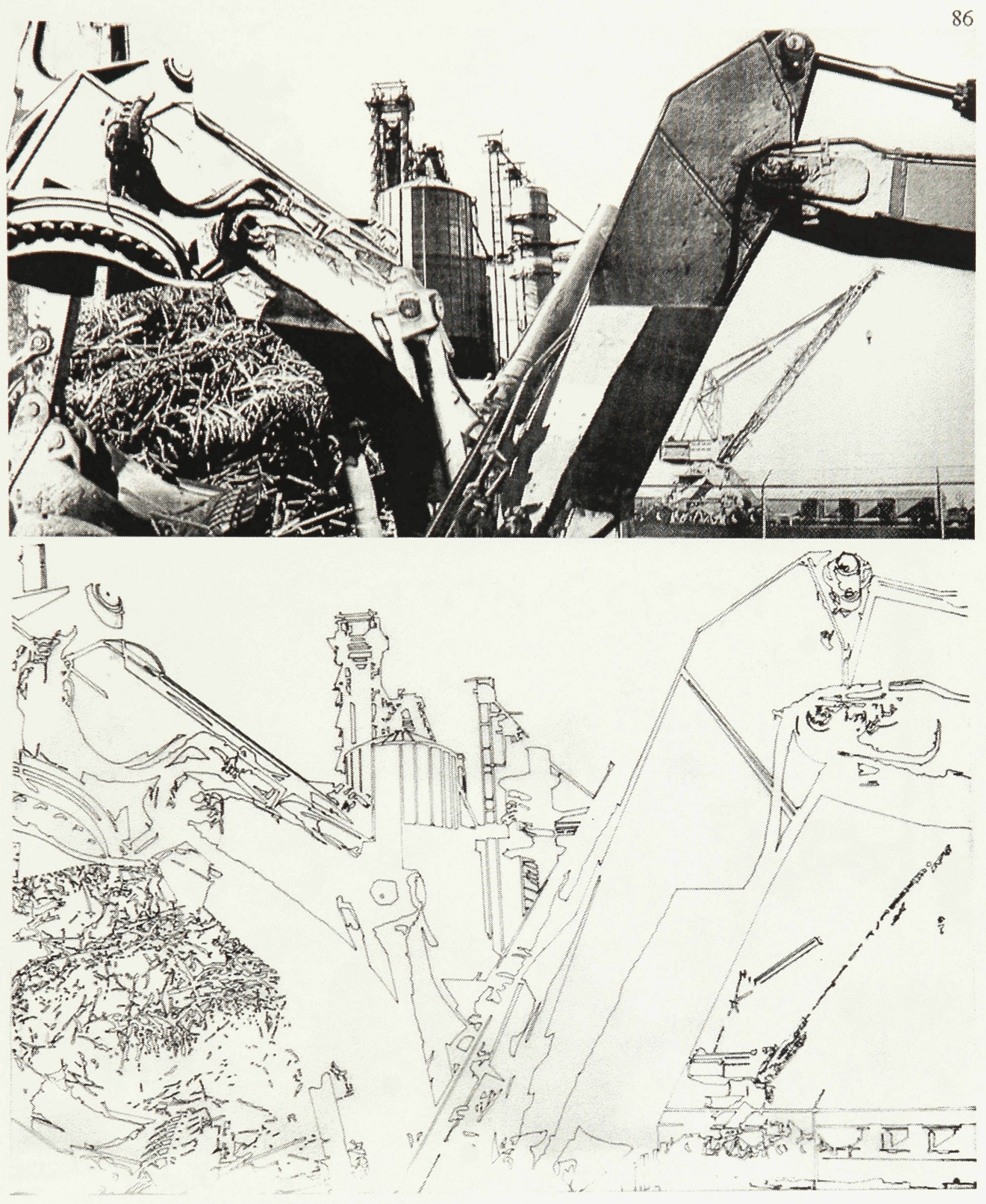

Plate 20

Verticality

Collage and Line Drawing Ink on Mylar 


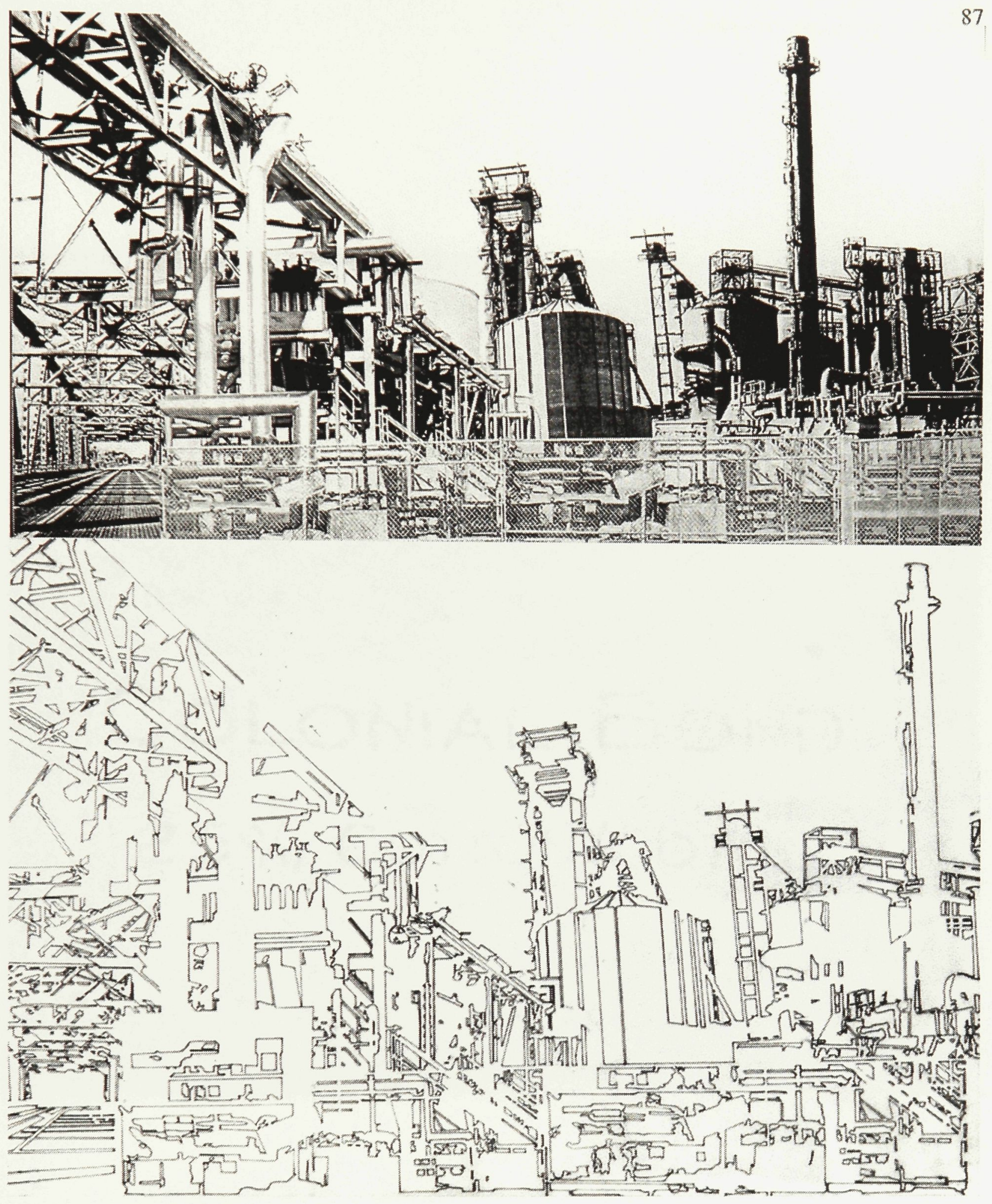

Plate 21

Repetition

Collage and Line Drawing Ink on Mylar 


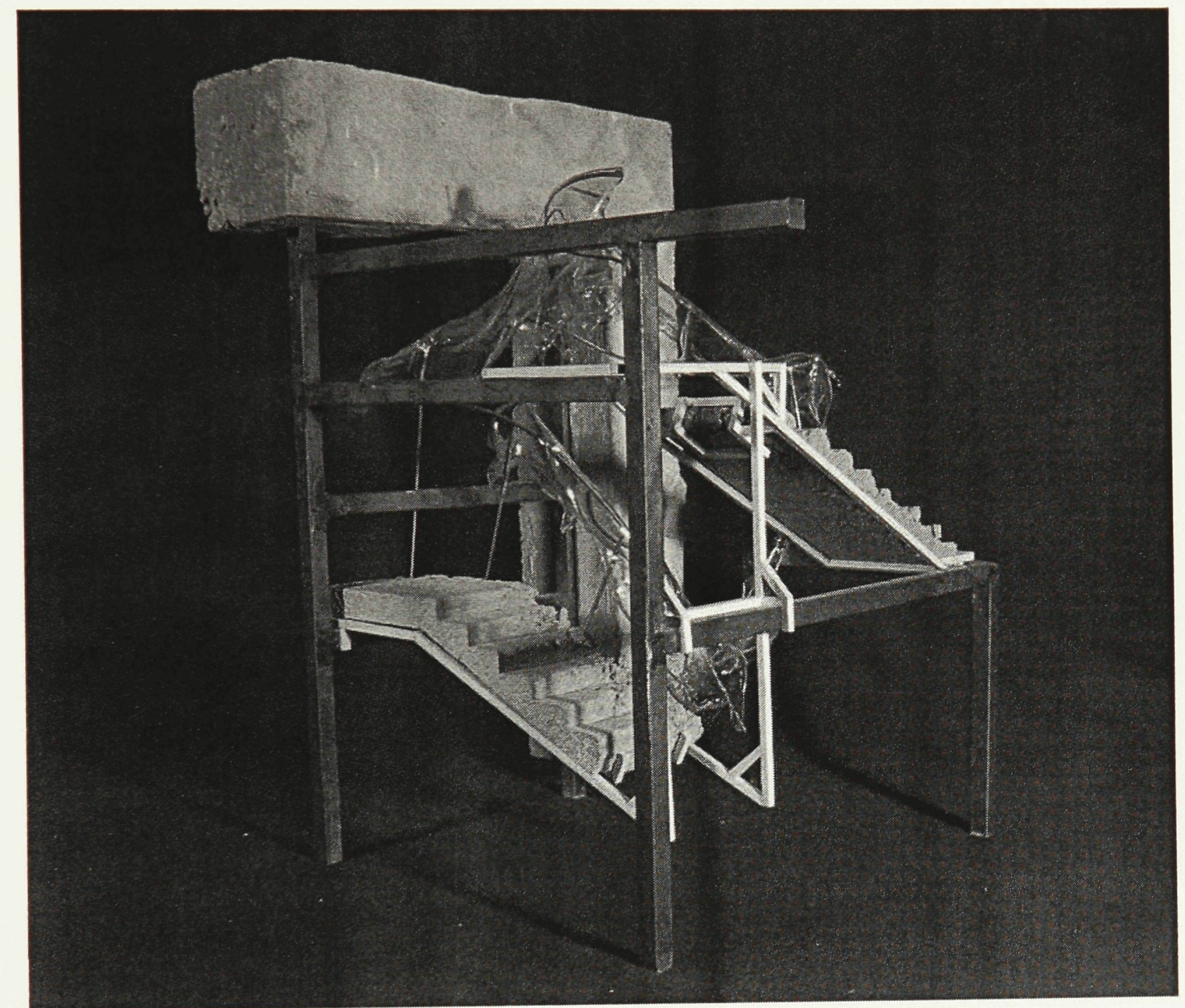

Plate 22

Verticality - Model

Model

Steel, Concrete, Wood, and Lexan 


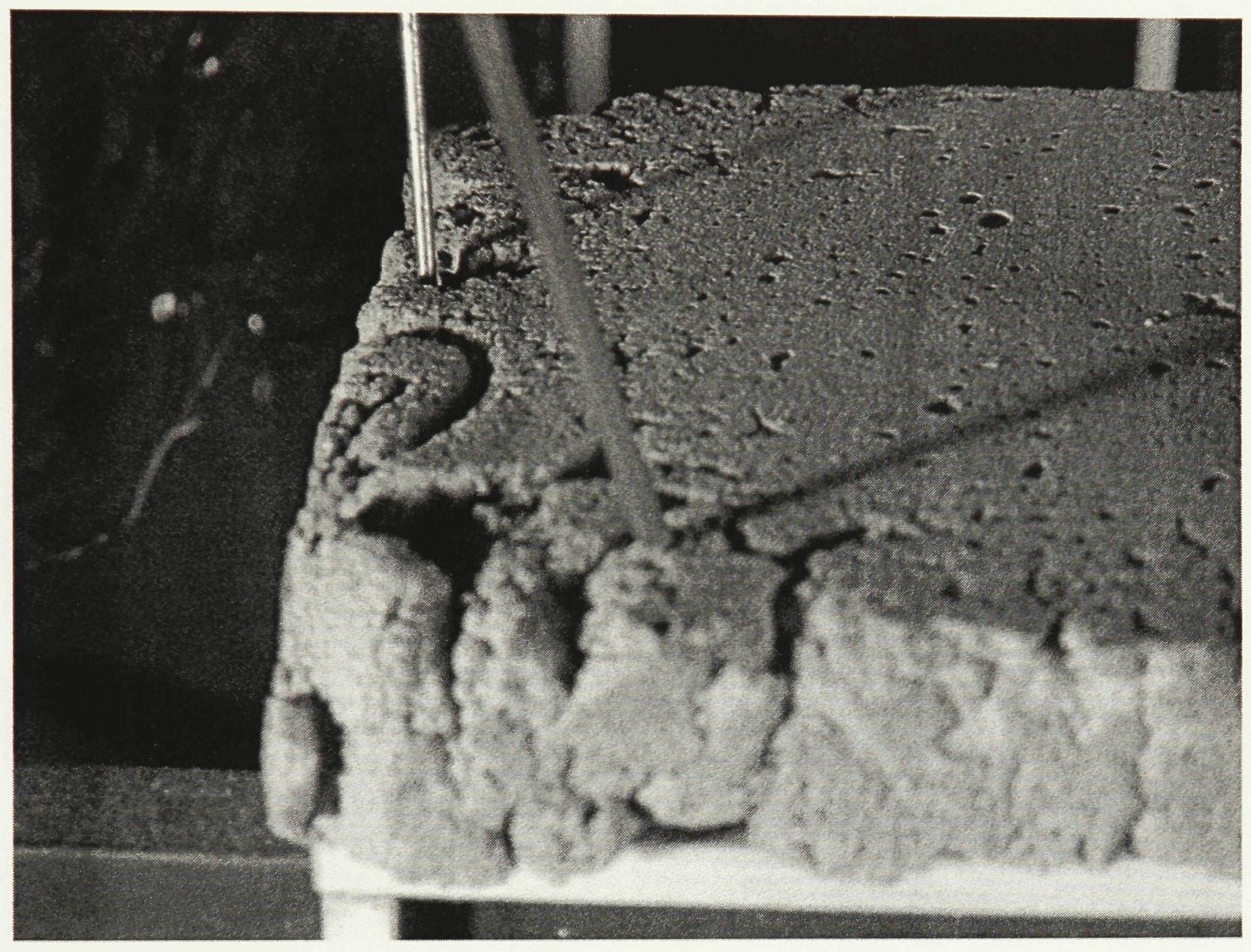

Plate 23

Verticality - Model - Detail 1

Model

Steel, Concrete, Wood, and Lexan 


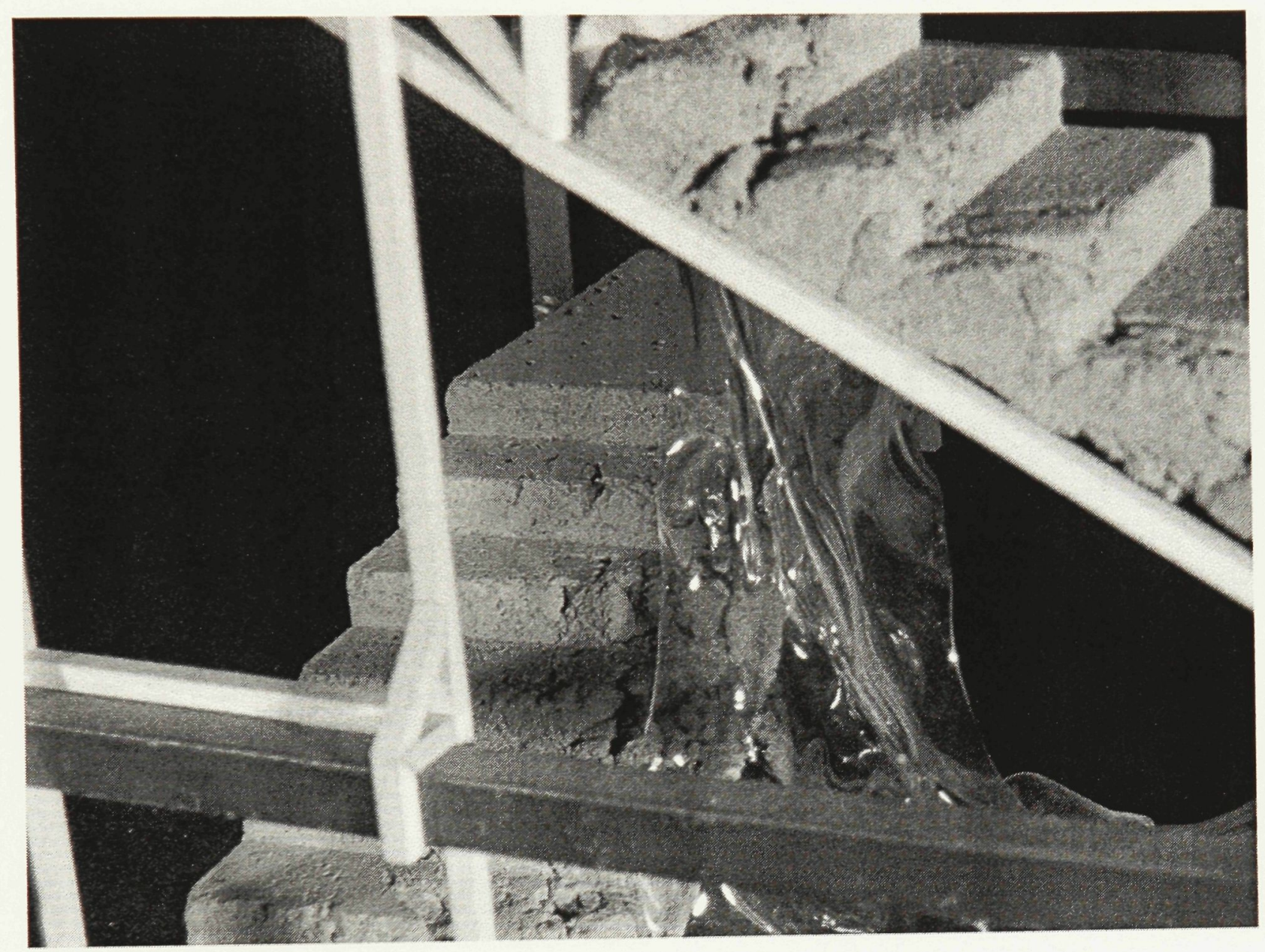

Plate 24

Verticality - Model - Detail 2

Model

Steel, Concrete, Wood, and Lexan 


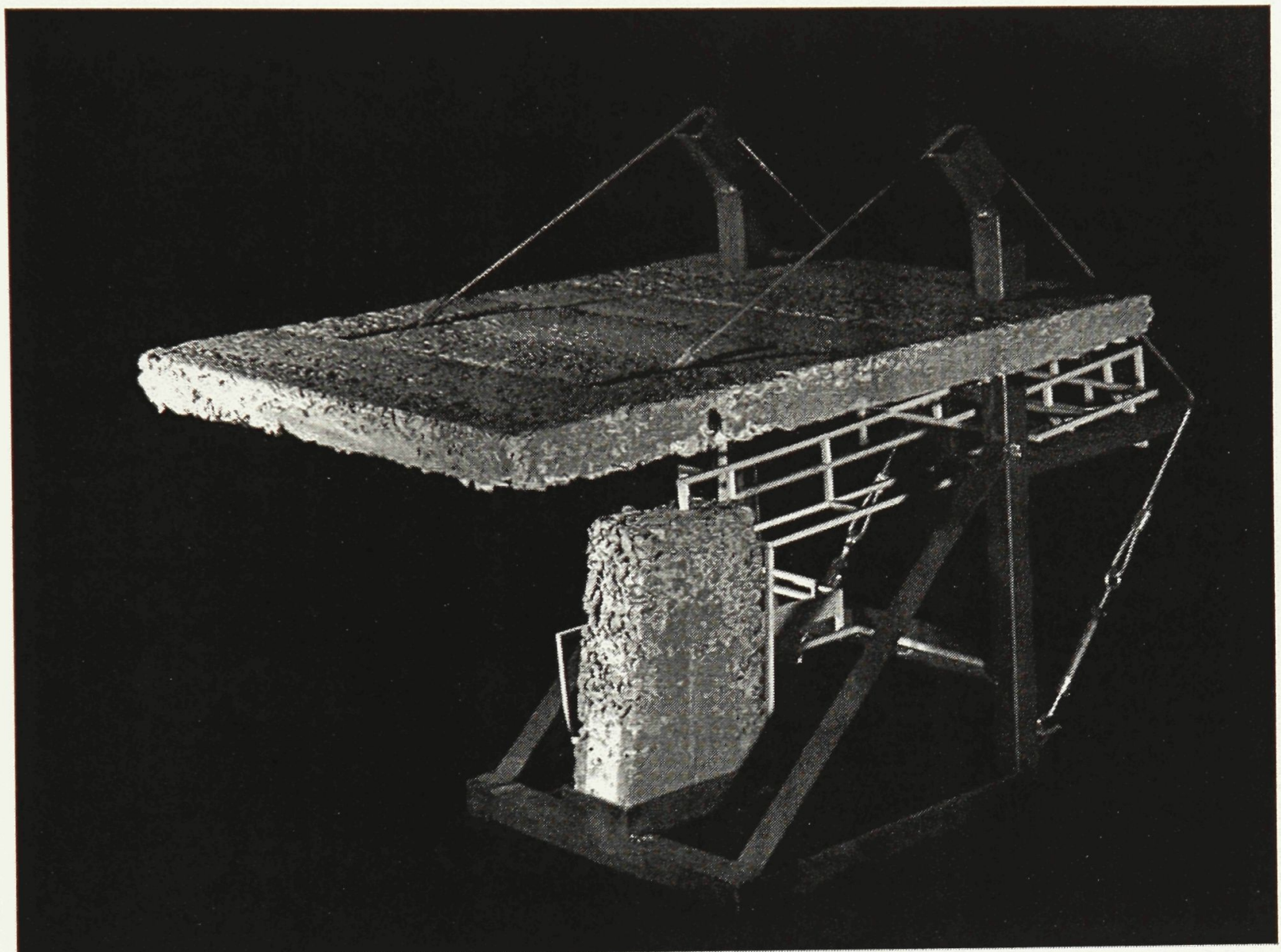

Plate 25

Horizontality - Model

Model

Steel, Concrete, Wood, and Glass 

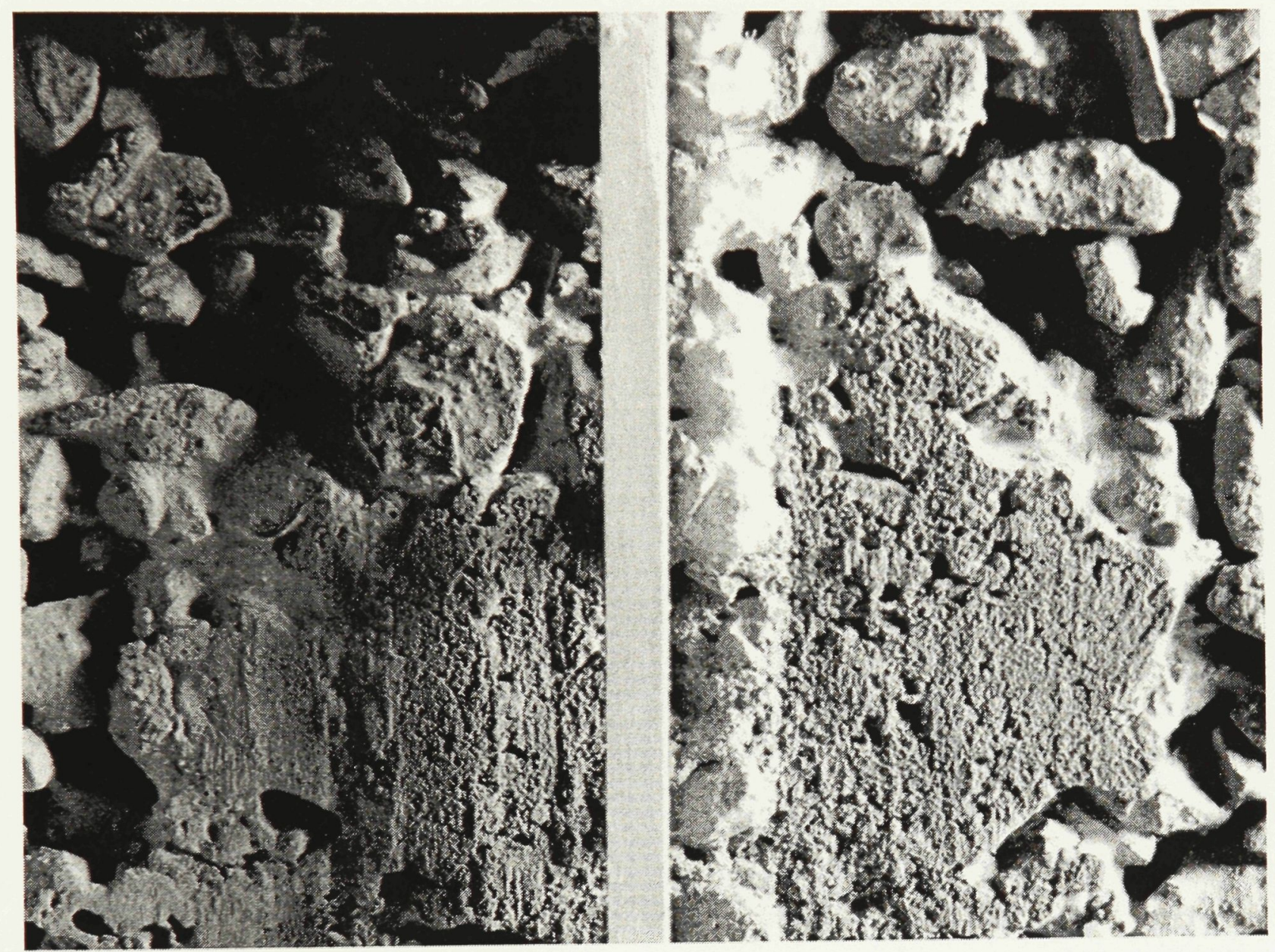

Plate 26

Horizontality - Model - Detail 1

Model

Steel, Concrete, Wood, and Glass 


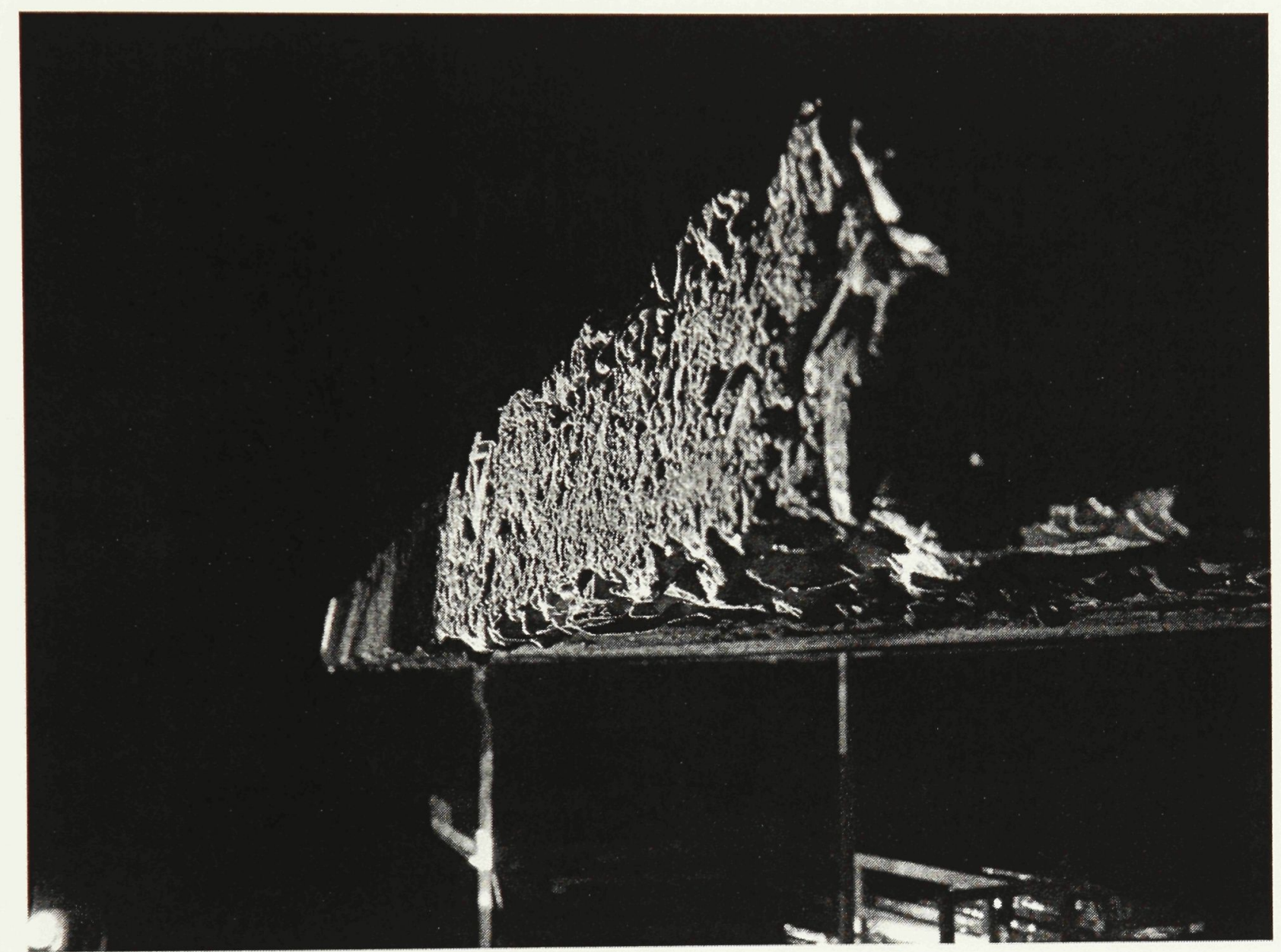

Plate 27

Horizontality - Model - Detail 2

Model

Steel, Concrete, Wood, and Glass 


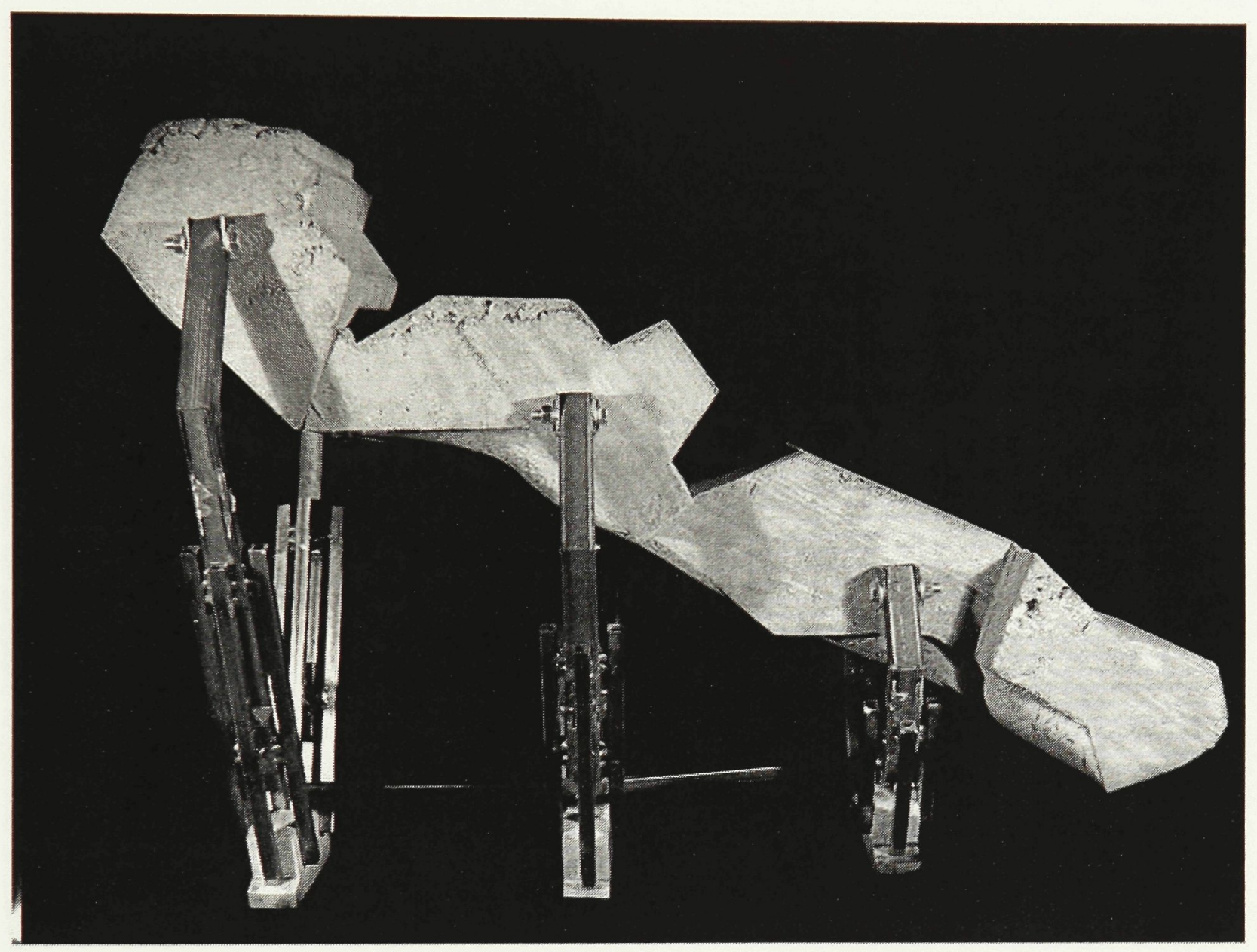

Plate 28

Repetition - Model

Model

Steel and Concrete 


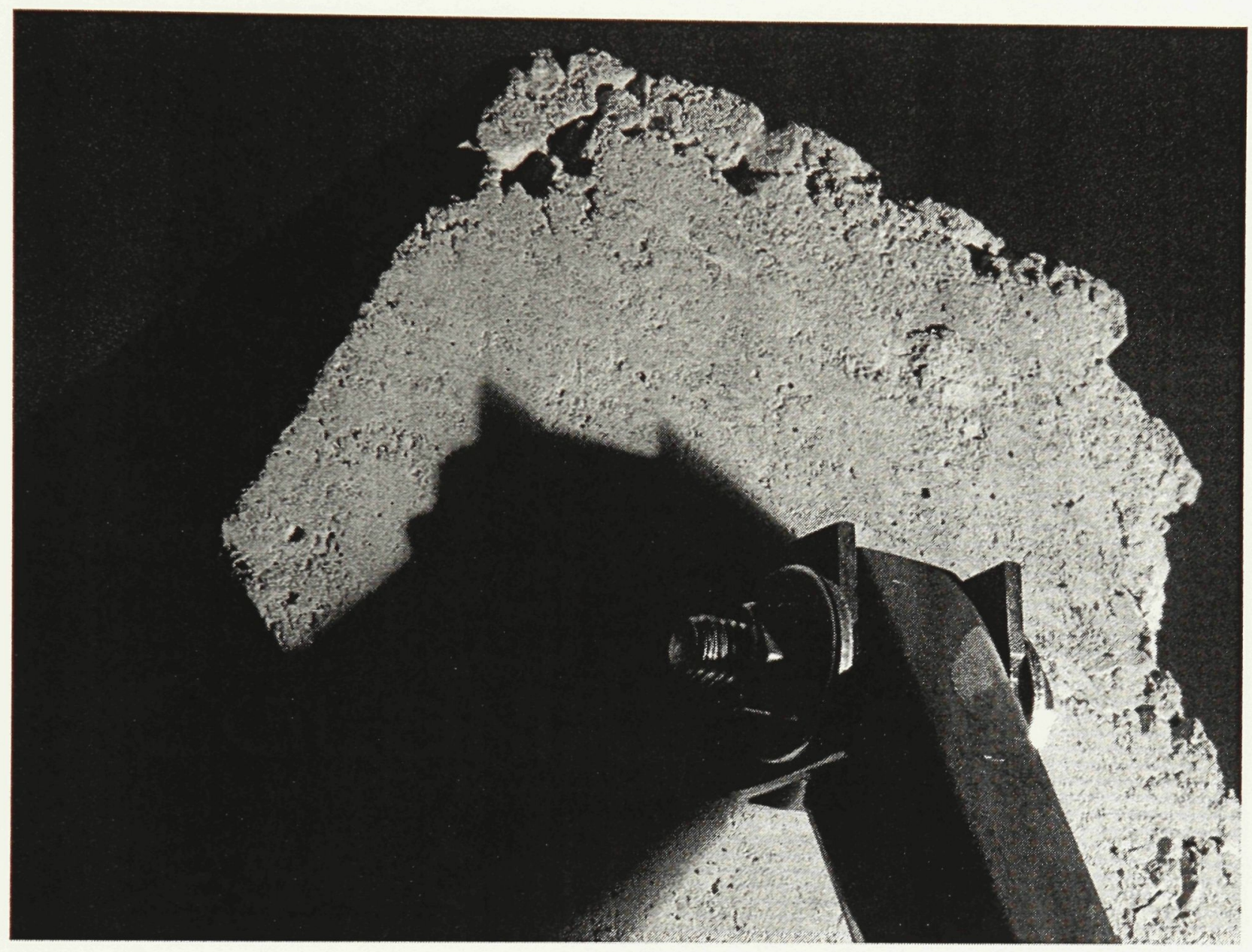

Plate 29

Repetition - Model - Detail 1

Model

Steel and Concrete 


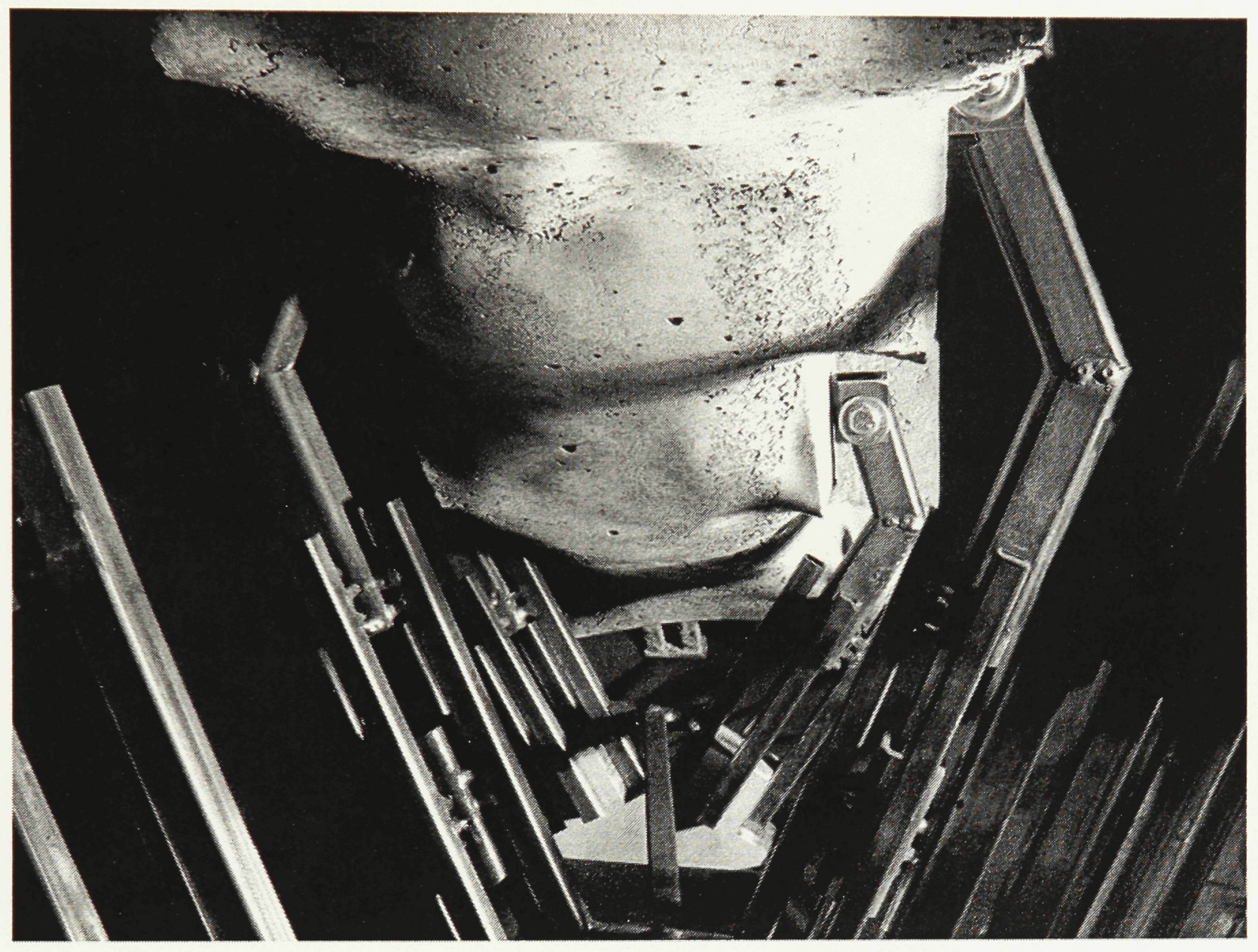

Plate 30

Repetition - Model - Detail 2

Model

Steel and Concrete 


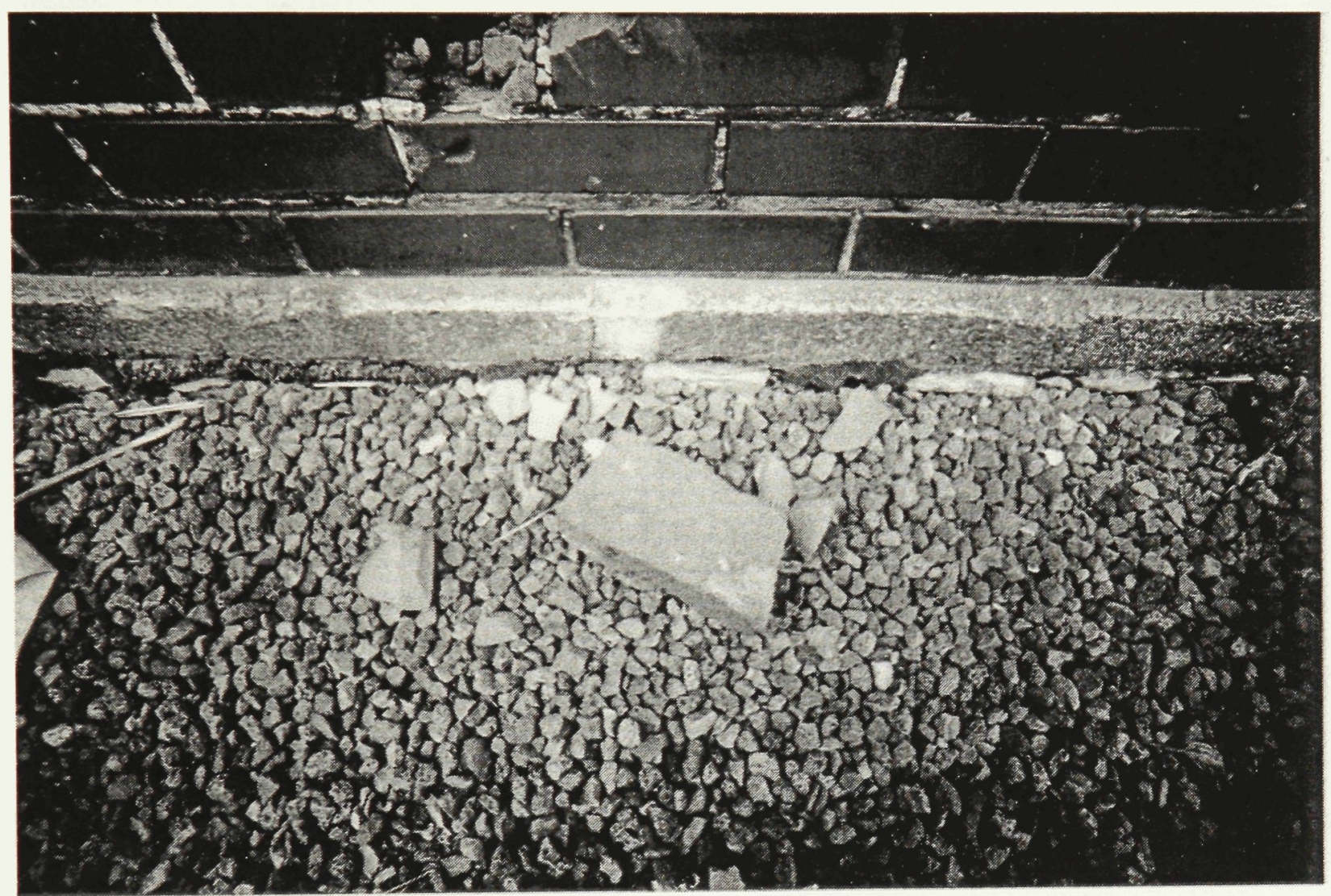

Plate 31 Planimetric Survey 1 


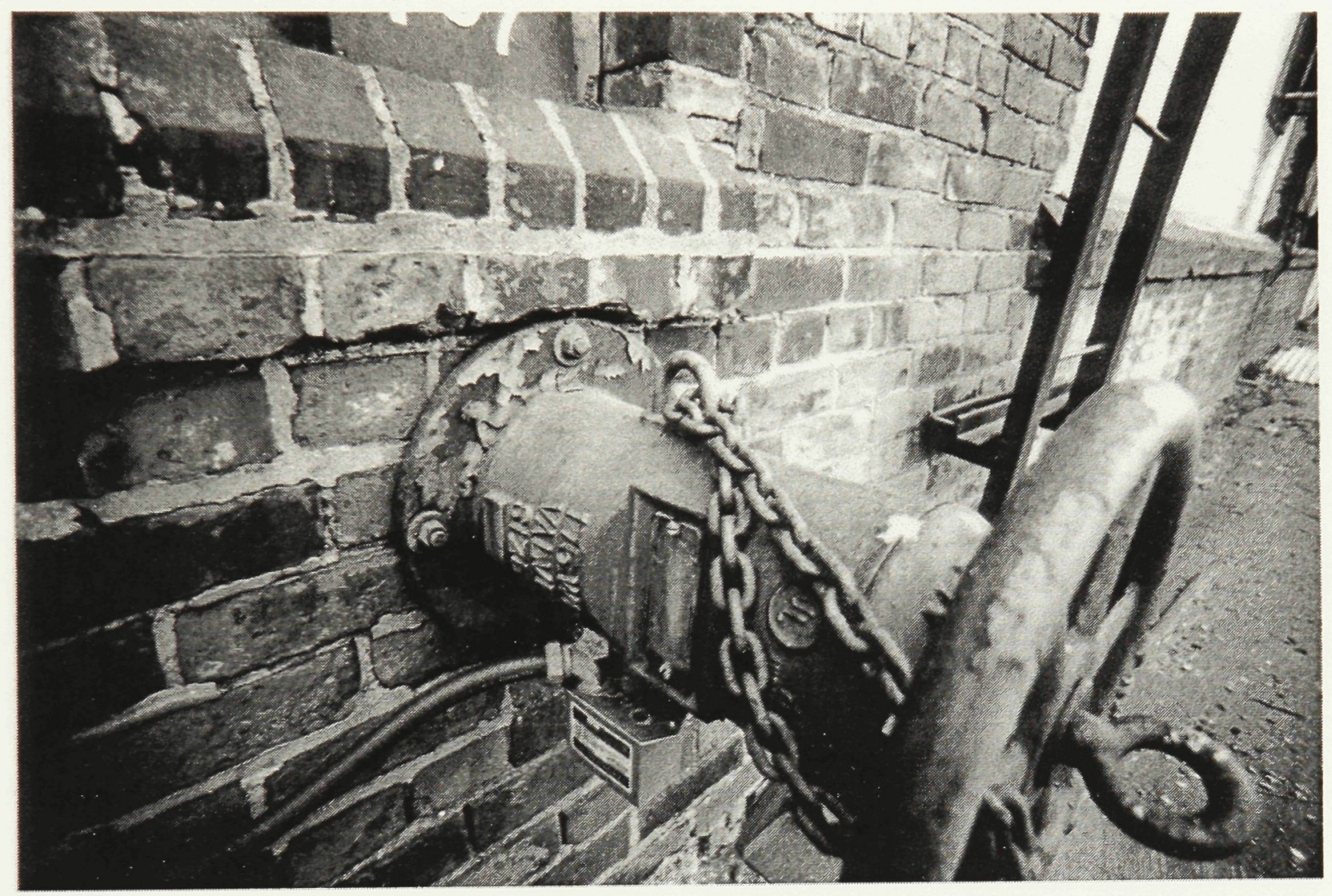

Plate 32

Planimetric Survey 2 


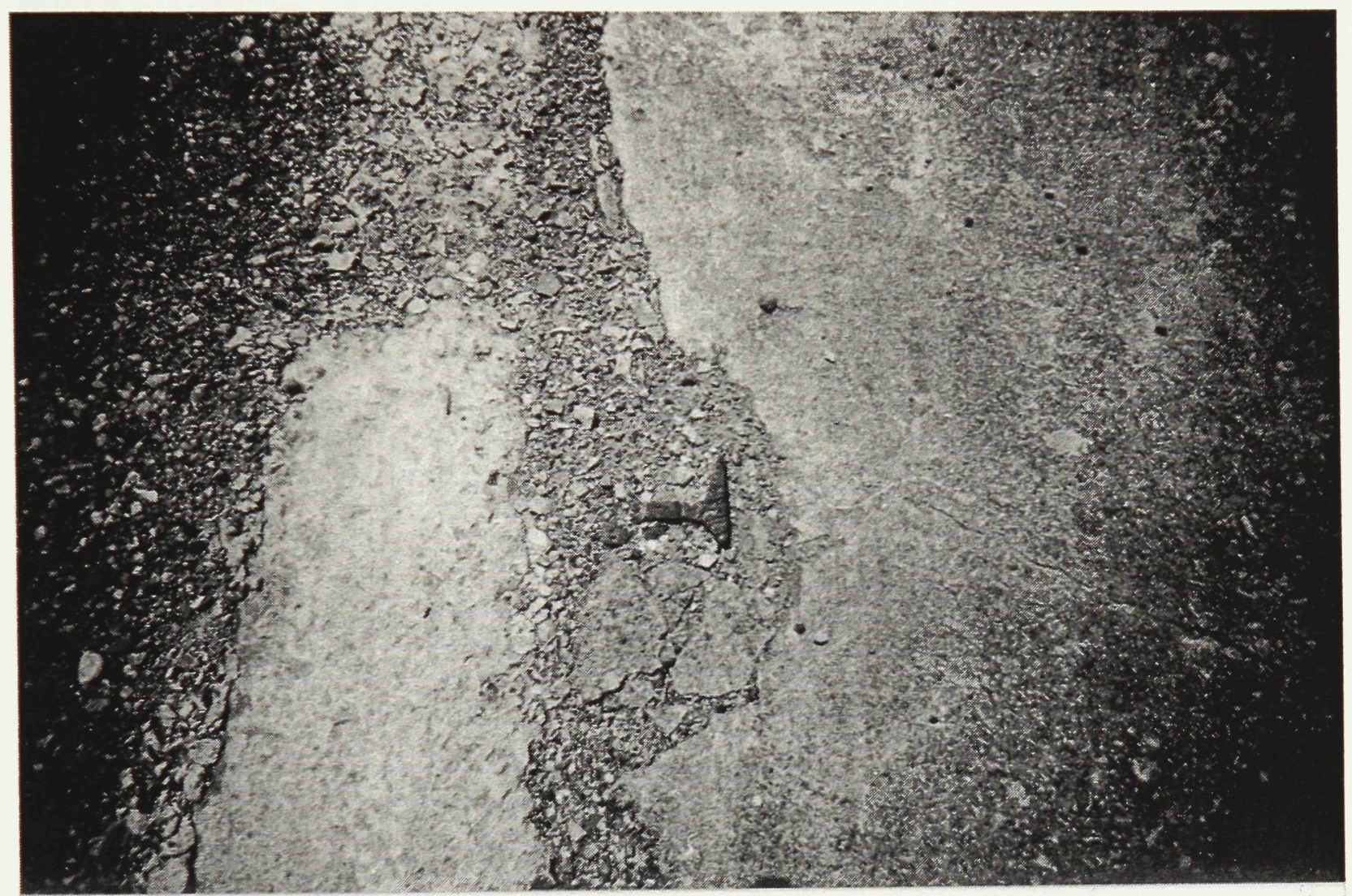

Plate 33

Planimetric Survey 3

Photograph 


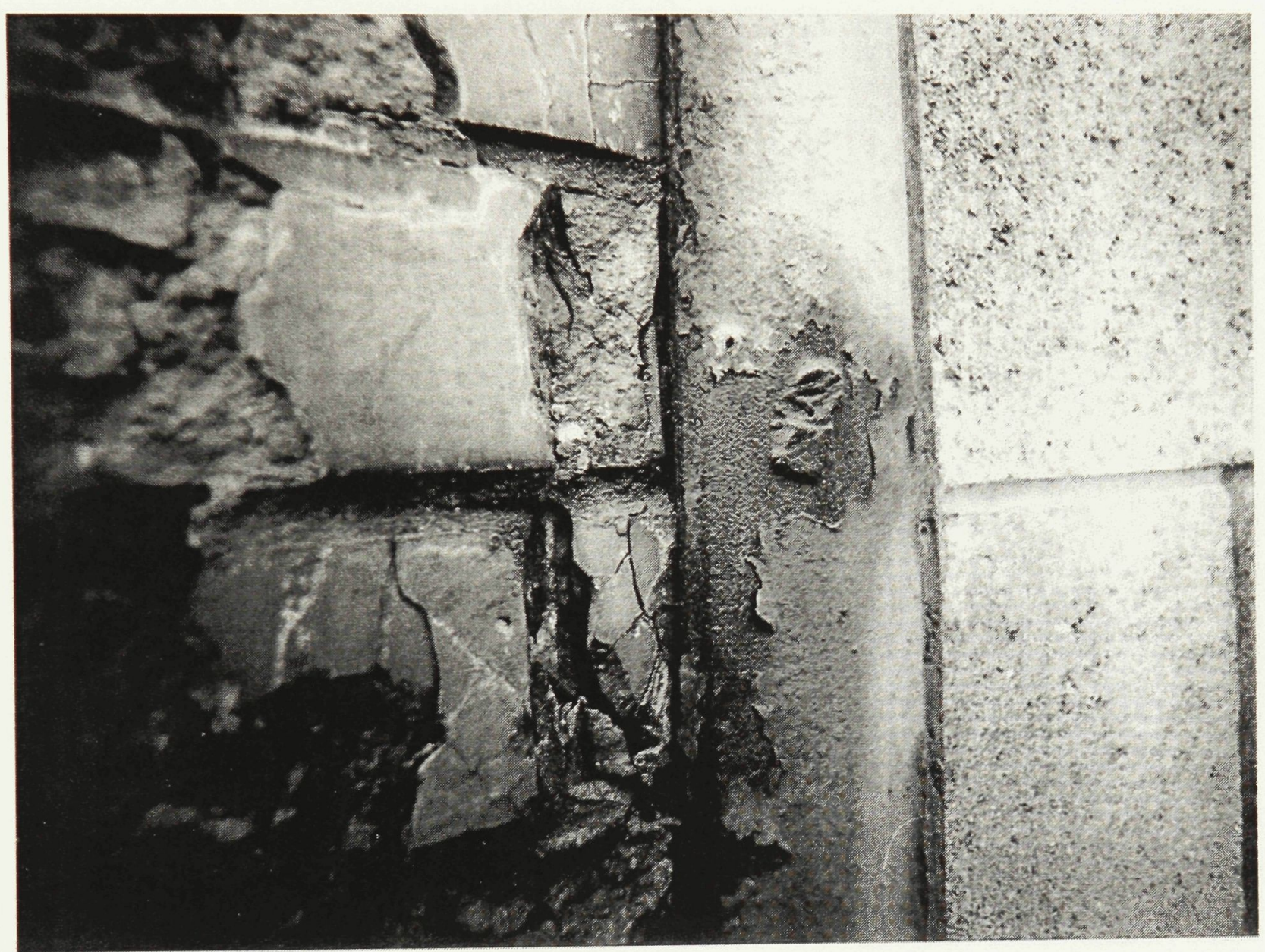

Plate 34

Sectional Survey 1

Photograph 


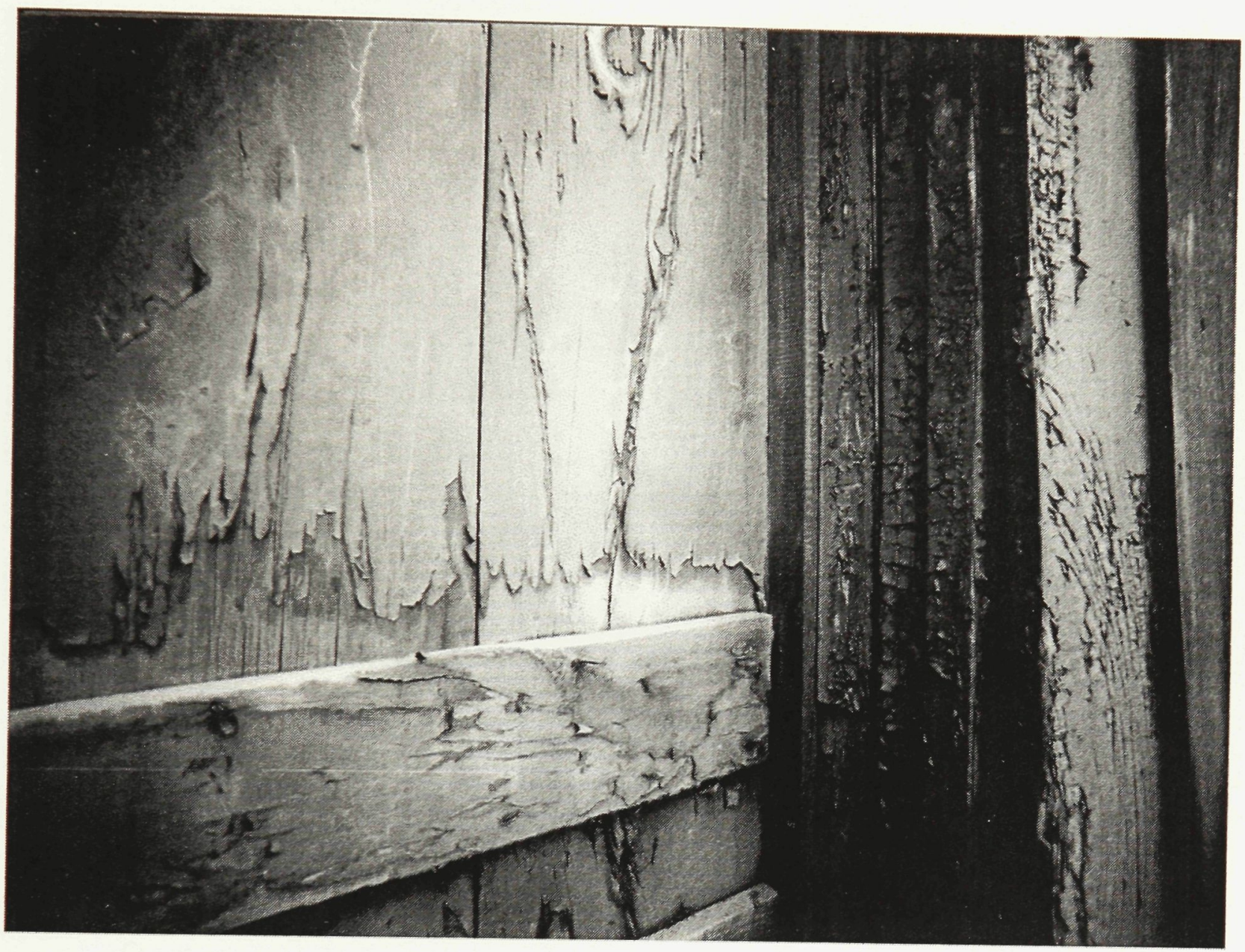

Plate 35

Sectional Survey 2

Photograph 


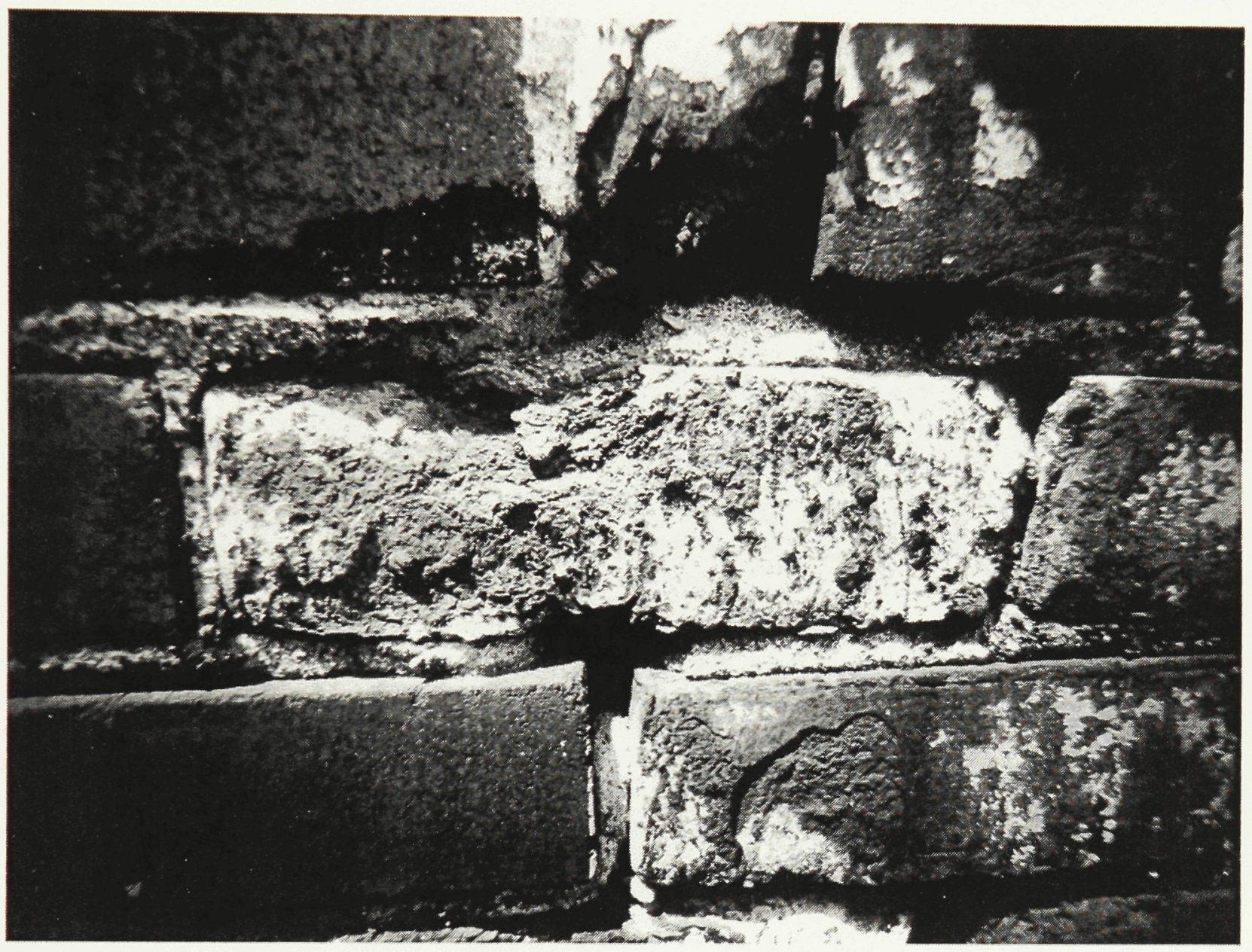

Plate 36

Sectional Survey 3

Photograph 


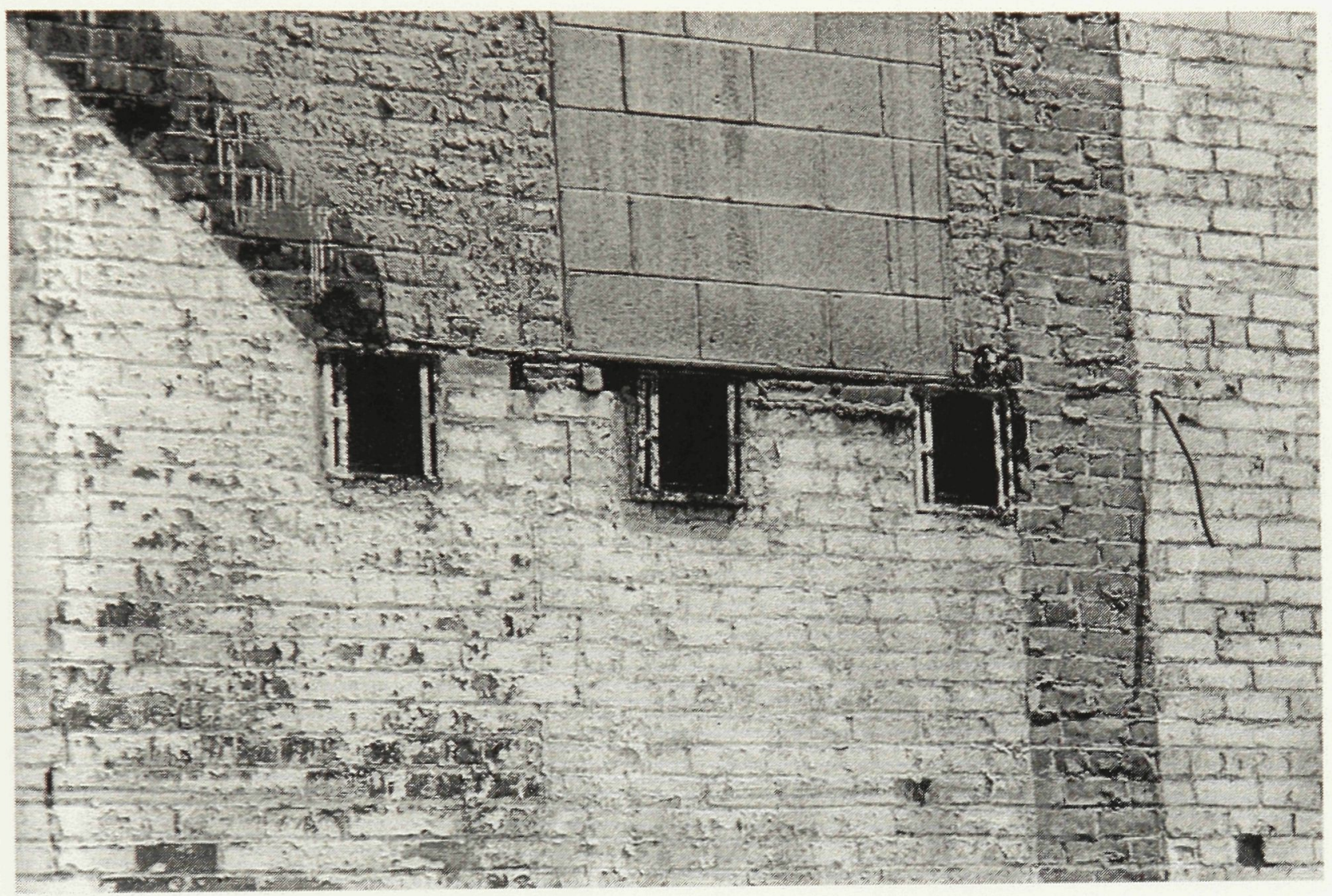

Plate 37

Elevational Survey 1

Photograph 


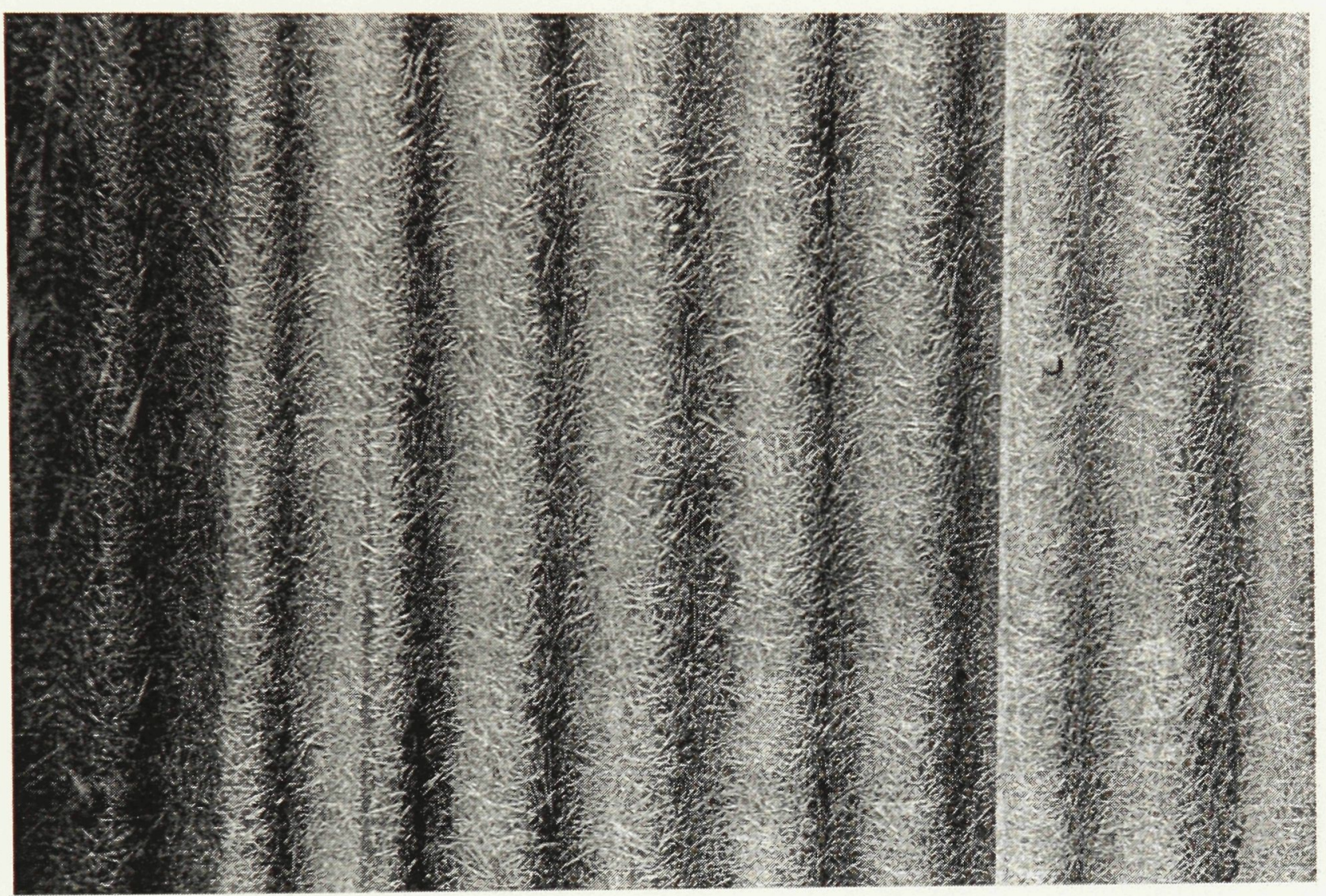

Plate 38

Elevational Survey 2

Photograph 


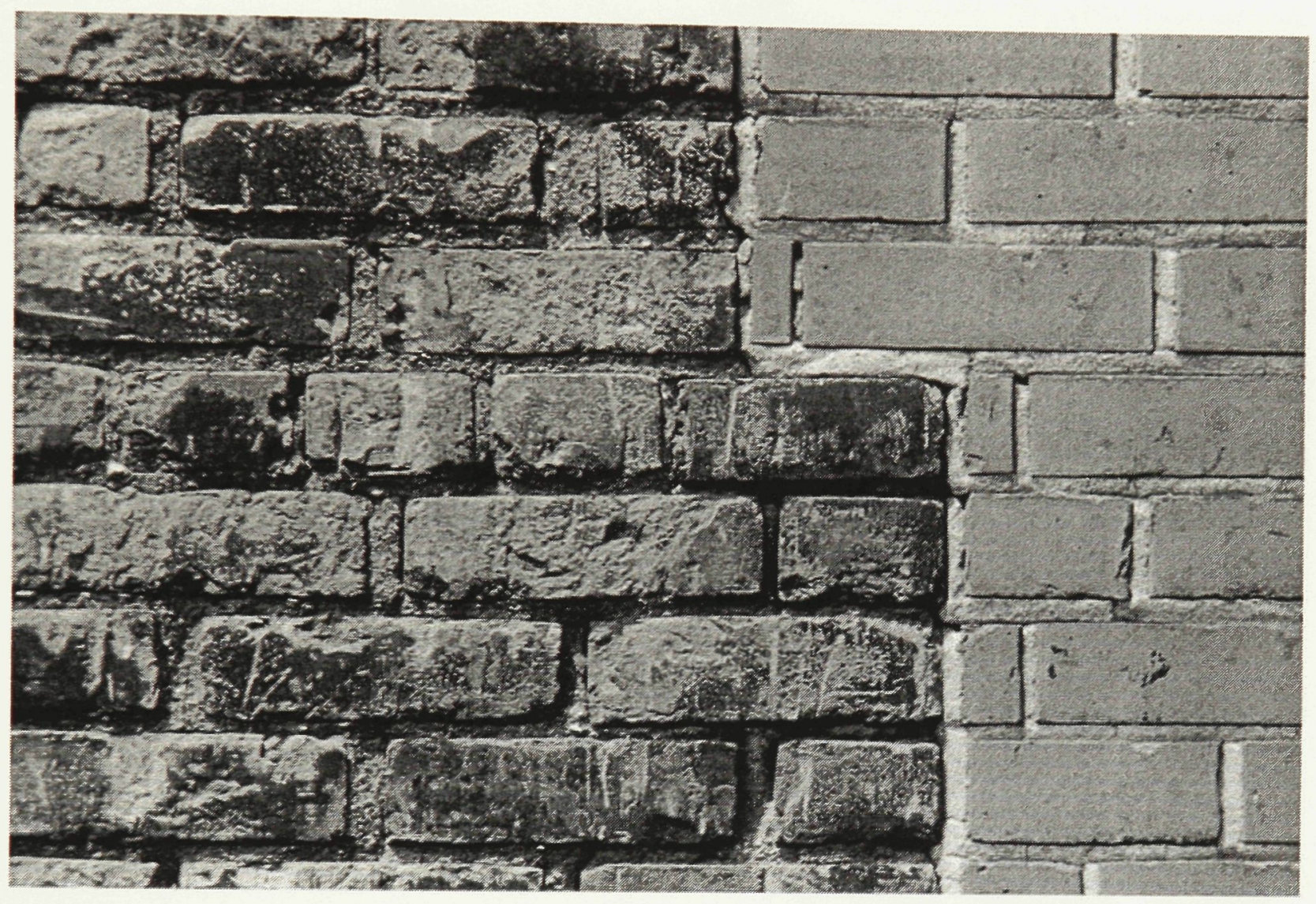

Plate 39

Elevational Survey 3

Photograph 


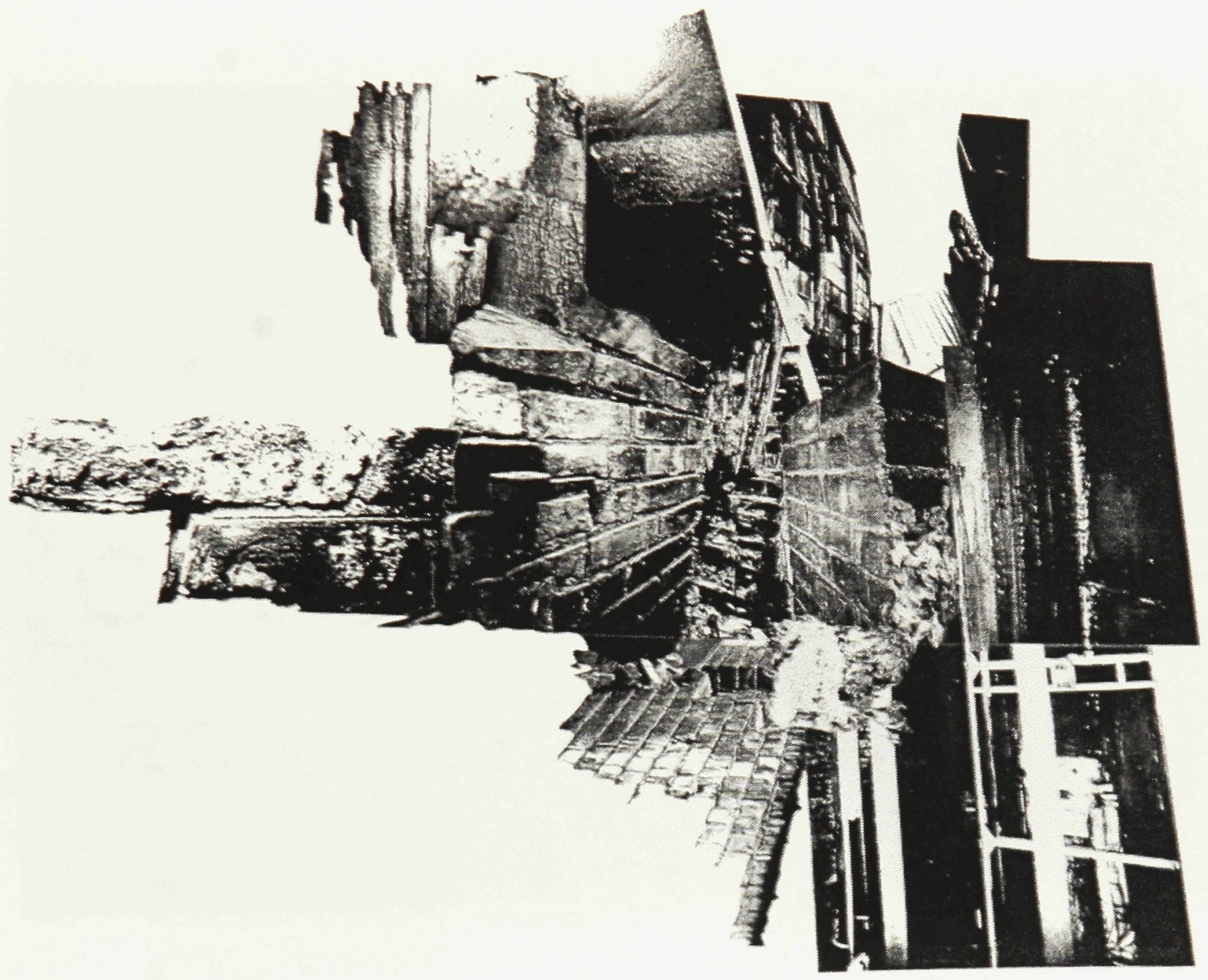

Plate 40

Section Collage

Xerox Laser Copies 


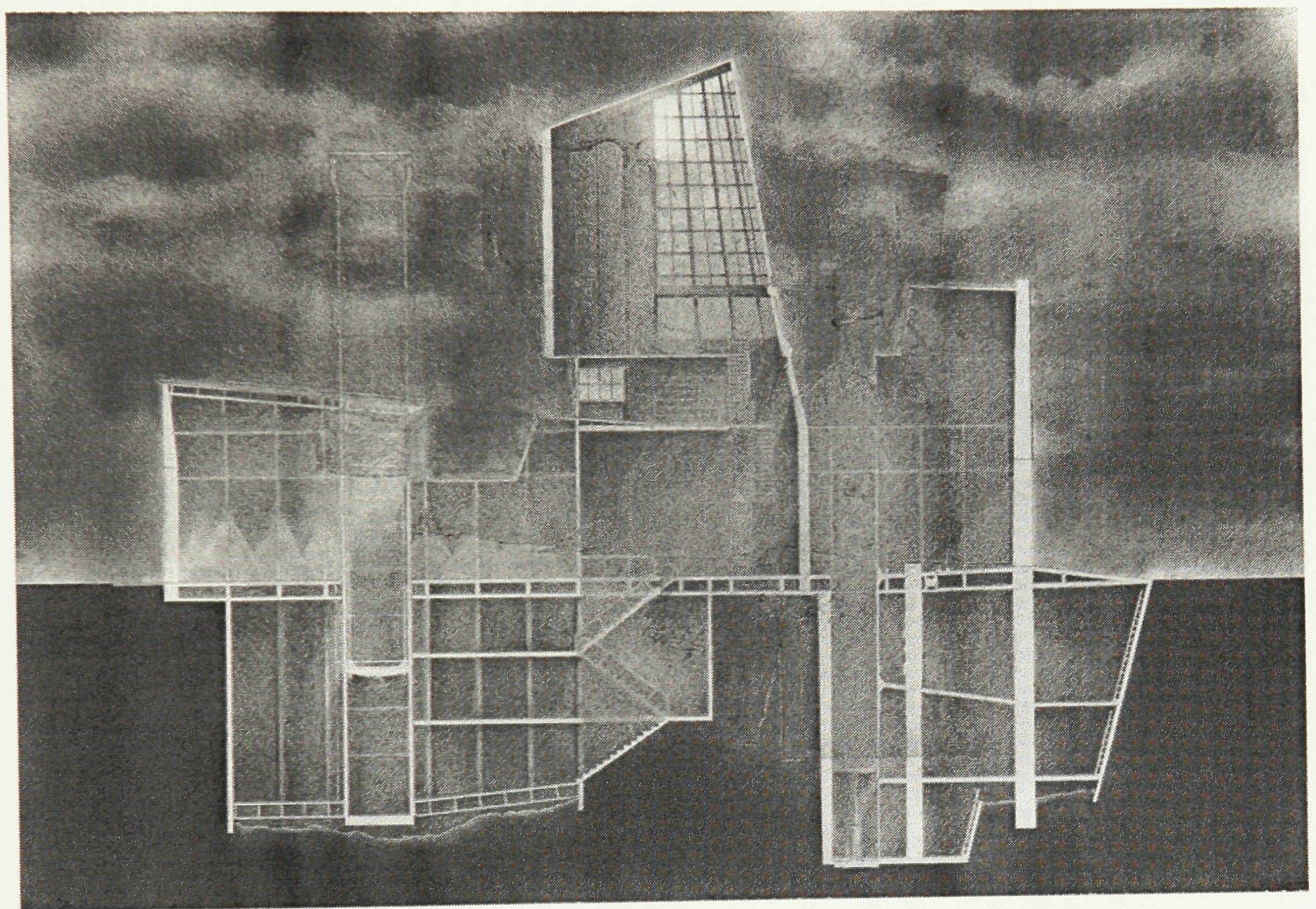

Plate 41 Drawing - Section Collage, Graphite, White Colour Pencil 


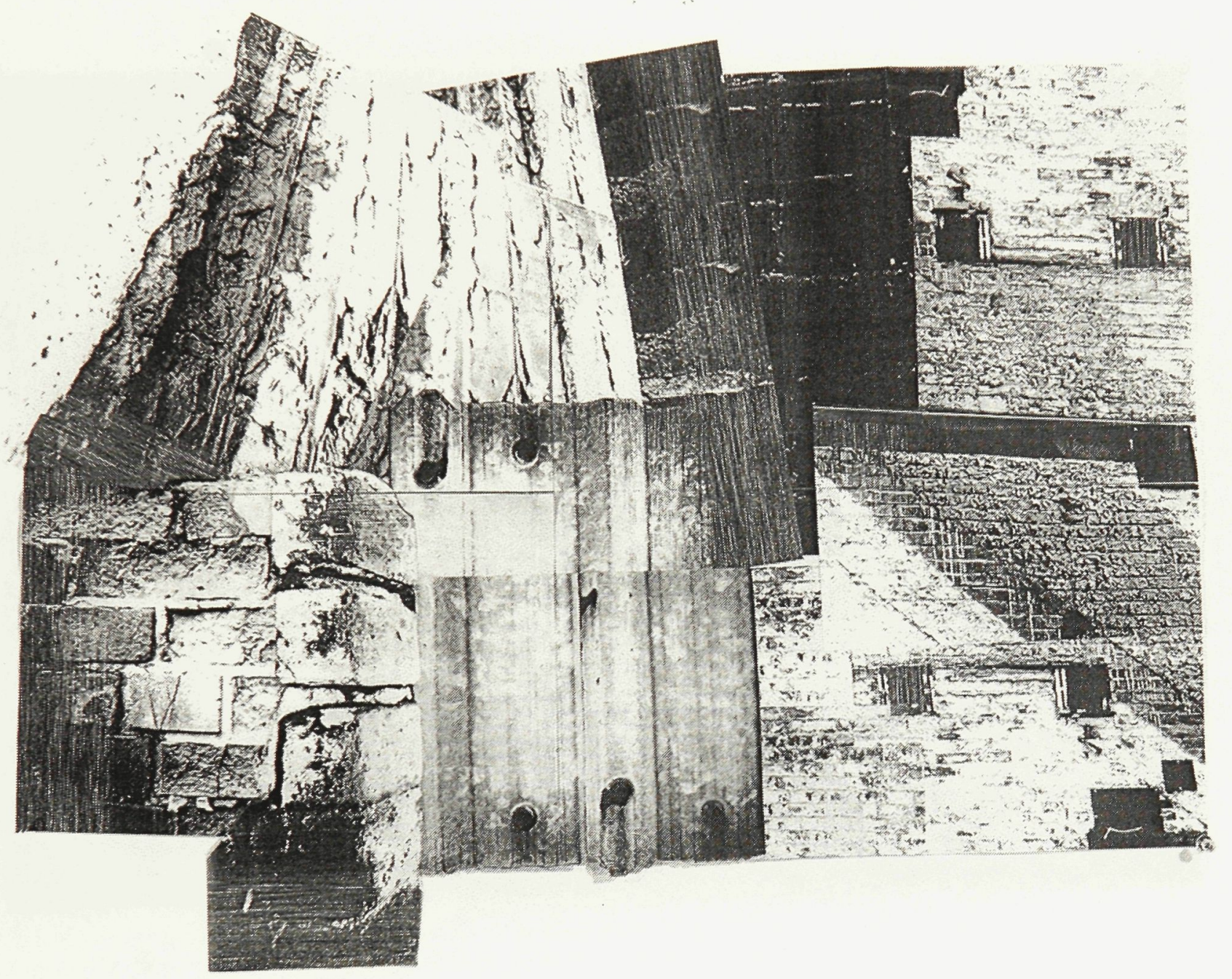

Plate 42

Elevation Collage

Xerox Laser Copies 


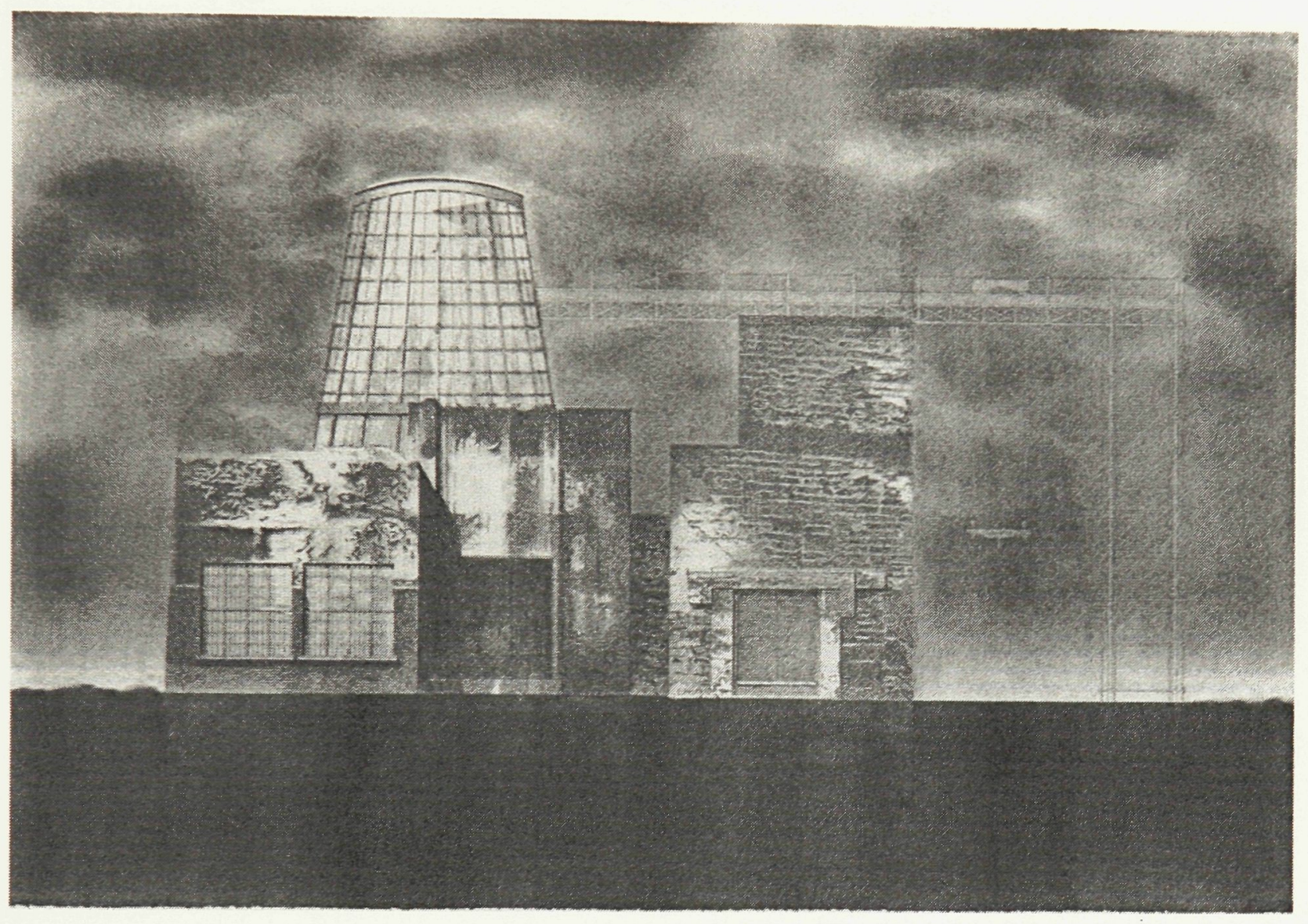

Plate 43

Drawing - Elevation

Transfer, Graphite, White Colour Pencil 


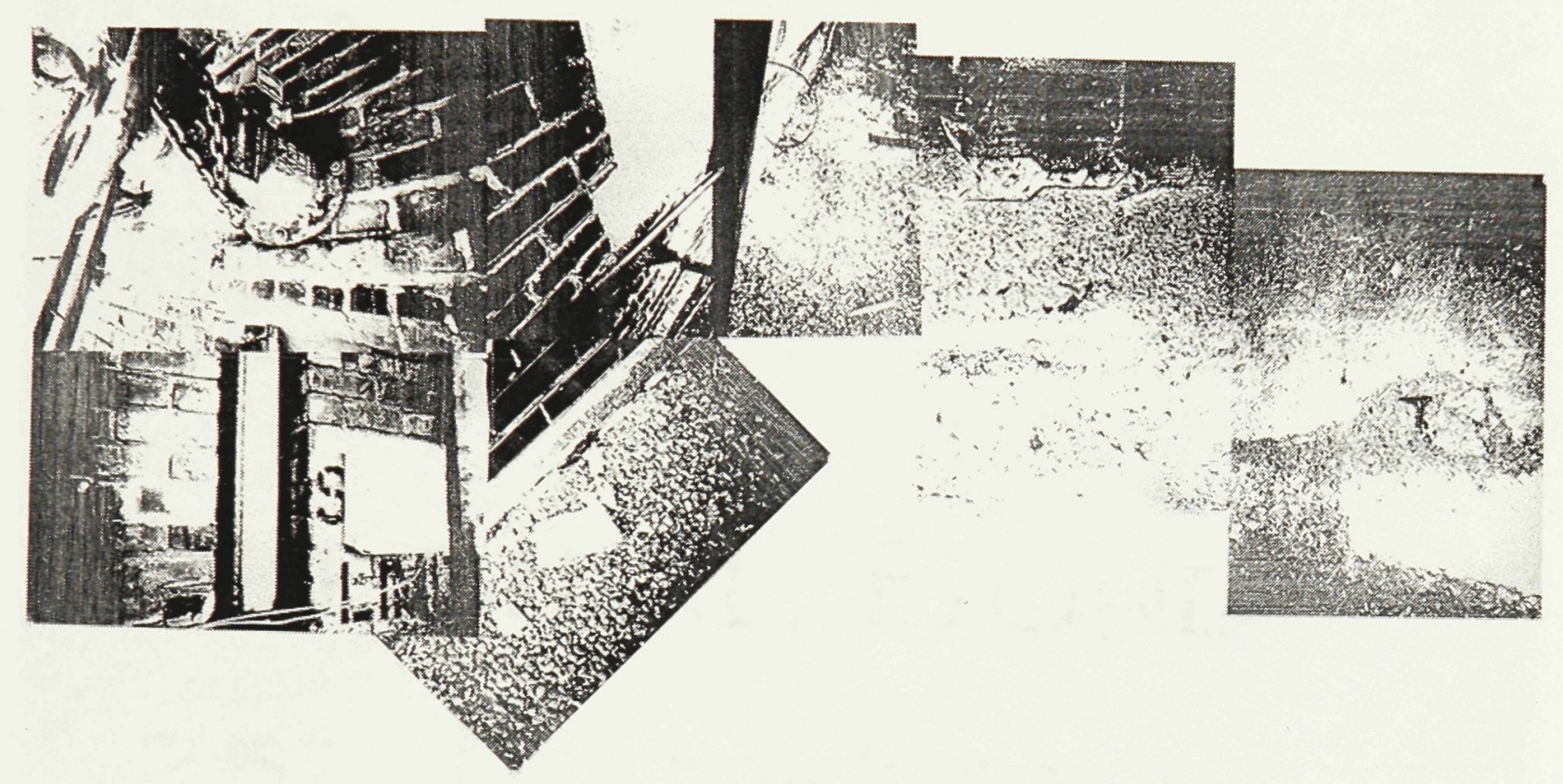

Plate 44

Plan Collage

Xerox Laser Copies 


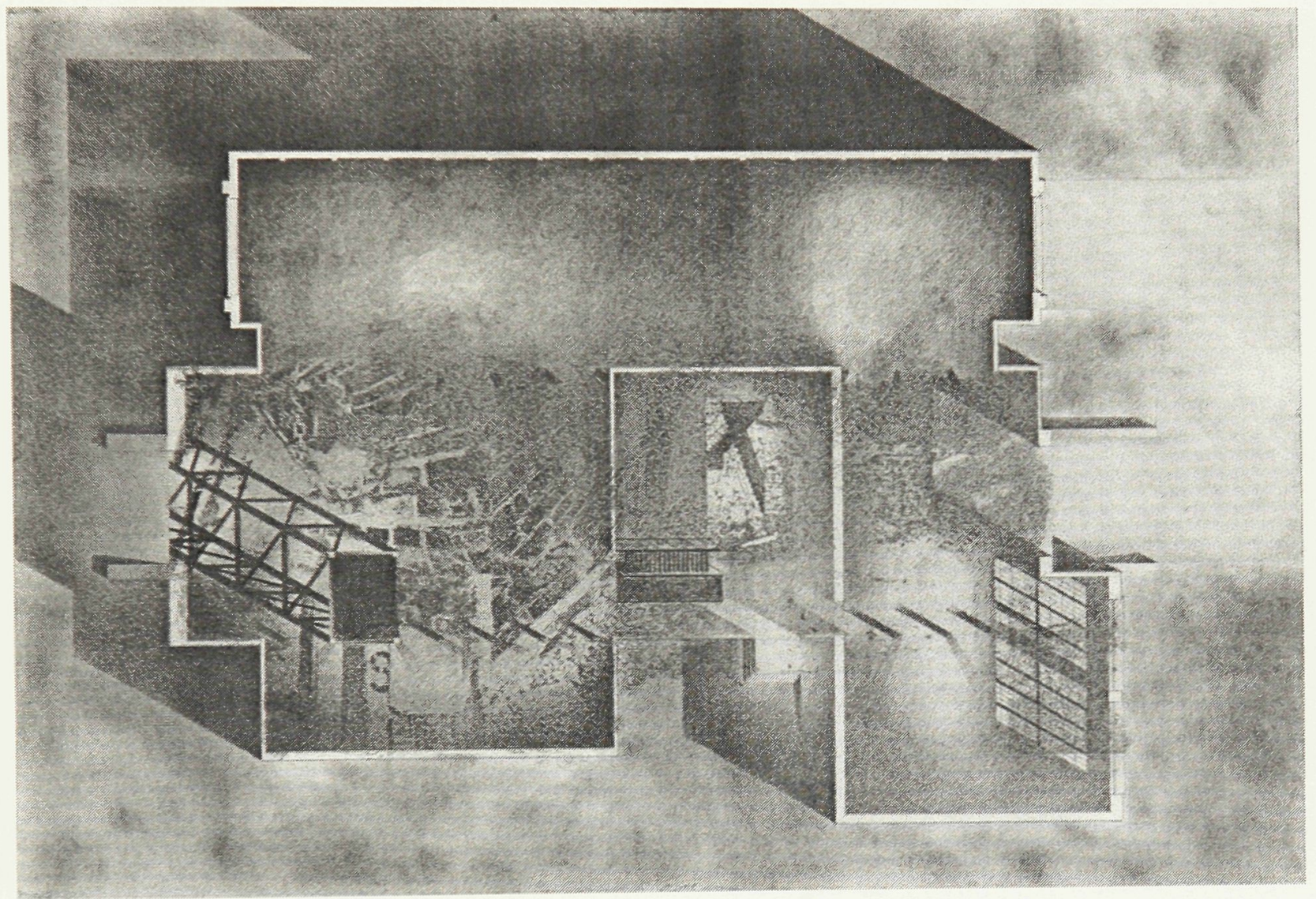

Plate 45

Drawing - Plan

Transfer, Graphite, White Colour Pencil 


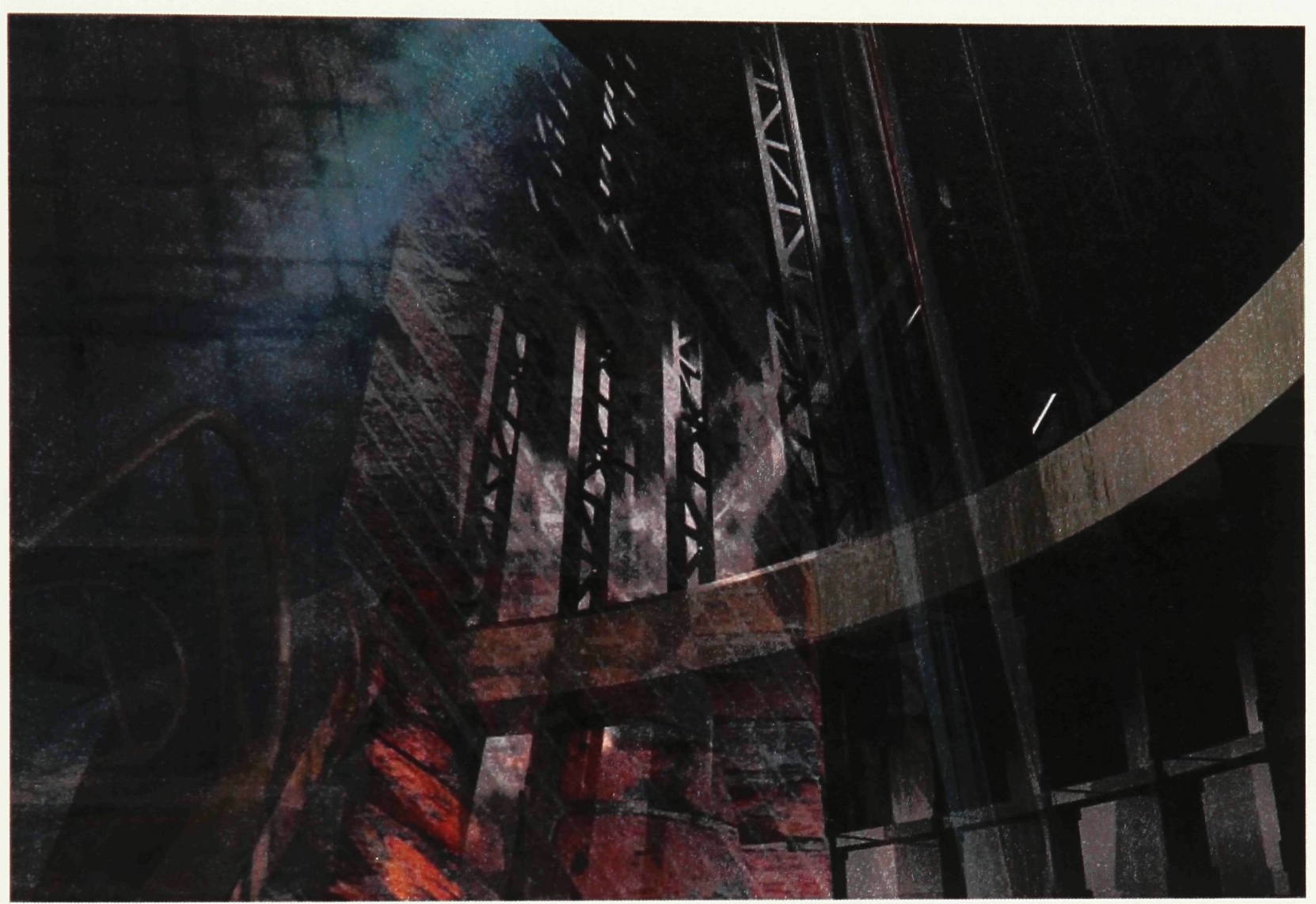

Plate 46

Computer Panel One - Curtain Wall

3dStudio and Photoshop 


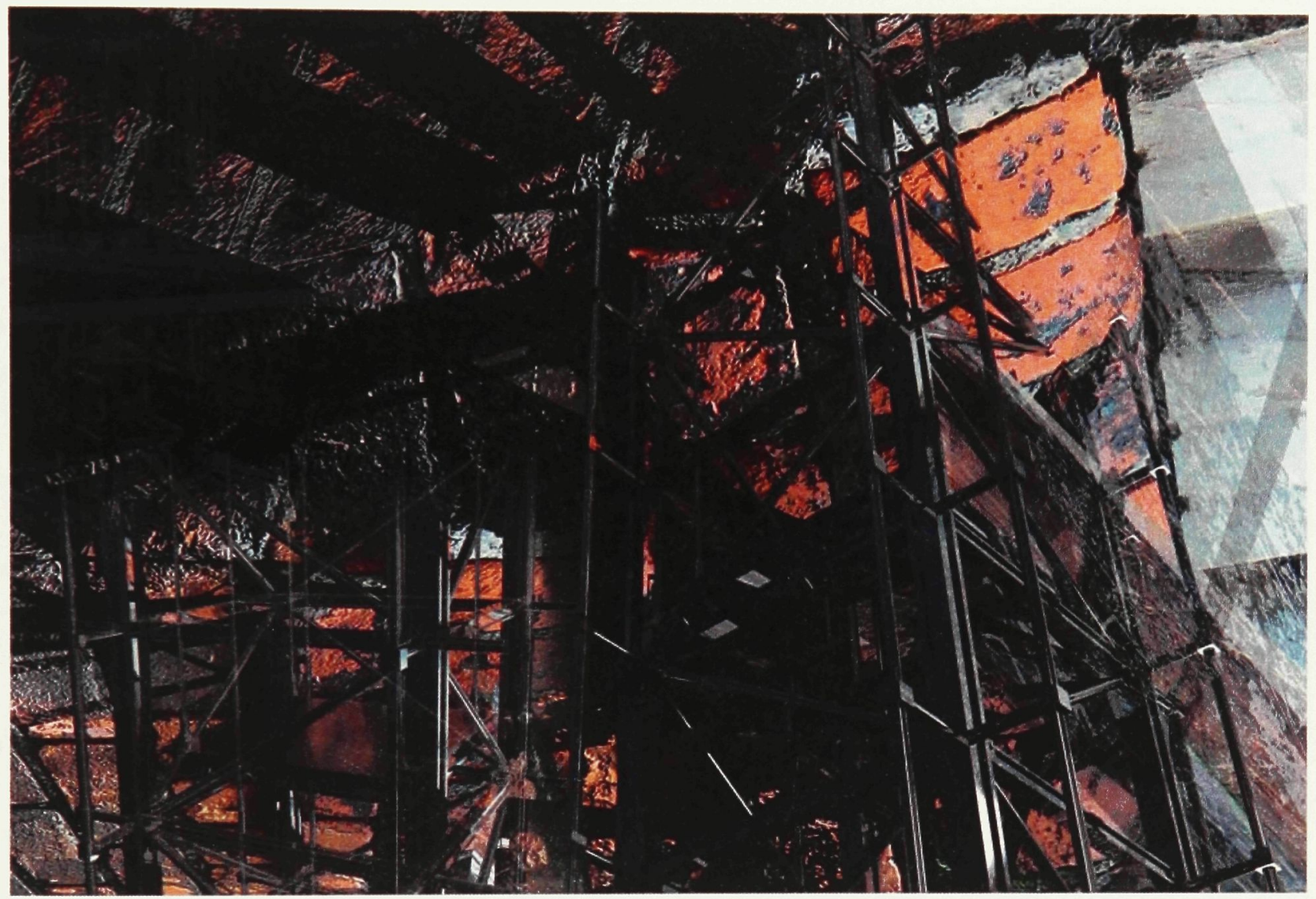

Plate 47

Computer Panel Two - Crane

3dStudio and Photoshop 


\section{Conclusion}

This document exists as a weaving of architectural threads in an attempt to address the current status of our gaze, and the implications of that gaze on the art of architecture. By directly engaging an 'architecture of desire', the interested viewer is enticed to acknowledge their subjective participation in the construction of the architectural project, and make associative links between the work, and their own recollection of memories and experiences. It is because of the exchange of the virtual that the viewer projects their intersubjectivity through the plane of representation, to 'dwell' in the virtual.

Through the specific representation techniques, and the weaving together of architectural elements, the architect is able to construe ideas and events, that shape the embodied experience of the project. The common thread that interlaces these elements together in this document are the specific site con(texts) and history. Which are not only apparent in the project itself, but help to define both the terminology as 
well as the positing the process in which the art of architecture can be revitalized.

These threads work their way throughout each part of the text continually influencing the development of the terminology, theory, and project, while at the same time linking each part. This process of textual weaving intends to restore the contemplative view to architectural composition, and representations.

Inherent in this process of weaving is the idea of 'return'. This return is at the heart of desire, and characterized by the cyclical nature of desire, or Lacan's aim and goal. If the real purpose of drive is not its goal, but rather its aim, then drives ultimate goal is to reproduce itself as drive. In the same way, the goal of representation is not to present a building, but reconstitute itself as idea. This can be further exemplified if we revisit Darden's Oxygen House, particularly Abraham's desire to return to the site of his near fatal accident. The return to the site for Abraham is about his fantasy to reconstruct his life from the moment of his accident (the point from which he was forever changed). It is through this idea of return that the viewer is permitted to revisit previous representations.

The cyclical nature of desire and our ability to return to the specific fragments within the architectural project, is what will preserve the "alternative orders" of time; which are crucial in establishing the exchange of the virtual, and allowing the embodied and speculative projection into it. Through the process of 
this return, the existing fragments are reassembled within the context of the overall project. This does not exclude their original function, but rather adds to it, to create a multi-layered "object of desire".

This process of return allows the contemplative understanding and subjective interpretation of representation to manifest itself within the representations. By turning away from the pornographic reliance on mediation, and towards the erotic qualities of the image, (thus putting an end to 'show'), the representations used to convey the architectural project will be understood as being inundated with meanings and interpretations inherent to the architectural project. With this turn to the contemplative view, the content of the image is inscribed in the context, and like Piranesi's Carceri, the two are no longer separable back into their distinct forms. The representations, combined with their context, history, theory and terminology, epitomize the inseparability of modes of representation inherent in the craft of making itself. This creates the multifaceted process of ideation, representation, interpretation, and imagination that is the fabric of the architectural project. 


\section{Bibliography}

Baudrillard, Jean. The Perfect Crime. London: Verso, 1996.

Darden, Douglas. Condemned Building: an Architect's Pre-text. New York: Princeton Architectural Press, 1993.

Dibbets, Jan. Ian Dibbets: Essays. New York: Rissoli International Publication INC., 1987.

Evans, Robin. Translations from Drawing to Building. Cambridge: MIT Press, 1997.

Felluga, Dino. "Modules on Lacan: On the Structure of the Psyche." Introductory Guide to Critical Theory. November 28, 2003. Purdue U. March 12, 2005. $<$ http://www.purdue.edu/guidetotheory/psychoanalysis/lacanstructure.ht $\mathrm{ml}>$.

Ficacci, Luigi. Giovanni Battista Piranesi. Trans. Bradley B. Dick. Ed. Thierry Nebois. New York: Taschen, 2001.

Frascari, Marco. Monsters of Architecture: Anthropomorhism in Architectural Theory. Maryland: Rowman \& Littlefield Publishers, INC., 1991.

Foti, Veronique. "Turning at the Limits of Closure: Heidegger's and MerleauPonty's Turn from Technicity to Art." Philosophy Today. (1986): 306-316.

Gadamer, Hans-Georg. "The Relevance of the Beautiful: Art as Play, Symbol, and Festival." Trans. Nicholas Walker. The Relevance of the Beautiful and Other Essays. Ed. Robert Bernasconi. Cambridge: Cambridge University Press, 1986. 3-53.

Grosz, Elizabeth A. Architecture from the Outside: Essays on Virtual and Real Space. Cambridge, Mass.: MIT Press, 2001. 
Heidegger, Martin. “Building Dwelling Thinking." Poetry, Language, Thought. Trans. Albert Hofstadter. New York: Harper Colophon Books, 1971. 145161.

Hunt, Lynn. The Invention of Pornography: Obscenity and the Origins of Modernity 1500-1800. New York: Zone Books, 1996.

Illich, Ivan. "Guarding the Eye in the Age of Show." http://ournature.org/ novembre/illich/1995_guarding_the_eye.PDF. November 31, 2000. January 22, 2005. <http://ournature.org/ novembre/illich/1995_ guarding_the_eye.PDF>.

Kockelkoren, Petran. Technology: Art, Fairground and Theatre. Rotterdam: Nai Publishers, 2003.

Kunze, Donald. "Evil Enchantment: The Anacoluthic Structure of Architectural Composition." Working paper, n.d.

---. "Marks of the Abject Artifact." Working paper, n.d.

Lacan, Jacques. Ecrits: A Selection. New York and London: W.W. Norton and Company, INC., 1977.

Macdonald, Andrew, Lisa Di Valintino, and Norman Pinder. "Industrial Hamilton: A Trail to the Future, Adams Ironsides, the Steam Man" History of industry in Hamilton. Hamilton Public Library. December 8, 2005. $<$ http://collections.ic.gc.ca/industrial/ironman.htm>.

---. "Industrial Hamilton: A Trail to the Future, International Harvester Company of Canada, Limit" History of industry in Hamilton. Hamilton Public Library. December 8, 2005. $<$ http://collections.ic.gc.ca/industrial/harvester.htm>.

Massumi, Brian. Parables of the Virtual: Movement, Affect, Sensation. Durham and London: Duke University Press, 2002. 
Mayné, Gilles. Eroticism in Georges Bataille and Henry Miller. Birmingham:

Summa Publications, 1993.

Merleau-Ponty, Maurice. The Primacy of Perception, and Other Essays on Phenomenological Psychology, the Philosophy of Art, History, and Politics. Evanston, Ill.: Northwestern University Press, 1962.

Roussell, Raymond. Locus Solus. New York: Riverrun Press, 1965.

Sernau, Scott. Bound: Living in the Globalized World. Connecticut: Kumarian Press Inc., 2000.

Stewart, Susan. On Longing : Narratives of the Miniature, the Gigantic, the Souvenir, the Collection. Durham: Duke University Press, 1993.

Tafuri, Manfredo. The Sphere and the Labyrinth. Trans. Pellegrino d'Acierno and Robert Connolly. Cambridge and London: MIT Press, 1987.

Weibel, Peter, and Timothy Druckrey. Net Condition: Art and Global Media. Cambridge/London: The MIT Press, 2001.

Weschler, Lawrence. Mr. Wilson's Cabinet of Wonder. New York: Pantheon Books, 1995.

Wright, Elizabeth, and Edmond Wright, eds. The Zizek Reader. Malden, Mass.: Blackwell Publishers Ltd., 1999.

Zizek, Slavoj. Looking Awry: An Introduction to Jacques Lacan Through Popular Culture. Cambridge and London: The MIT Press, 1991.

---. Organs Without Bodies: Deluze and Consequences. New York and London: Routledge, 2004.

---. The Plague of Fantasies. London and New York: Verso, 1997. 
Appendices

Appendix A

Oxygen House From: Douglas Darden, Condemned Building: an Architect's Pre-text, (New York: Princeton Architectural Press, 1993) 141-56. 


\section{Oxygen House}

A NEAR TRIPTYCH ON THE ACT OF BREATHING

FRENCHMAN'S BEND, MISSISSIPPI 


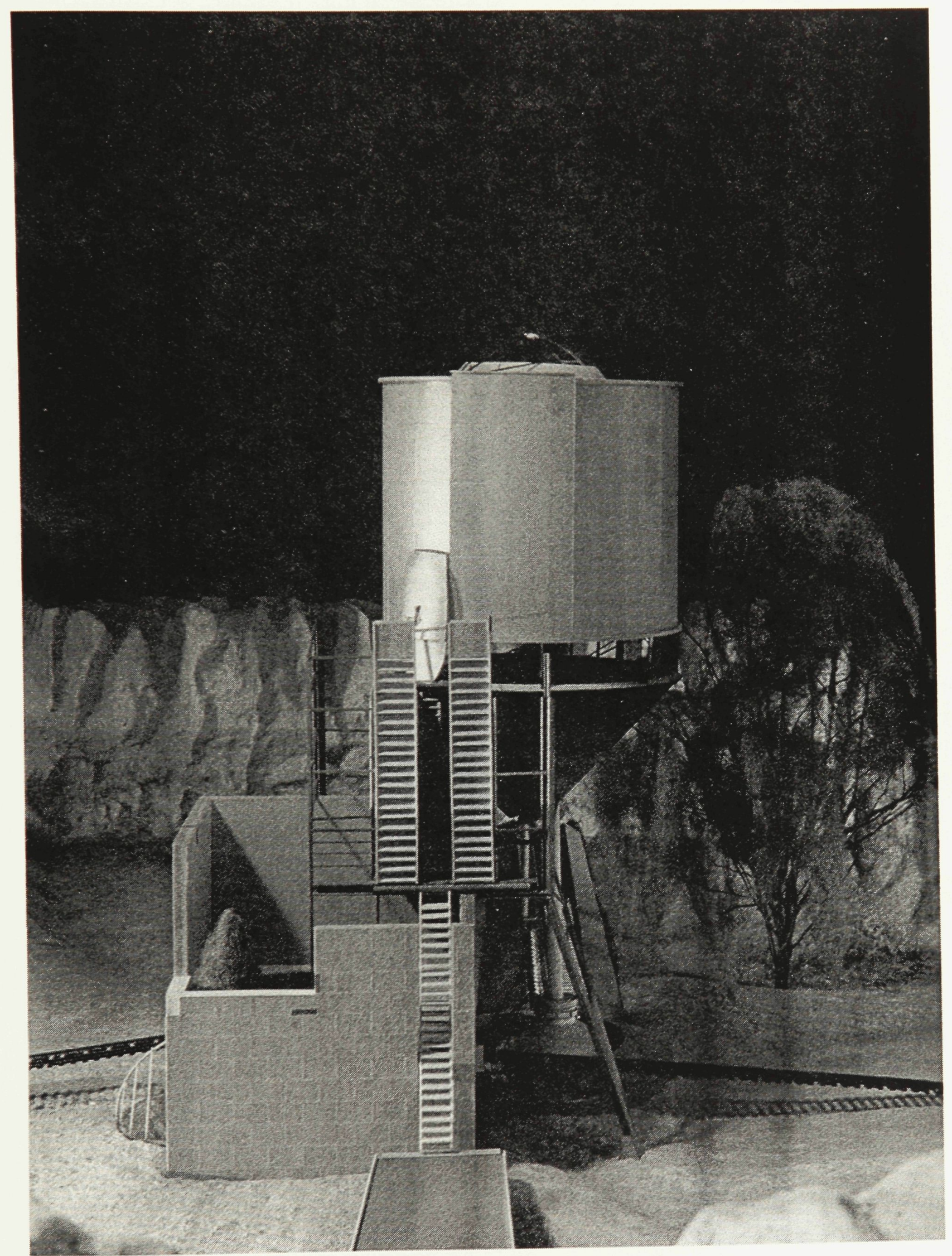


OxxGex House is perched on a depressed flood plain north-northwest of Frenchman's Bend, Mississippi. The structure is designed for Burnden Abraham, an ex-rrain signalman, who must live in an oxygen tent.

In the early spring of 1979 , after torrential rains, the railroad tracks on which Abraham worked were flooded. They were never fully repaired. That following surnmer during a routine operation, Abraham suffered a collapsed lung when a train jumped the track and sent metal debris puncturing his right lung.

Three years later the railroad company put the property up for sake. Abraham purchased the plot where he bad once worked. He requested that his house be buils over the scene of his near-fatal accident. Abraham also requested thar he finally be entombed in the house. 


\section{Instruments}

Liff kines

Diagonal: Exergmen, lift, bed, and willow (wertical)

Orehogonal: Yisitors' ar road and fratze axygen srockpile

fascending trom certer, West/facs)

Daxably Lines

Diagonal: Dried-12 waskl (herizontal)

Orthogonal: Broken tracks (dexcending from center. Northysoun

Mediating lisuey

Dragonal: Lise-in nutrec's station (vercical horzonmal)

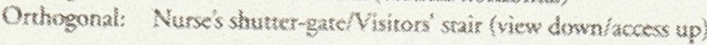

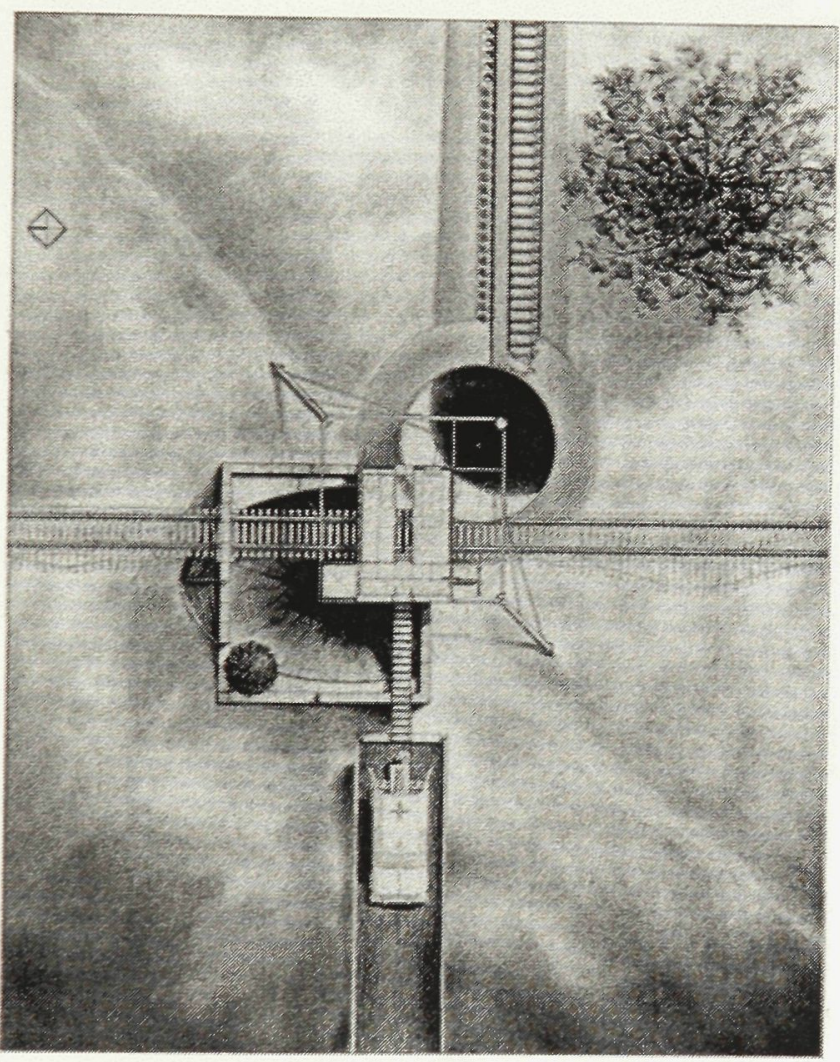

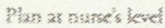


The following letrer was written by the client to the anchitec from the clienr's hospiral noom in Bythalia, Mississippi. The client died shorely after the foorings of the house swere pouned. The consurwcion of the house was never finished.

6 kuly 1979

\section{Dear Mr. Darden.}

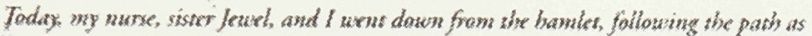

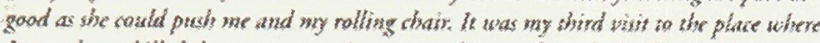
I wat almose killed three years ago. Anyone wathing we from the bluffs could bats scen Jewel's smawnoloned bair blowing more than af full hesd abour my own in the duts.

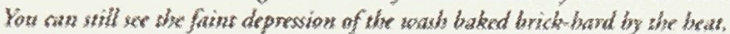
which andermined the tradk. The tracks sun straight as a plumbline, crosyed by the wash. I can mos look colmily at the break in the linc. My chest no longer goes churk couck. I am doing doe riglst bing te punchose this plat for my bouse.

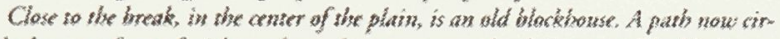

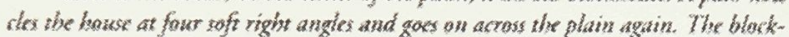
house is squark, with a brokes roof ret at a single pitch; it leans in empty dilapidations

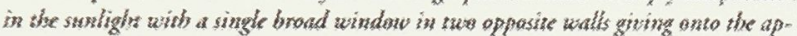

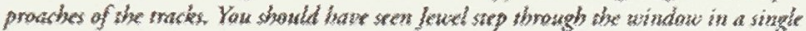
stride while 7 took in the shimmering swillow beyond.

Gewel teles we that there once was a spring ineat to the willows Fren from she foot

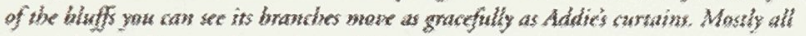
that is bere is this trec, the sxates, and the sand.

You have whed we 30 share suth you my thoughes ahout death. Naw is not the

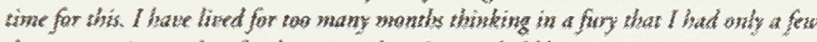

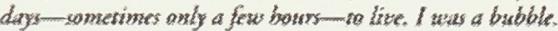

I can only say birat death wo honger bibreatens me. Io runs hike soly gold besureen she

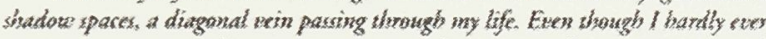
emorge from any tent, this bein gizes me an suduring sonse of sousd movement, of amazonem, and privilege. Let's go on and build the bonese.

Yours simerein

Busnden Aloration 


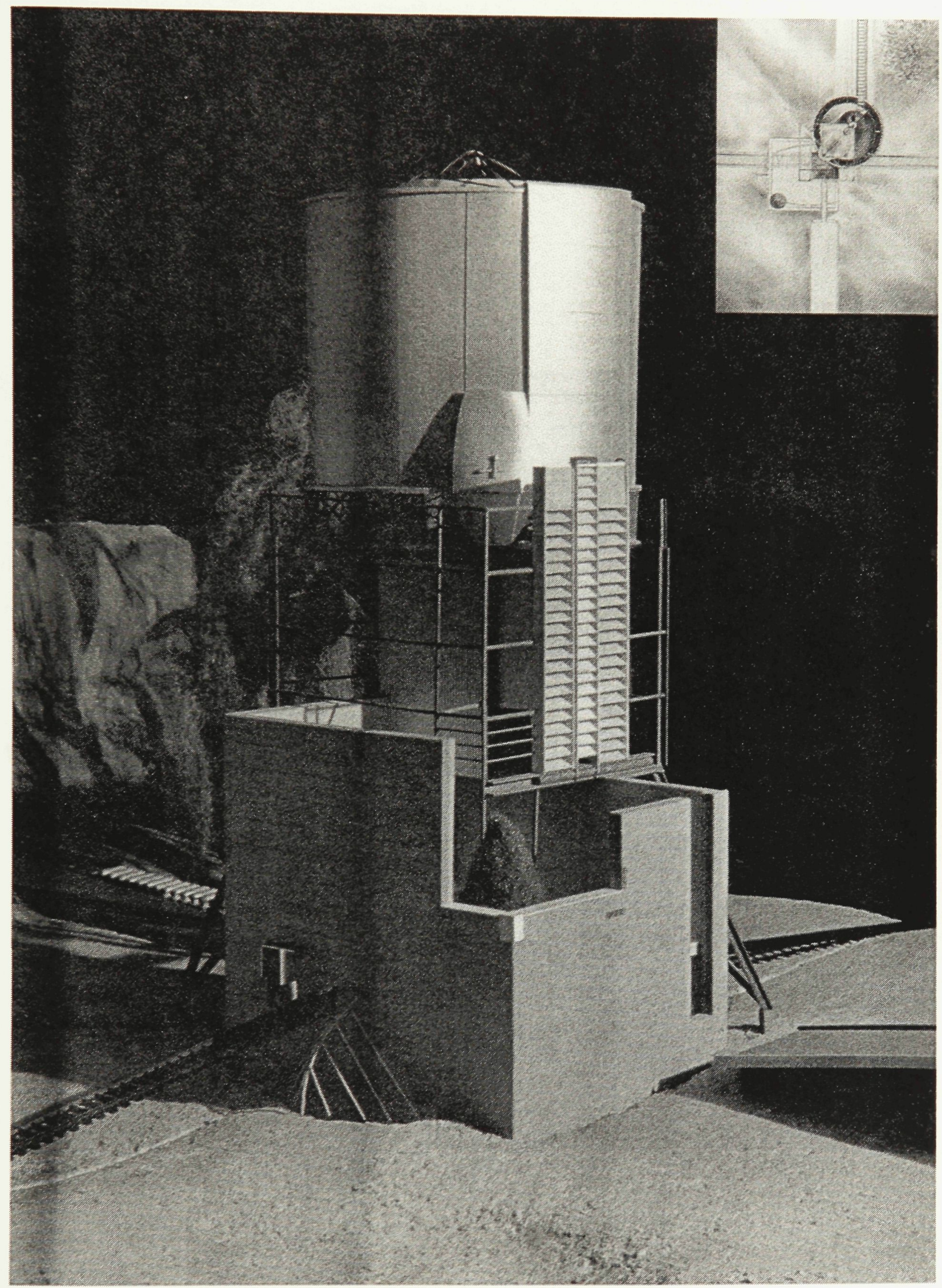


Nop wisdy nuspination of forcid breath
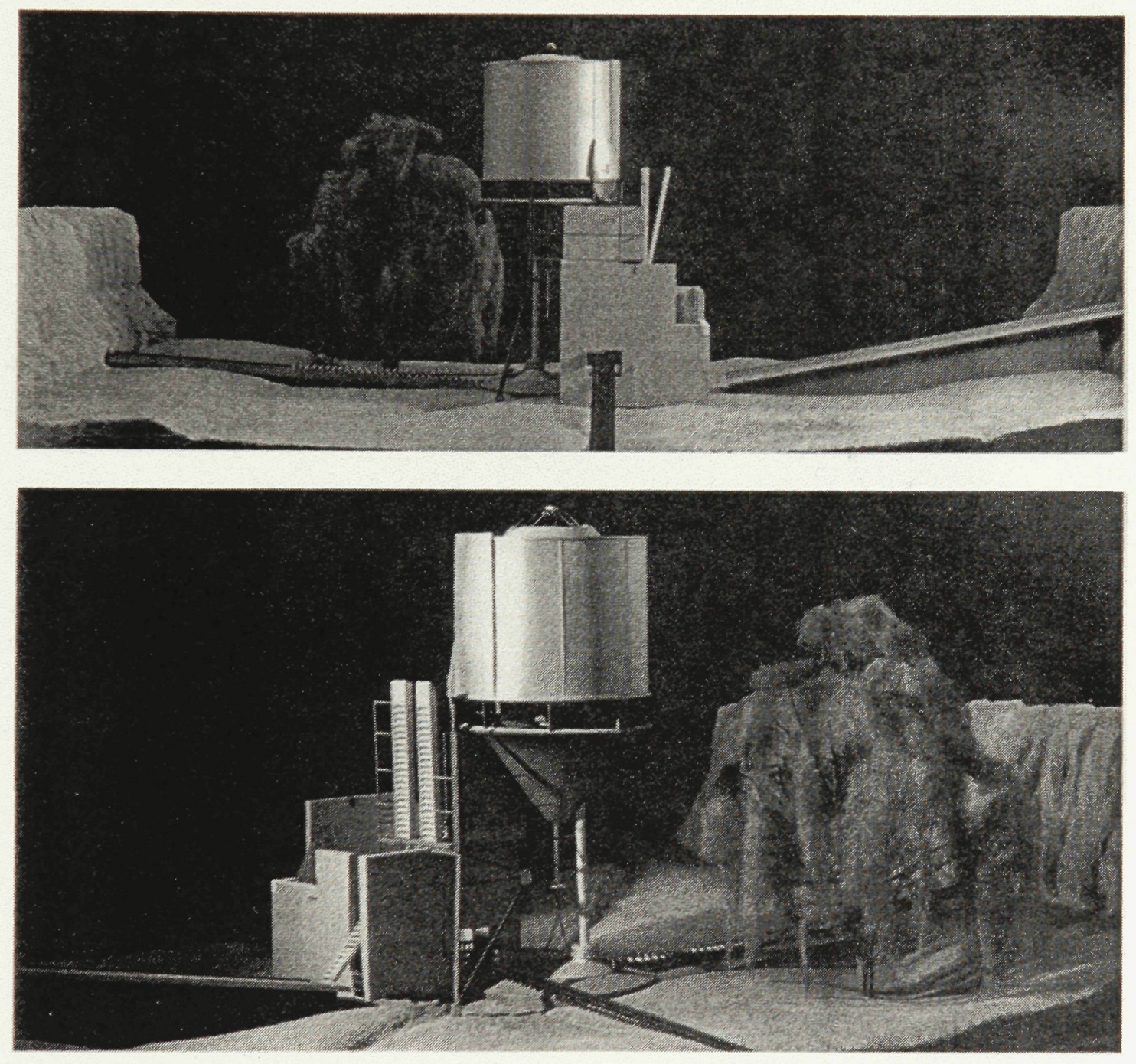

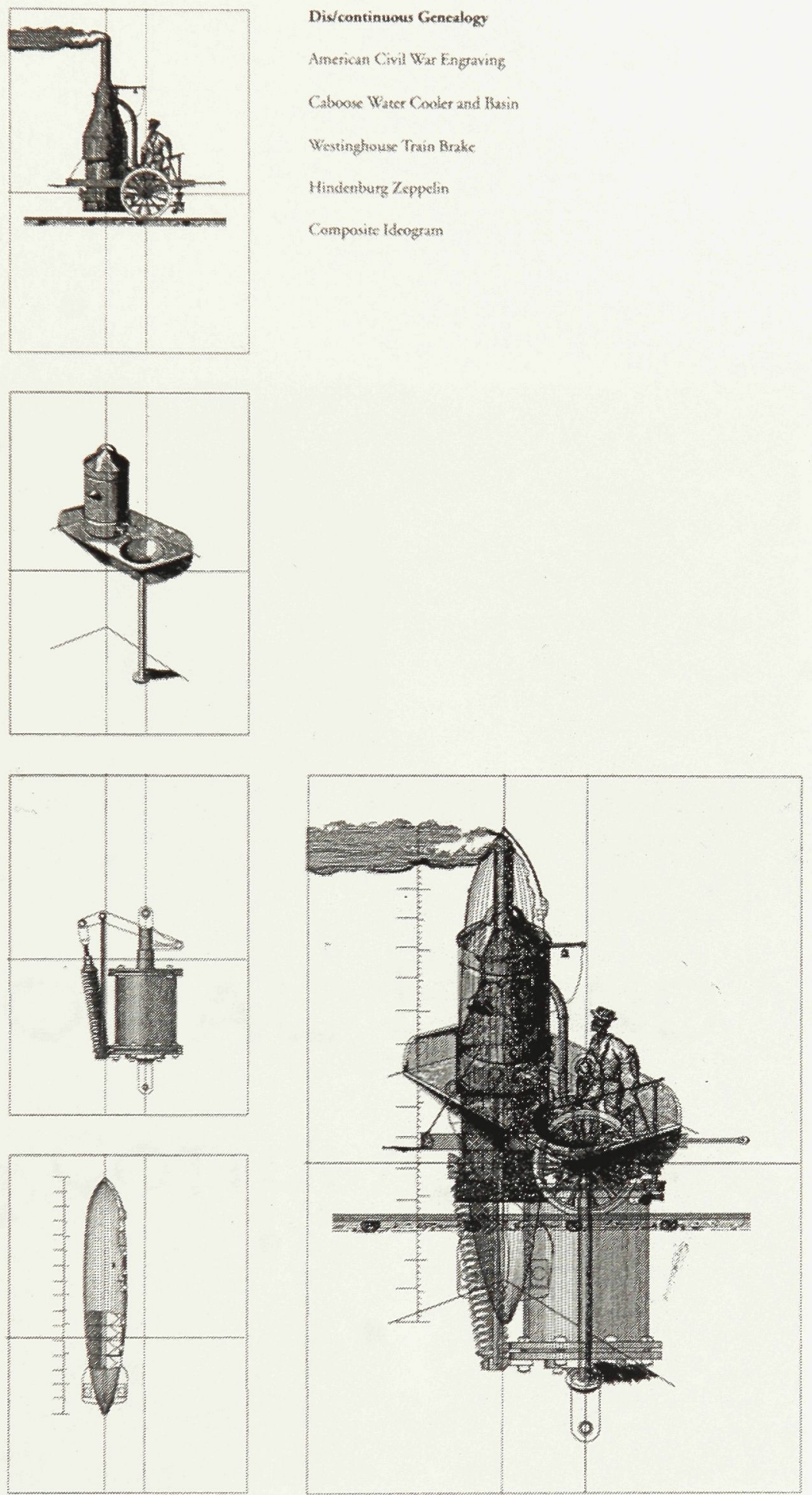


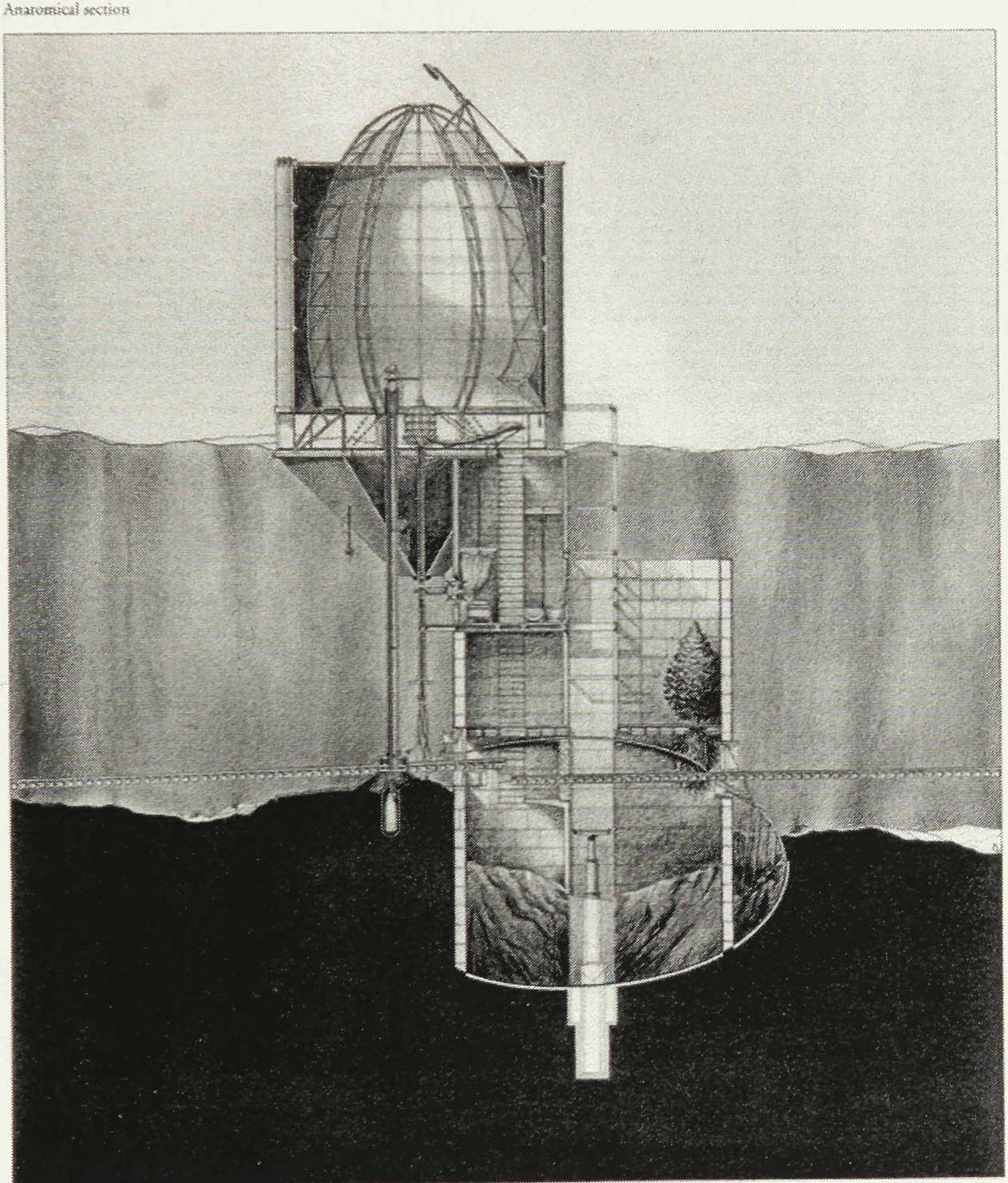




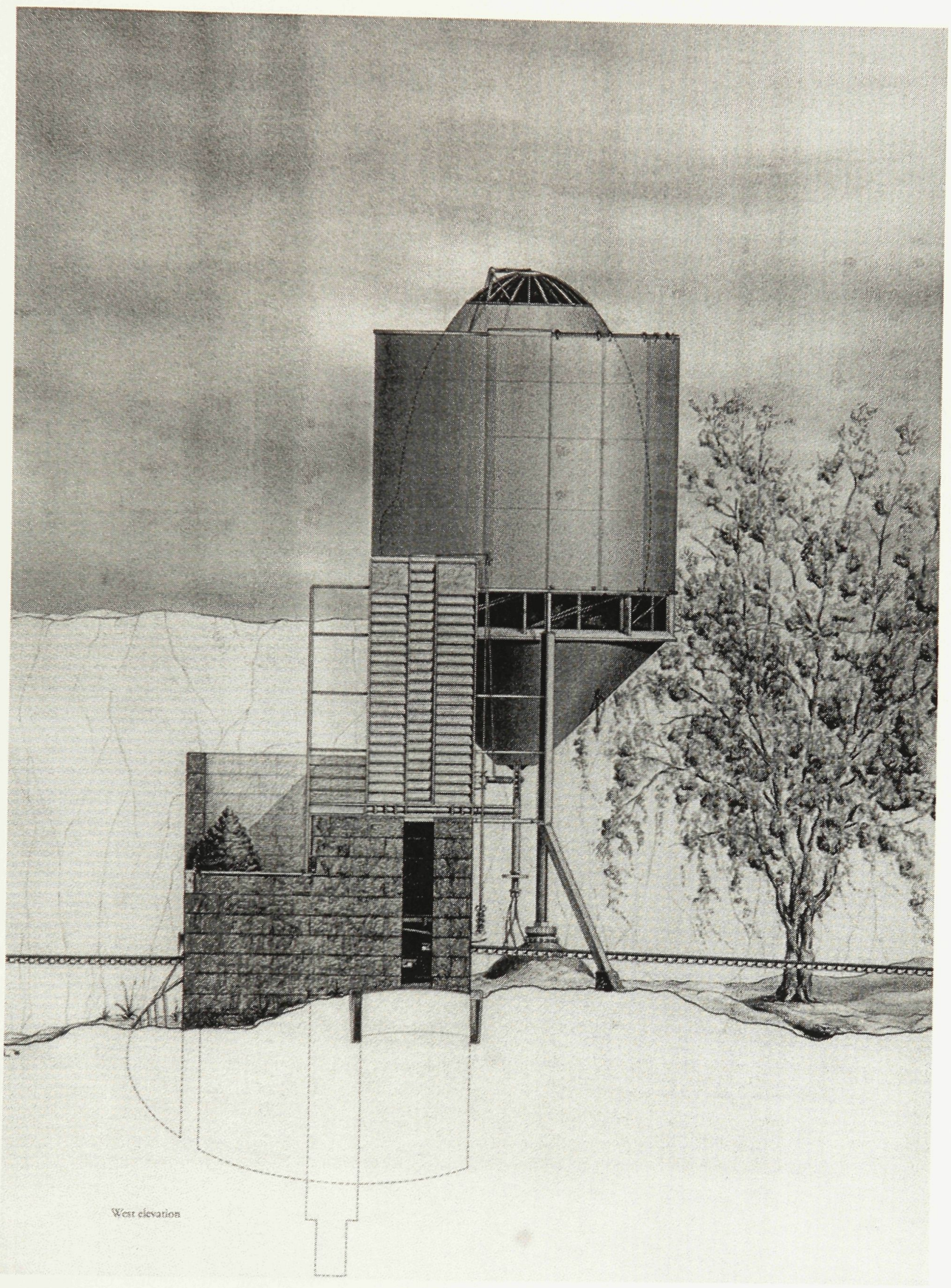




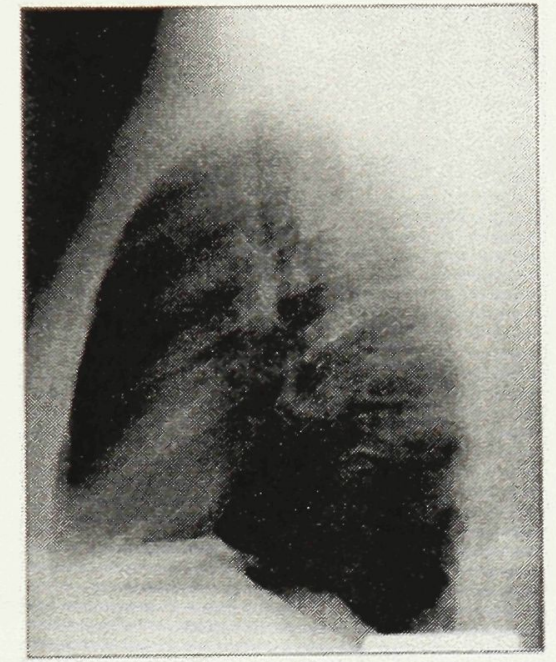

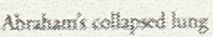

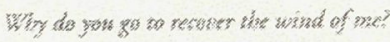




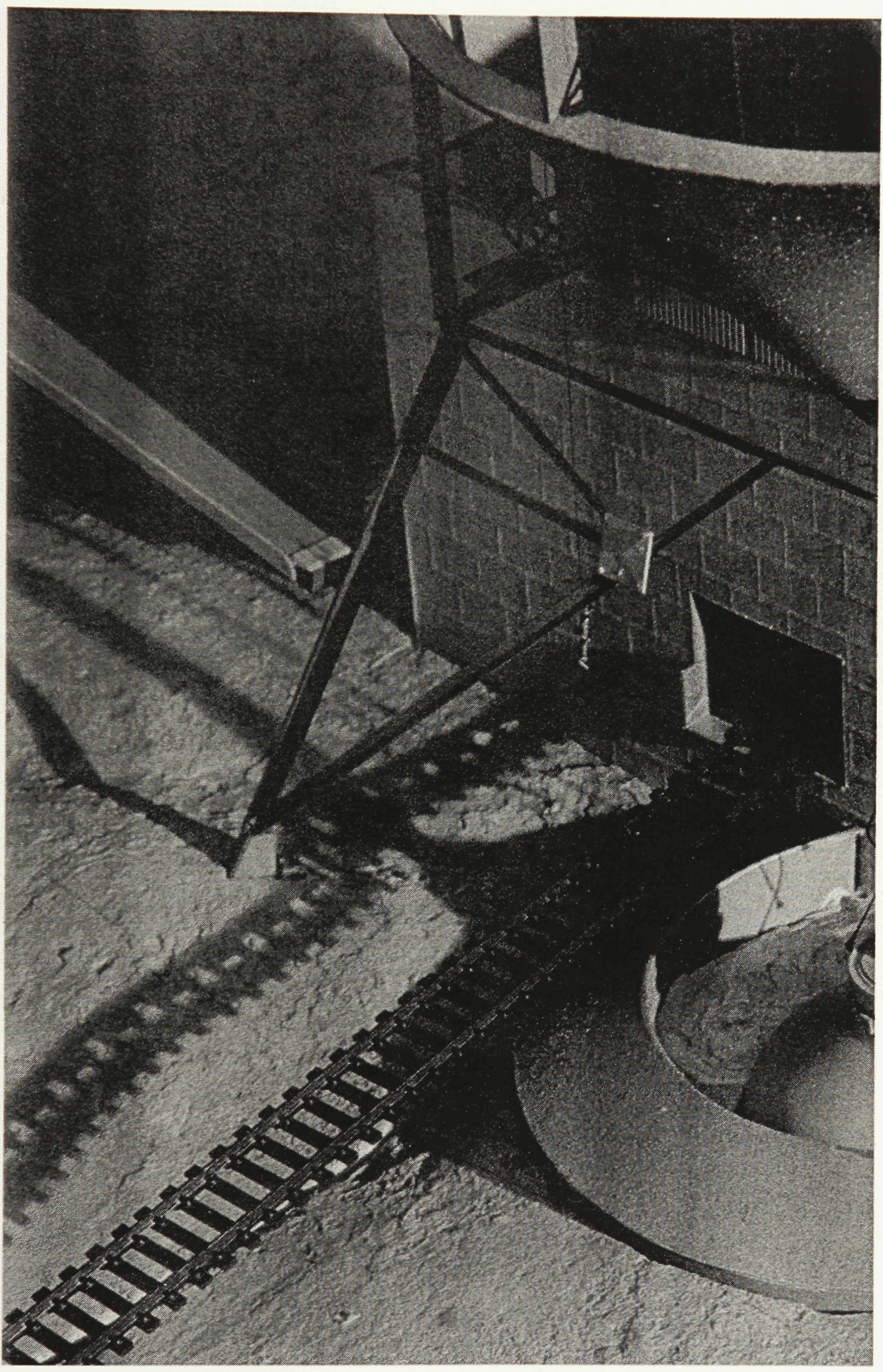




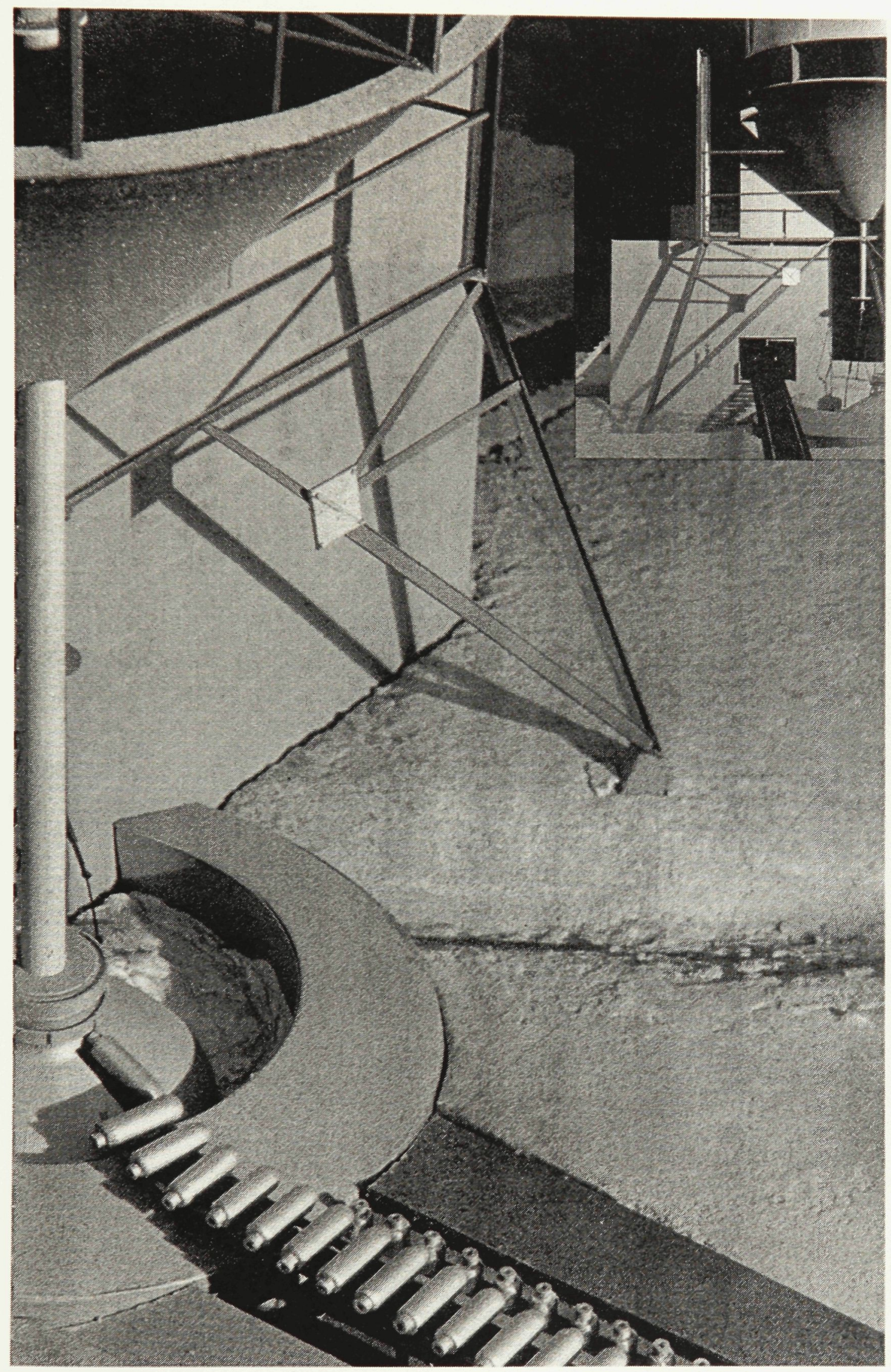




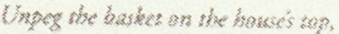

Let dist birds fiy

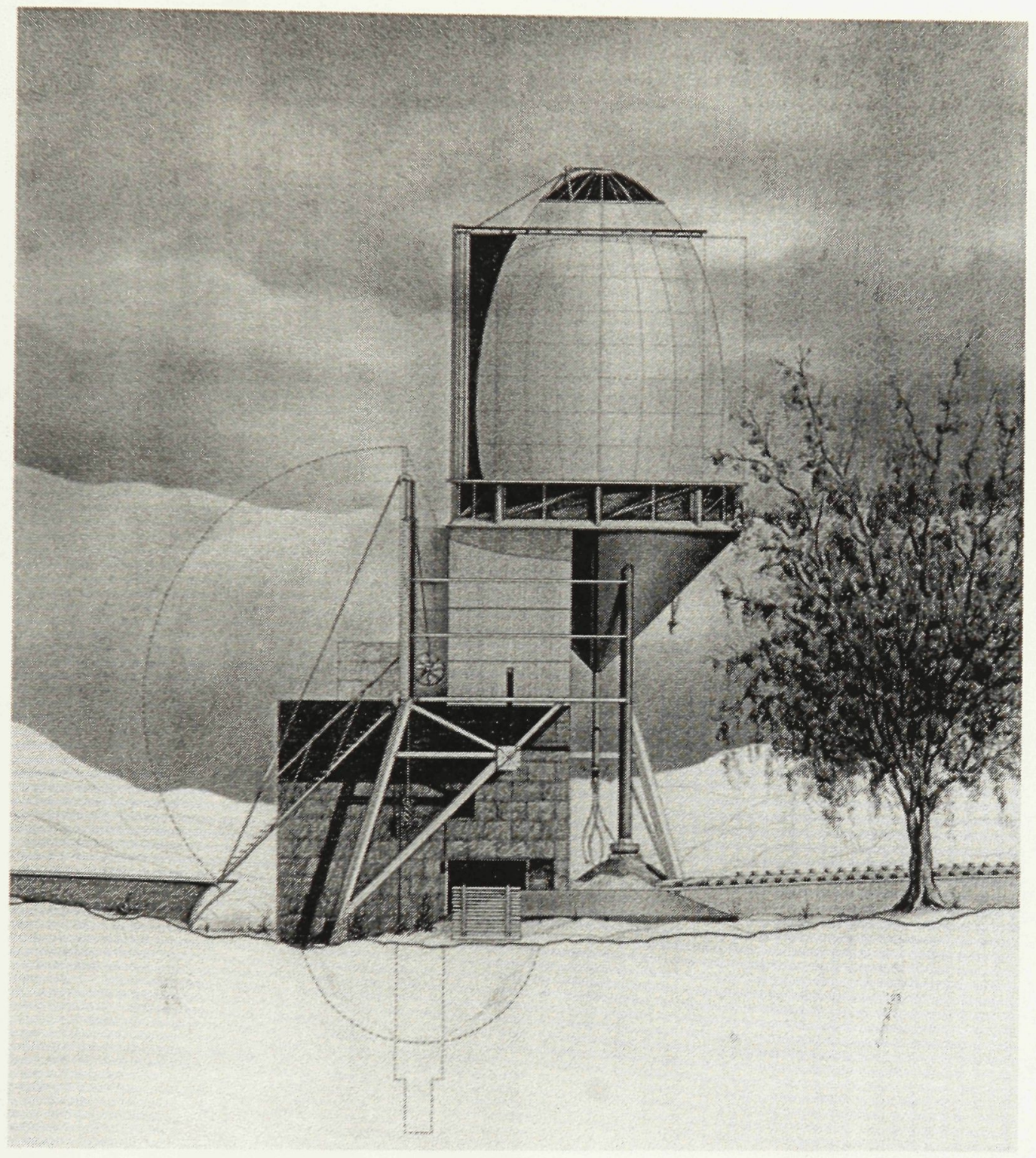

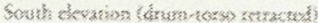




\section{Operations}

\section{During life}

Operation I Visitor is screened by nurxe.

Operation II Nurse releaces factide, visitor ascends stais.

Operation III Abrahanz reckives visitur.

Operation IV Visitor descends by lift.

\section{Afred Dests}

Operarion I Oxygen sent is dismantled. Abraham is wrapped in tent membrane.

Operation II Abrahasi's bendy is nerzoved and huried in buse of lif

Operation III Willow is ap-scored; replanted in drum base.

Operation IV Drum-torso is dismantled; relocated oxer well wspring

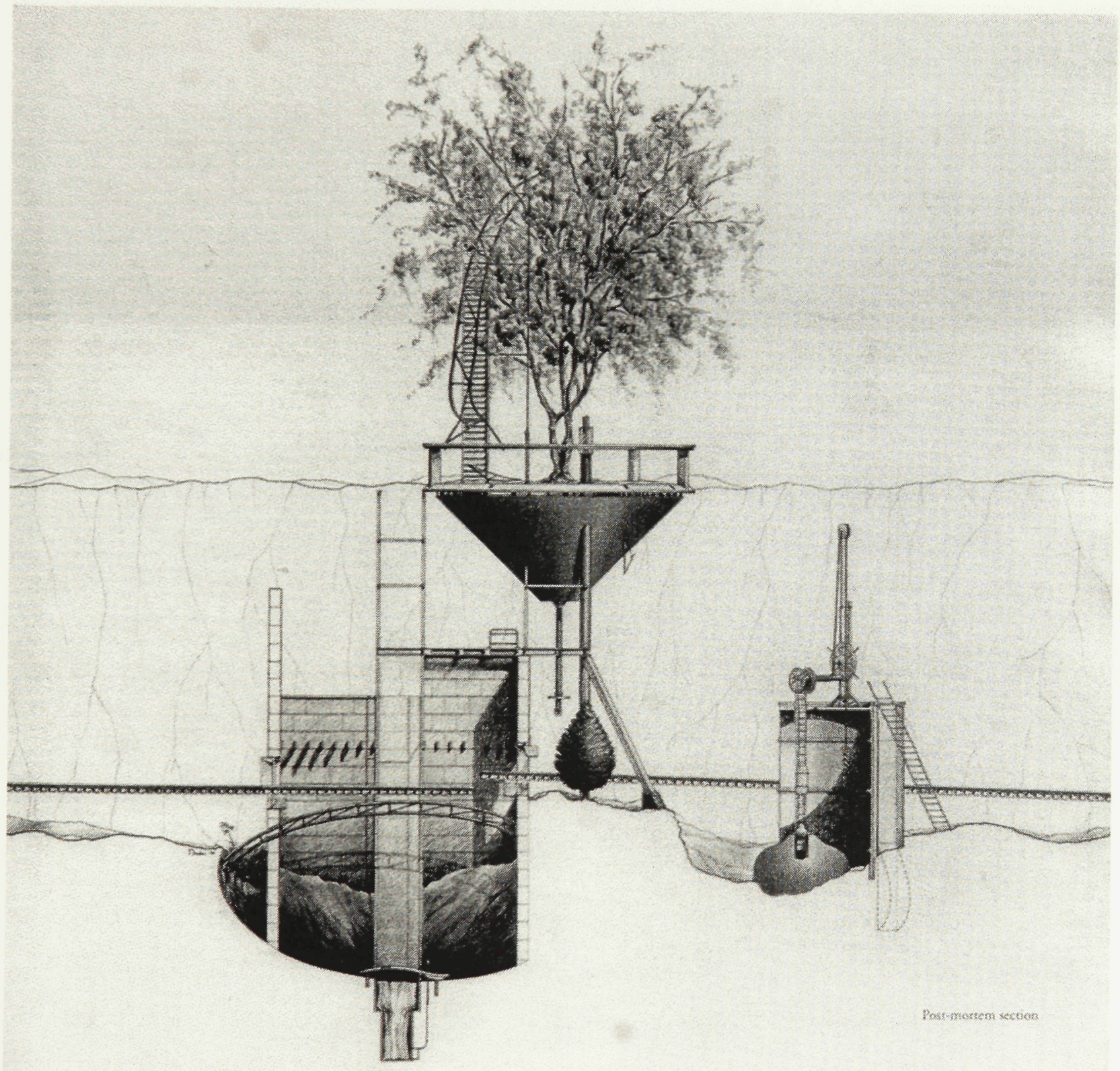




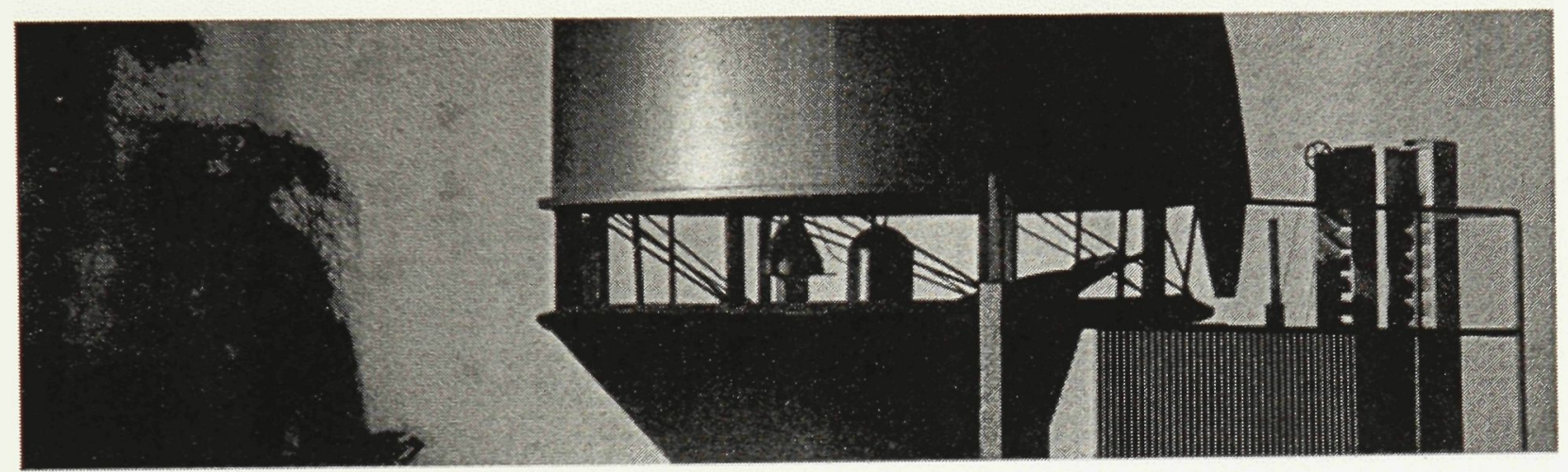

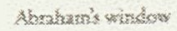




\section{Appendix B}

Drawing Details (Plan, Section, Elevation) 


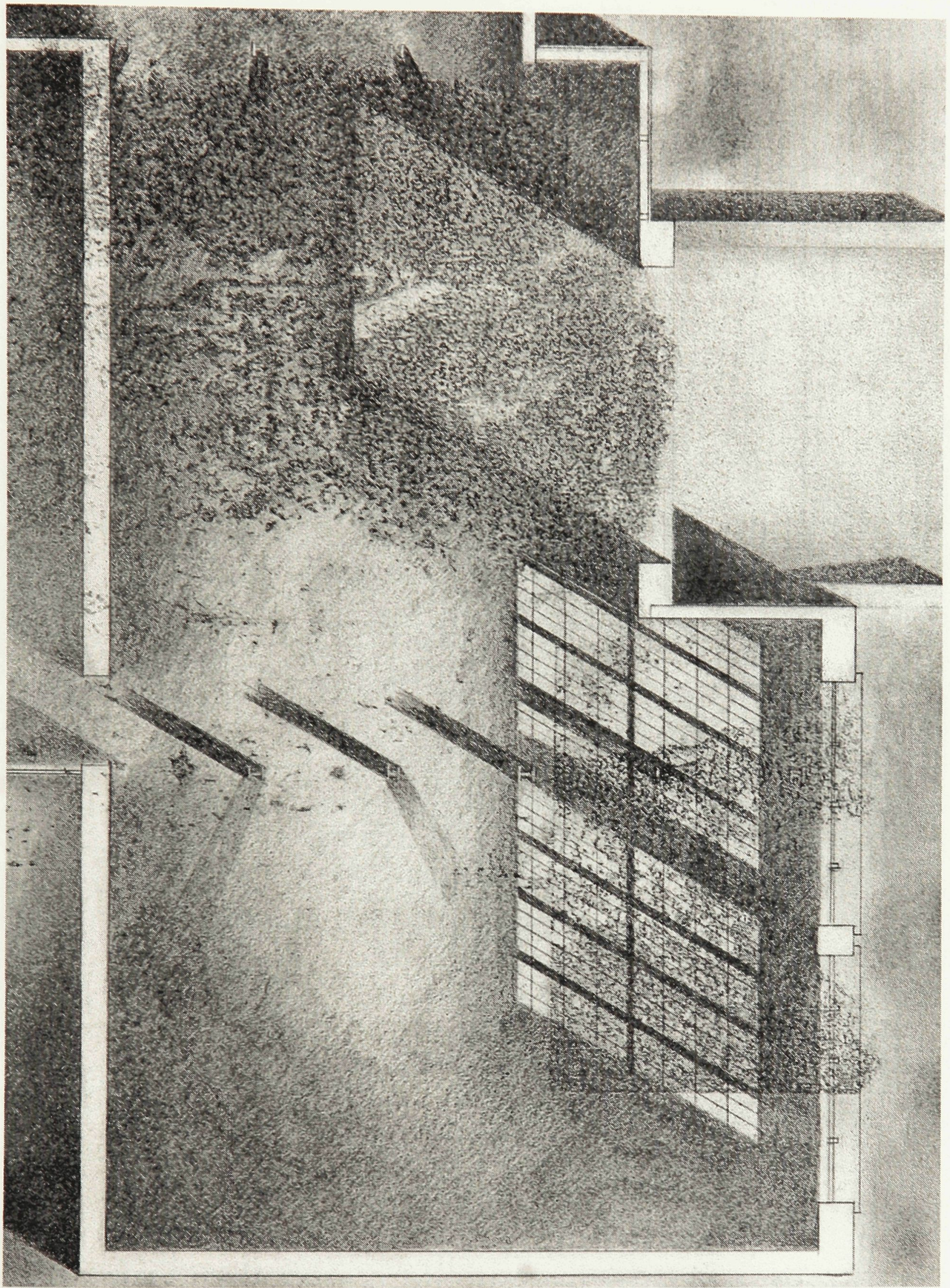

Plan Detail 1 


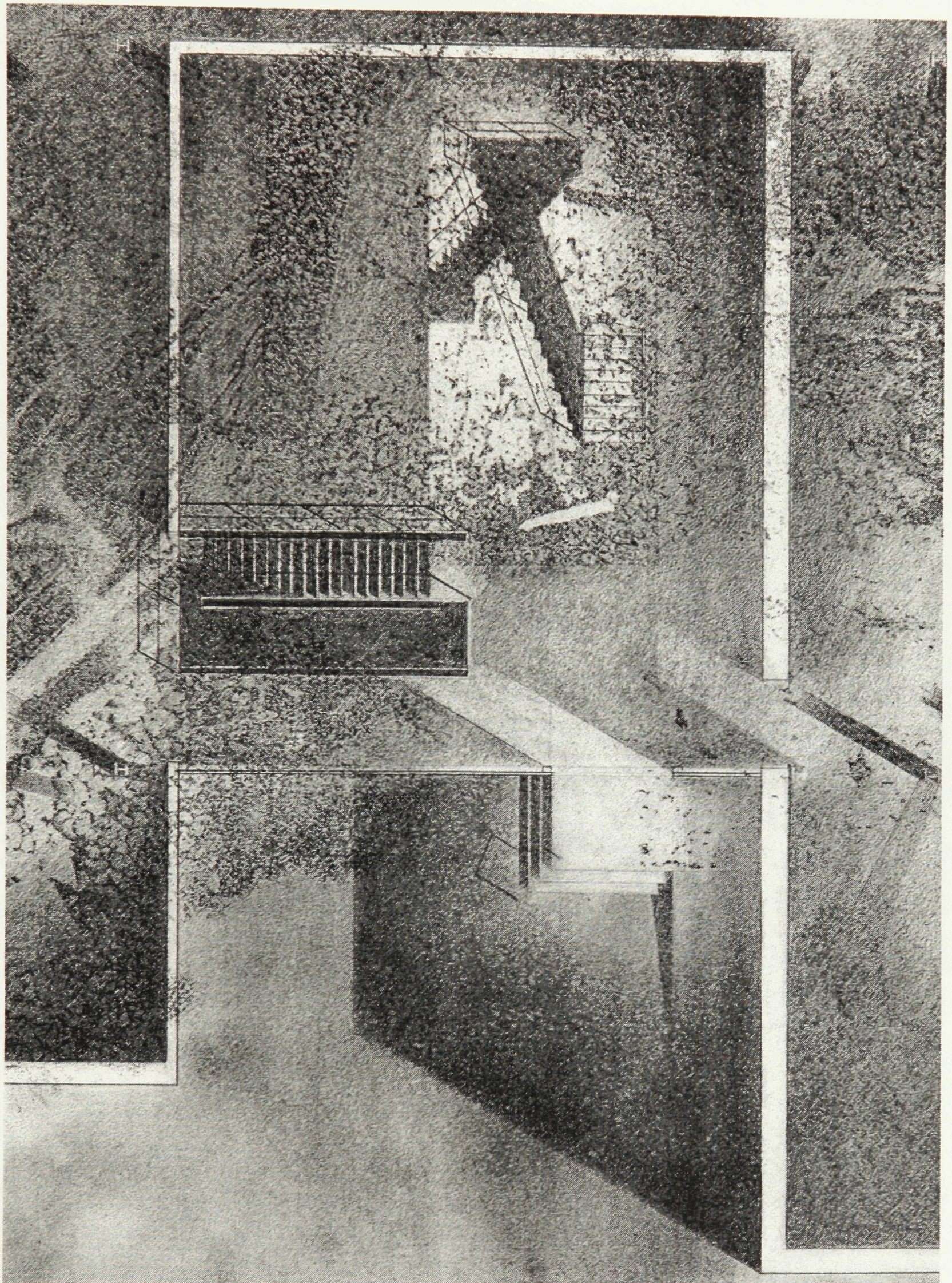

Plan Detail 2 


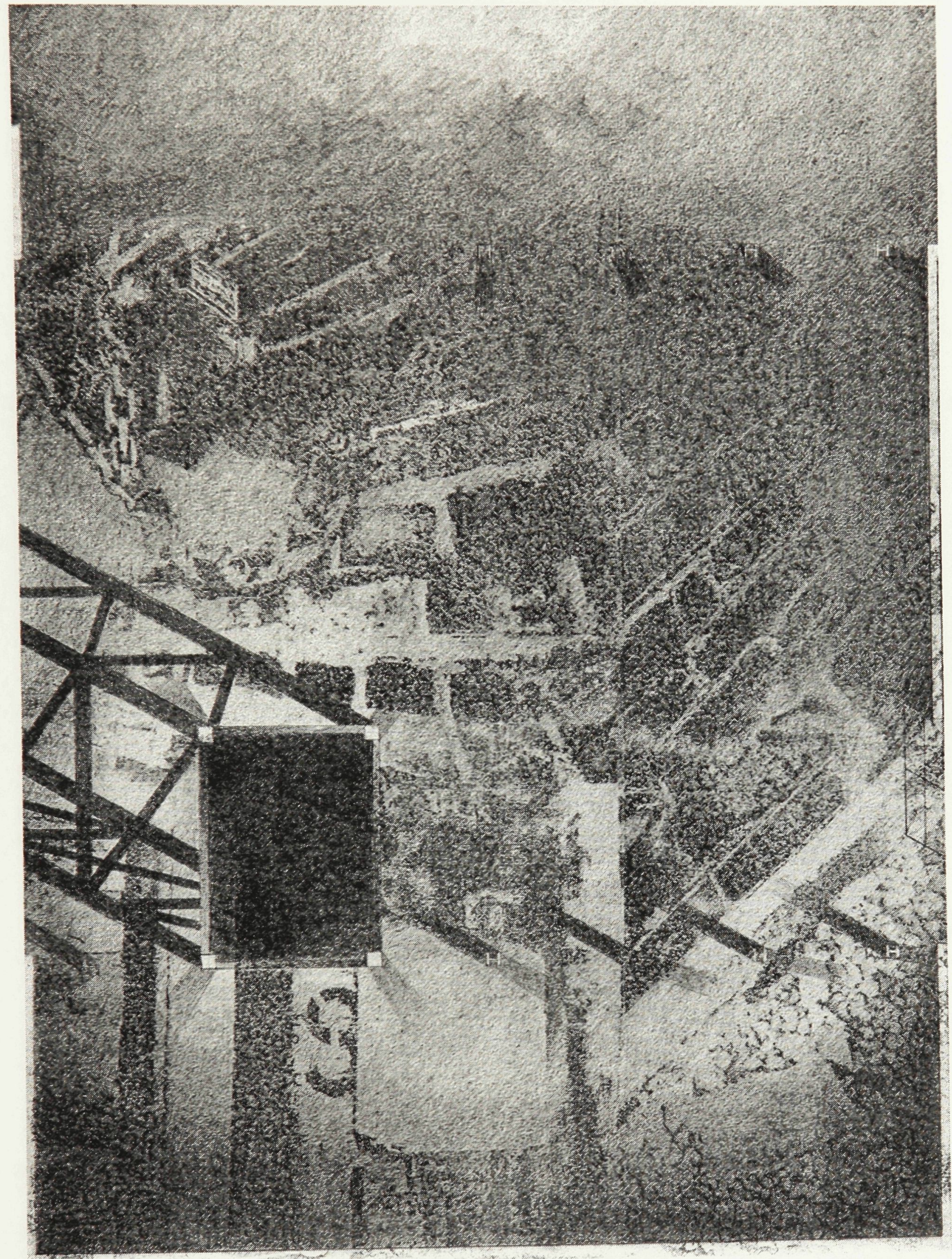

Plan Detail 3 


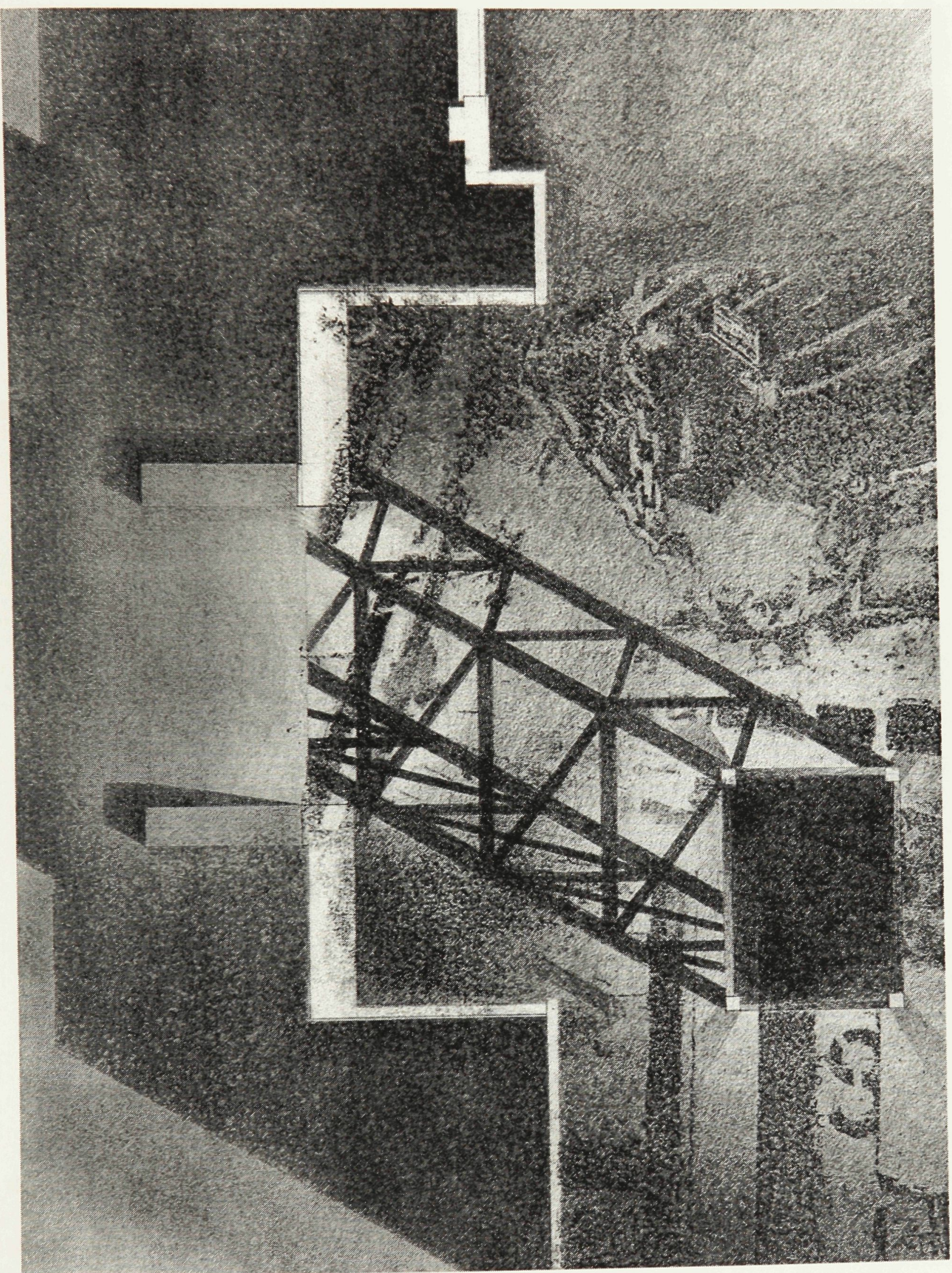

Plan Detail 4 


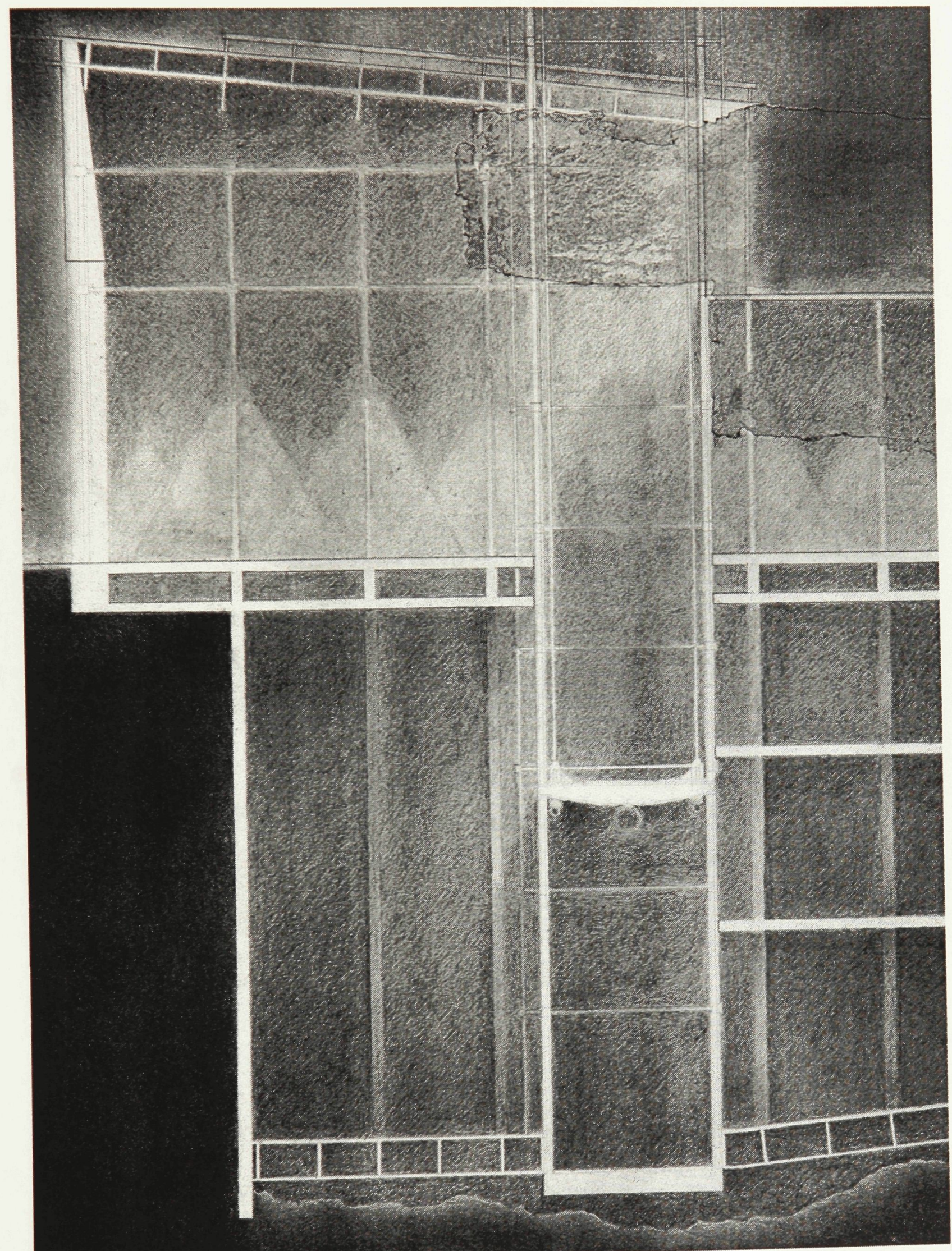

Section Detail 1 

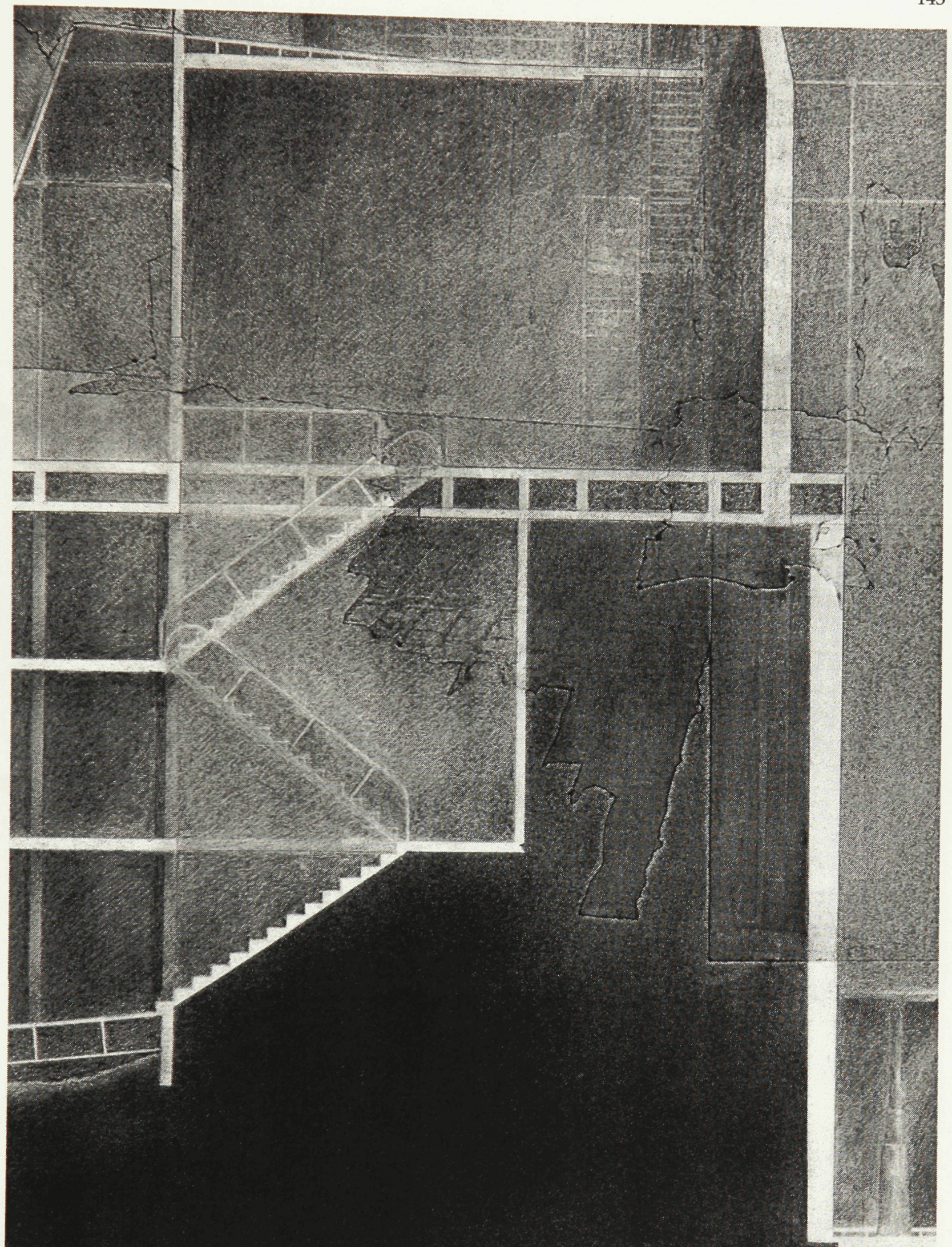

Section Detail 2 


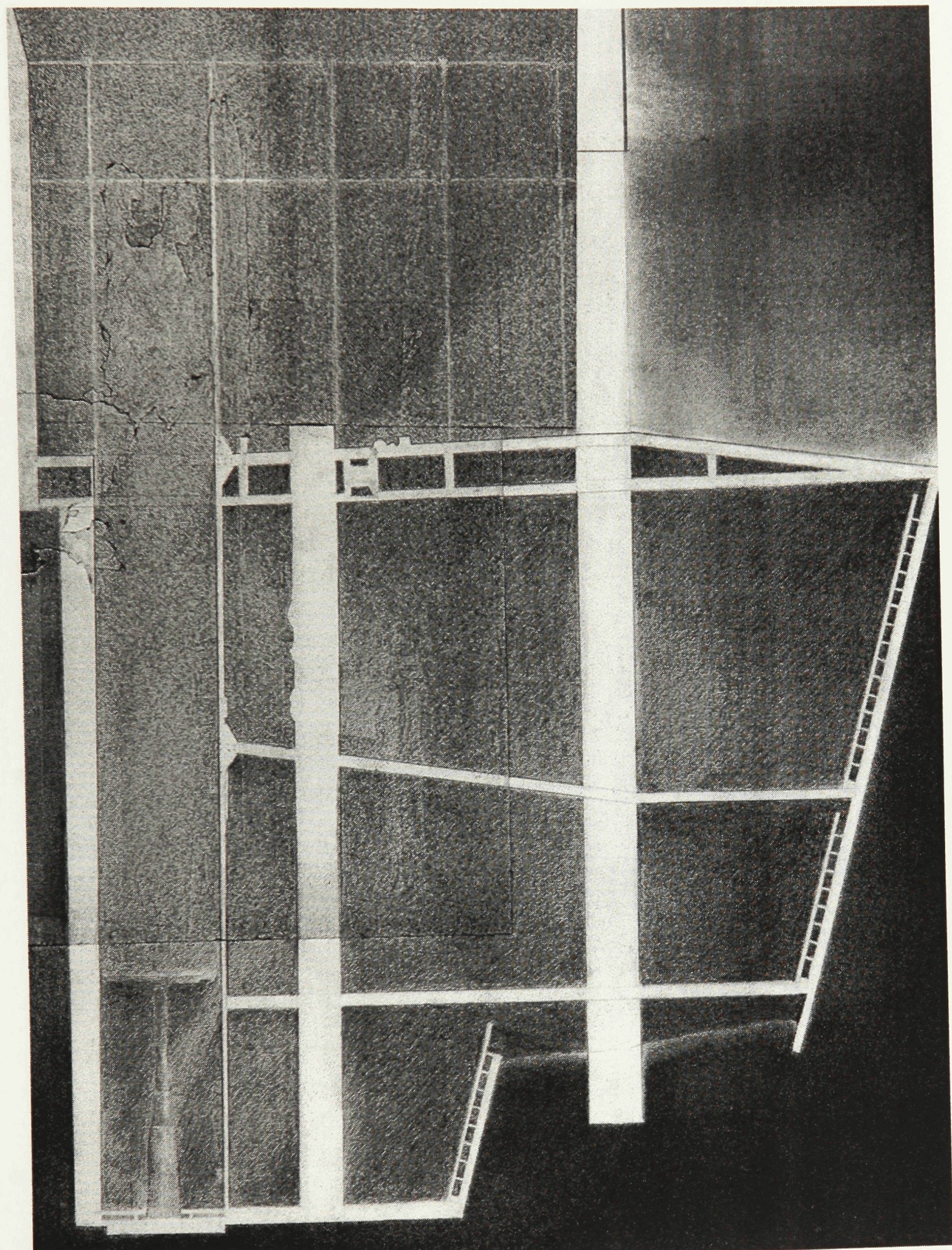

Section Detail 3 


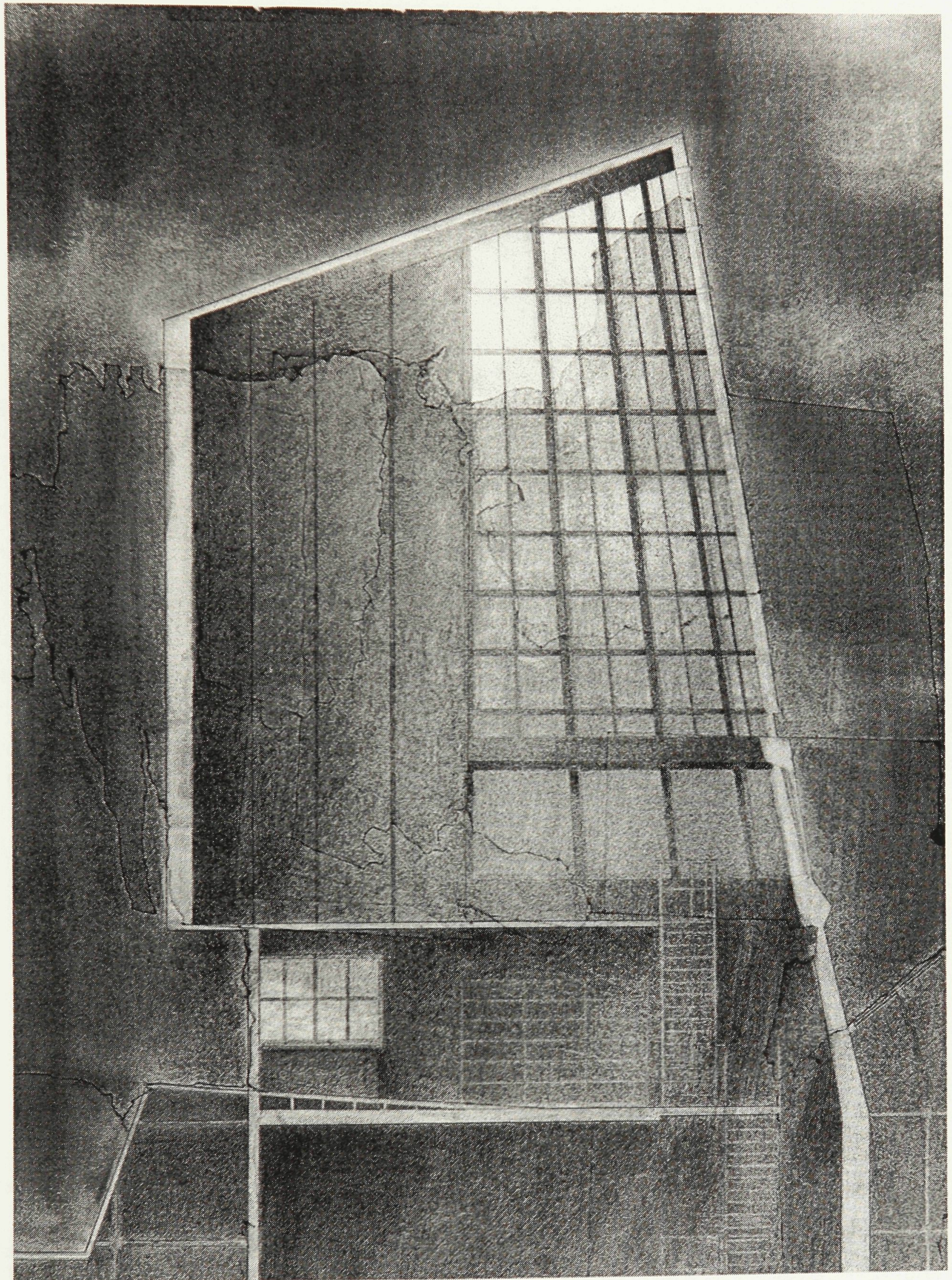




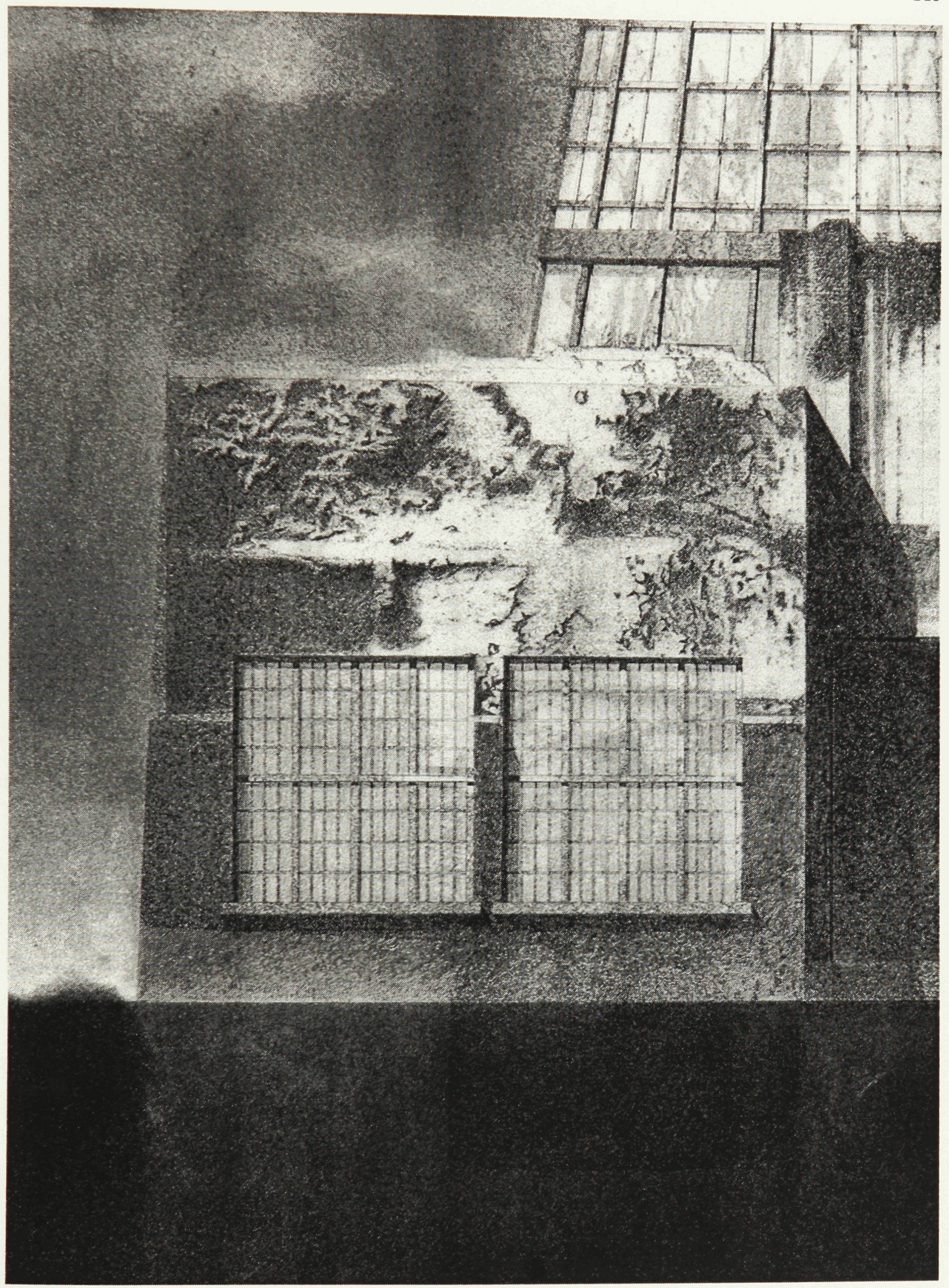

Elevation Detail 1 


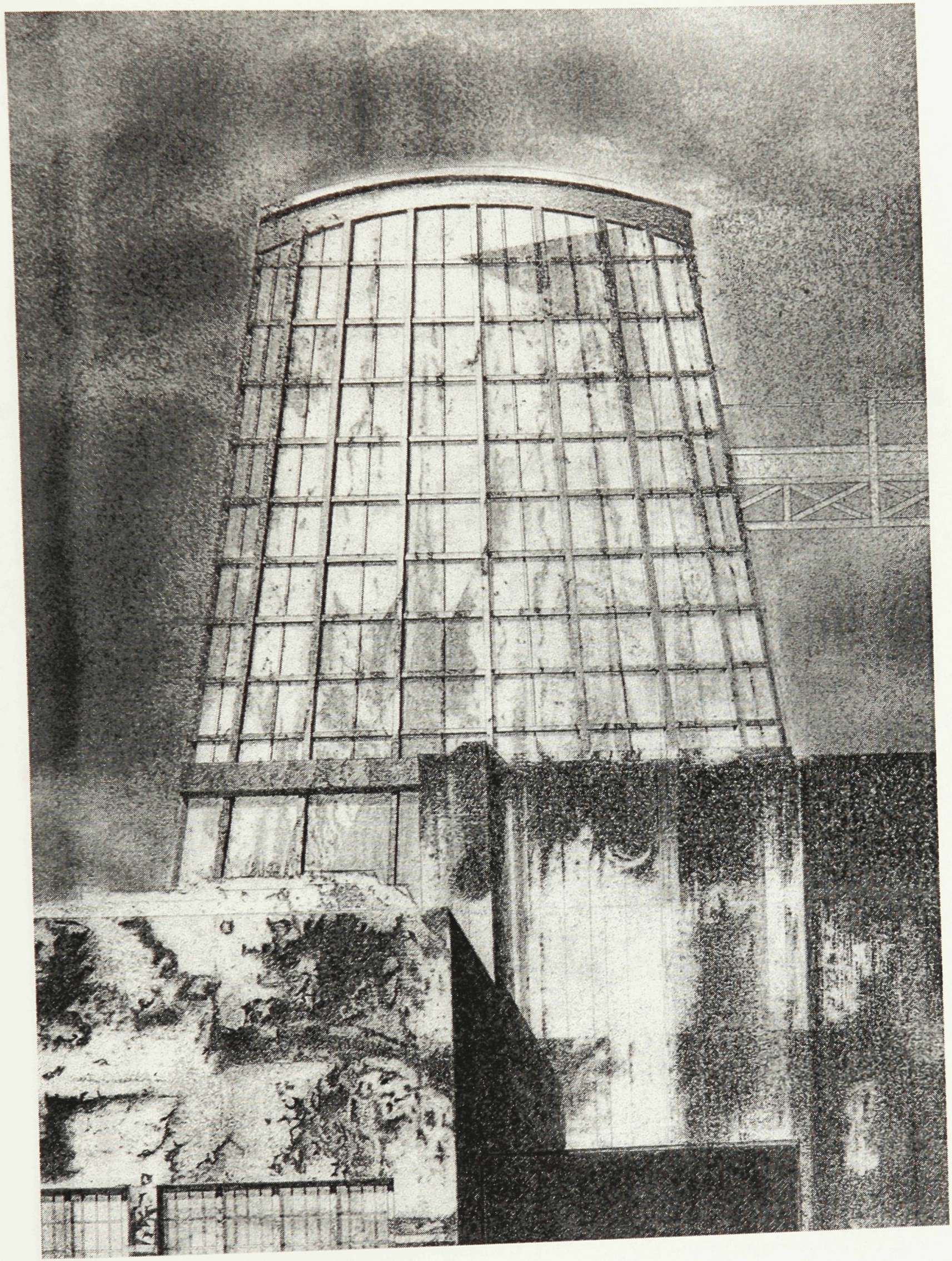

Elevation Detail 2 


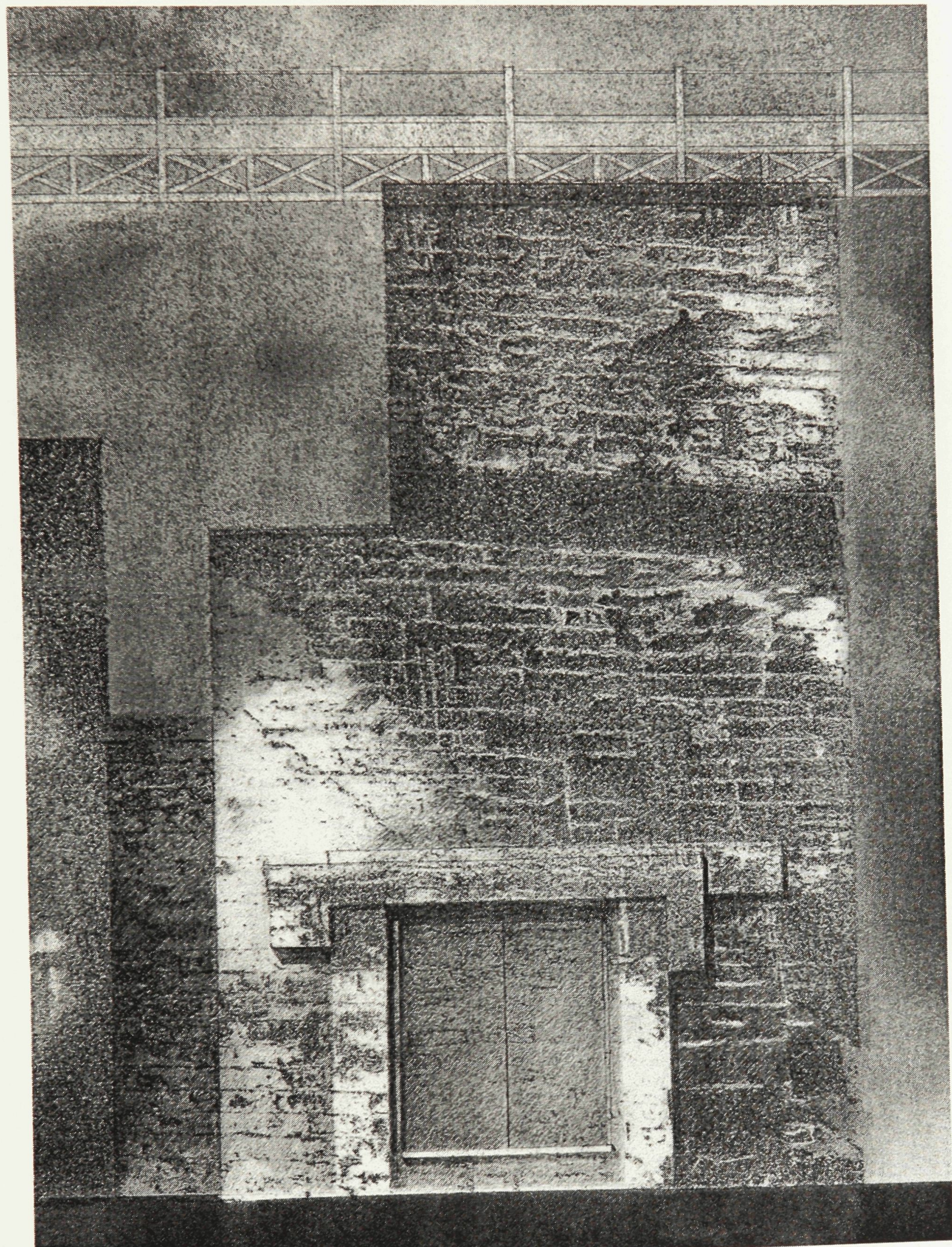

Elevation Detail 3 


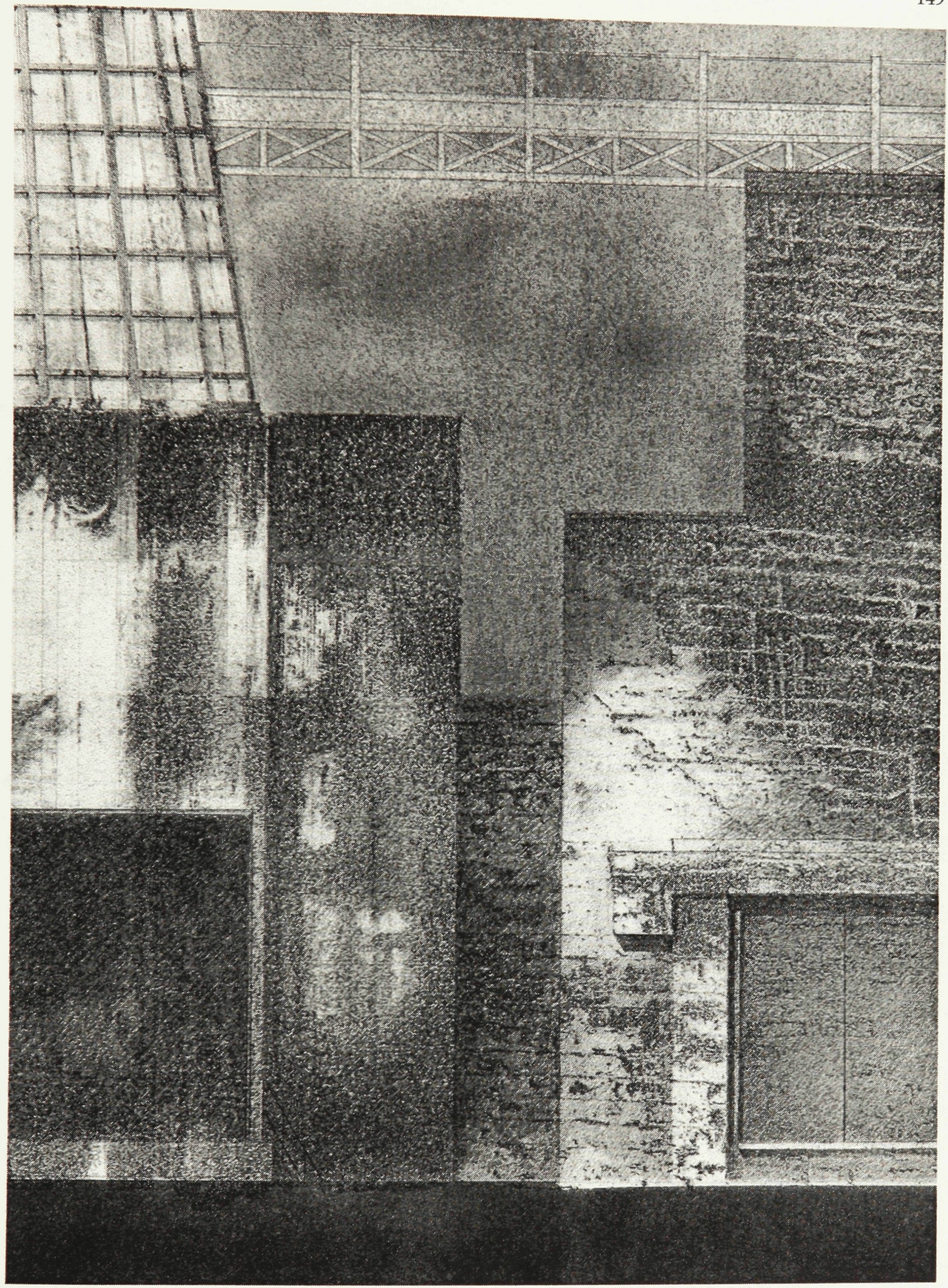

Elevation Detail 4 
Appendix C

Computer Panal Details (Crtainwall and Crane) 


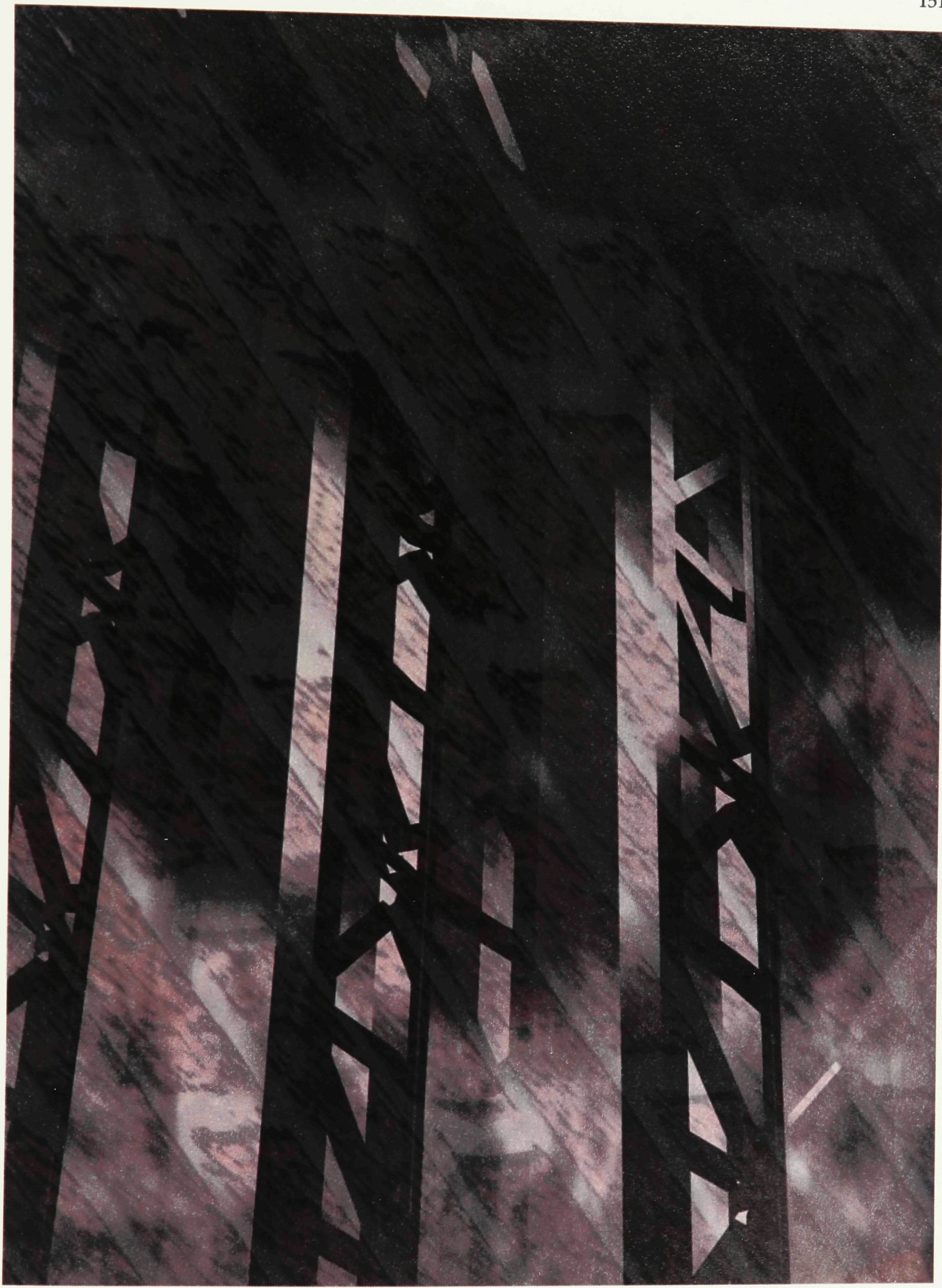

Curtain Wall Detail 1 3dStudio and Photoshop 


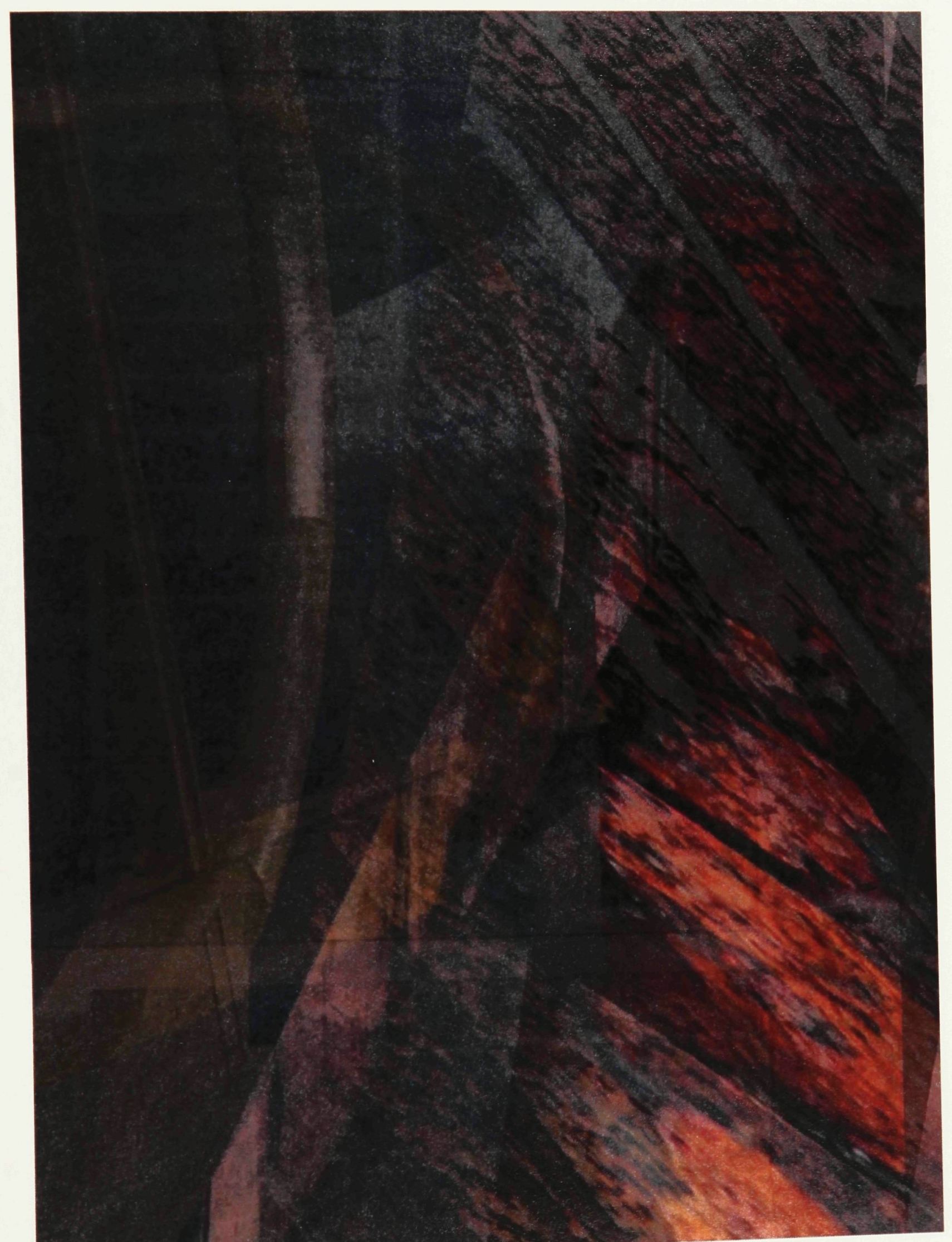

Curtain Wall Detail 2 3dStudio and Photoshop 


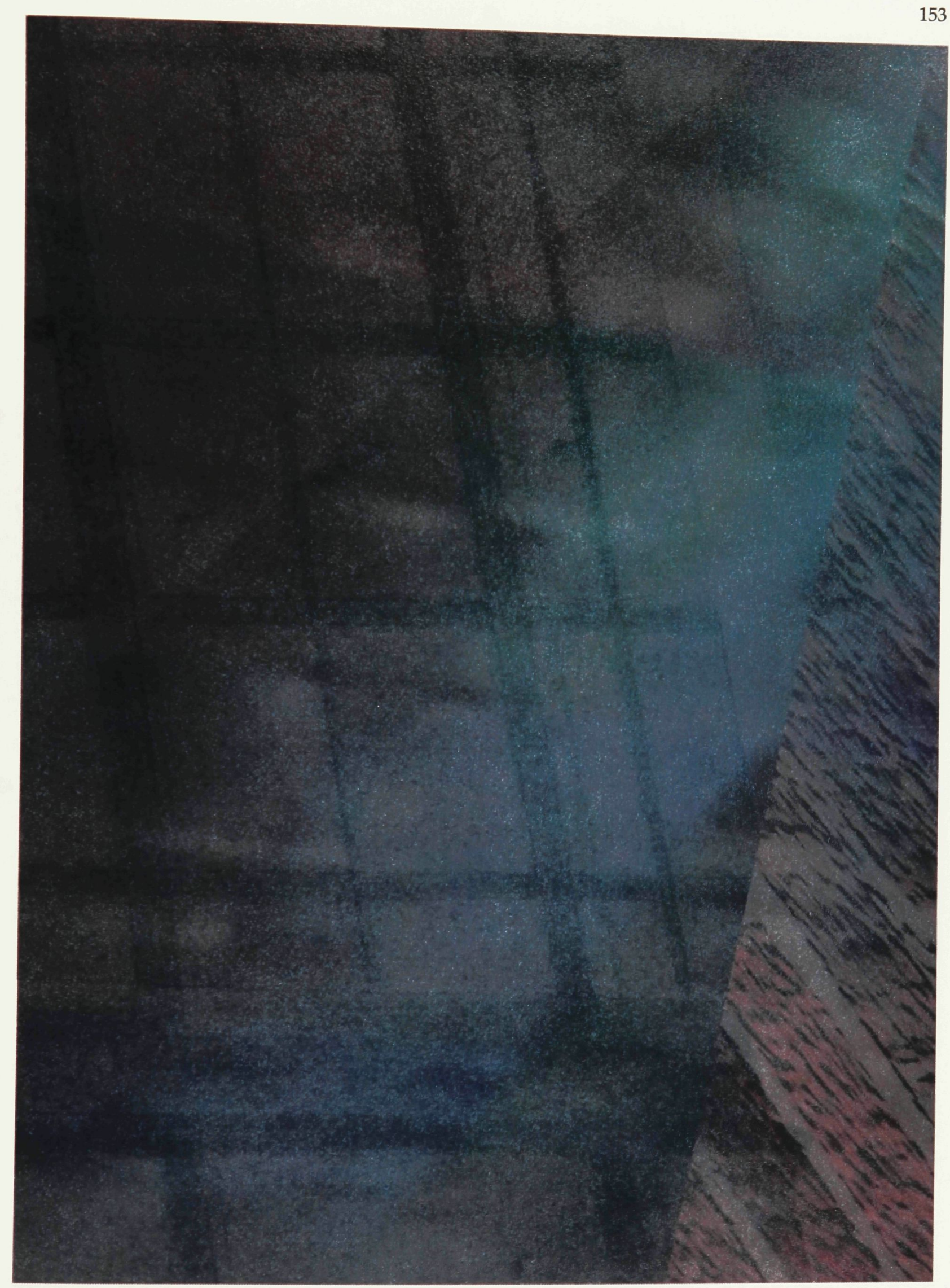

Curtain Wall Detail 3 3dStudio and Photoshop 


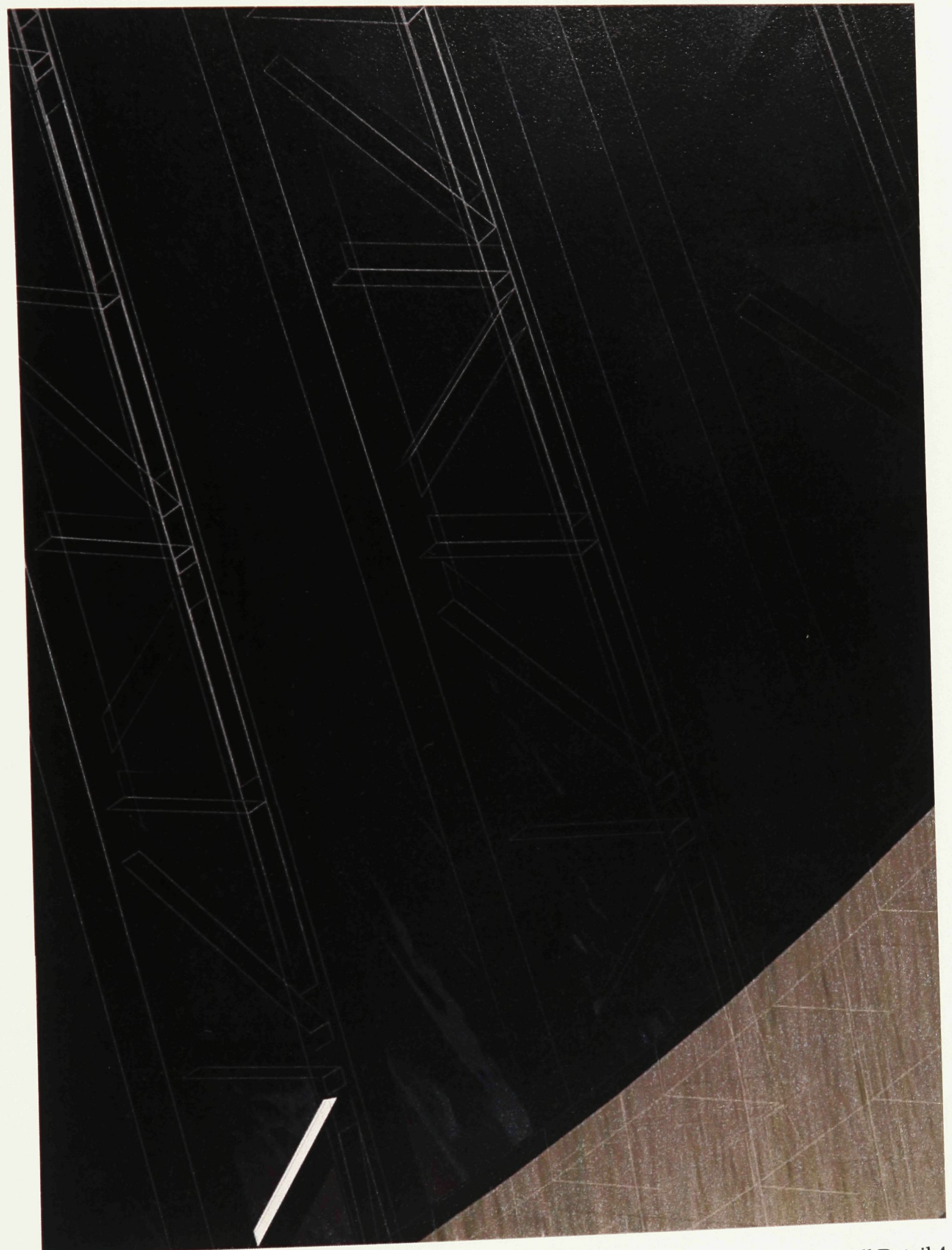

Curtain Wall Detail 4 3dStudio and Photoshop 


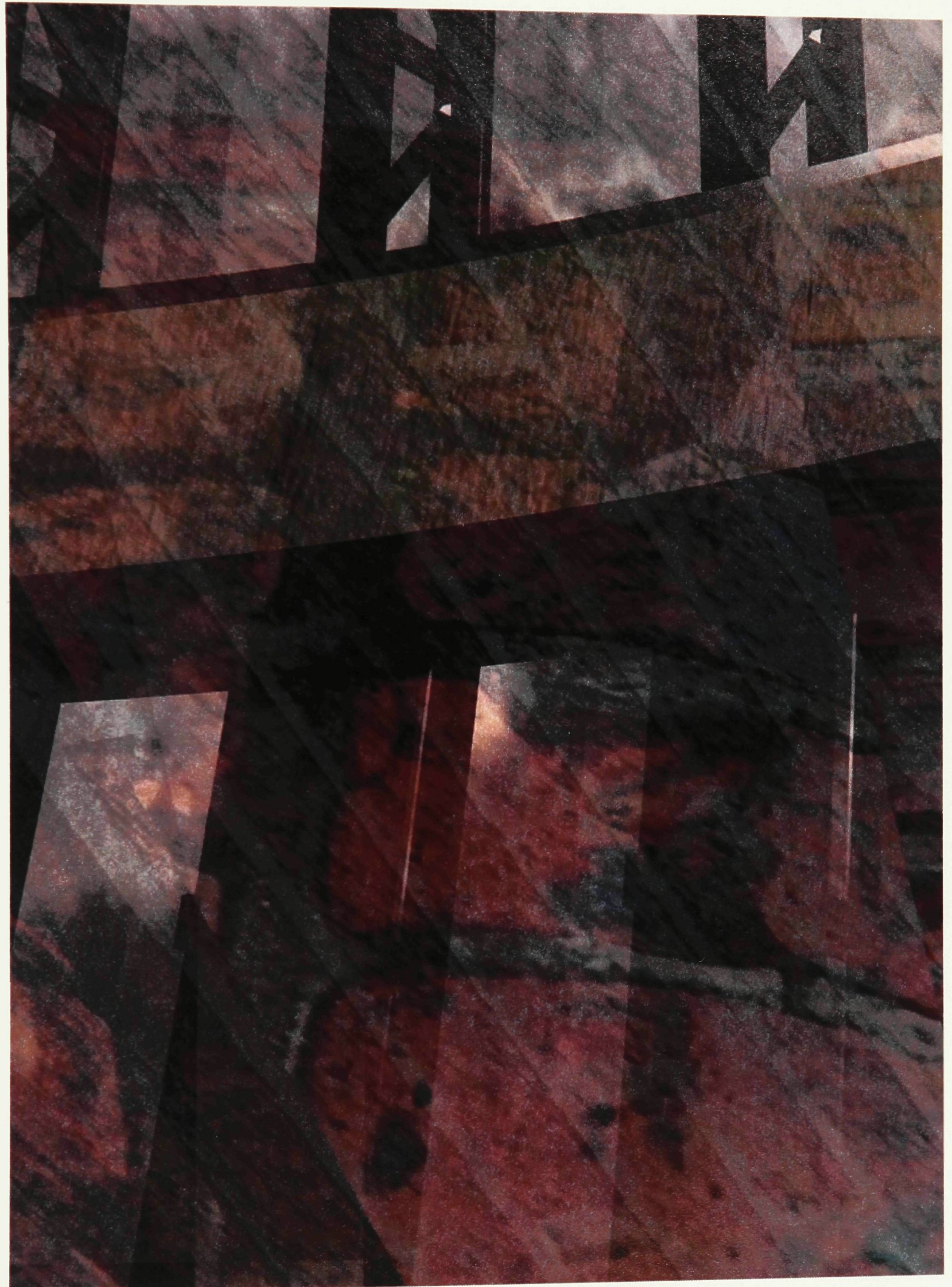

Curtain Wall Detail 5 3dStudio and Photoshop 


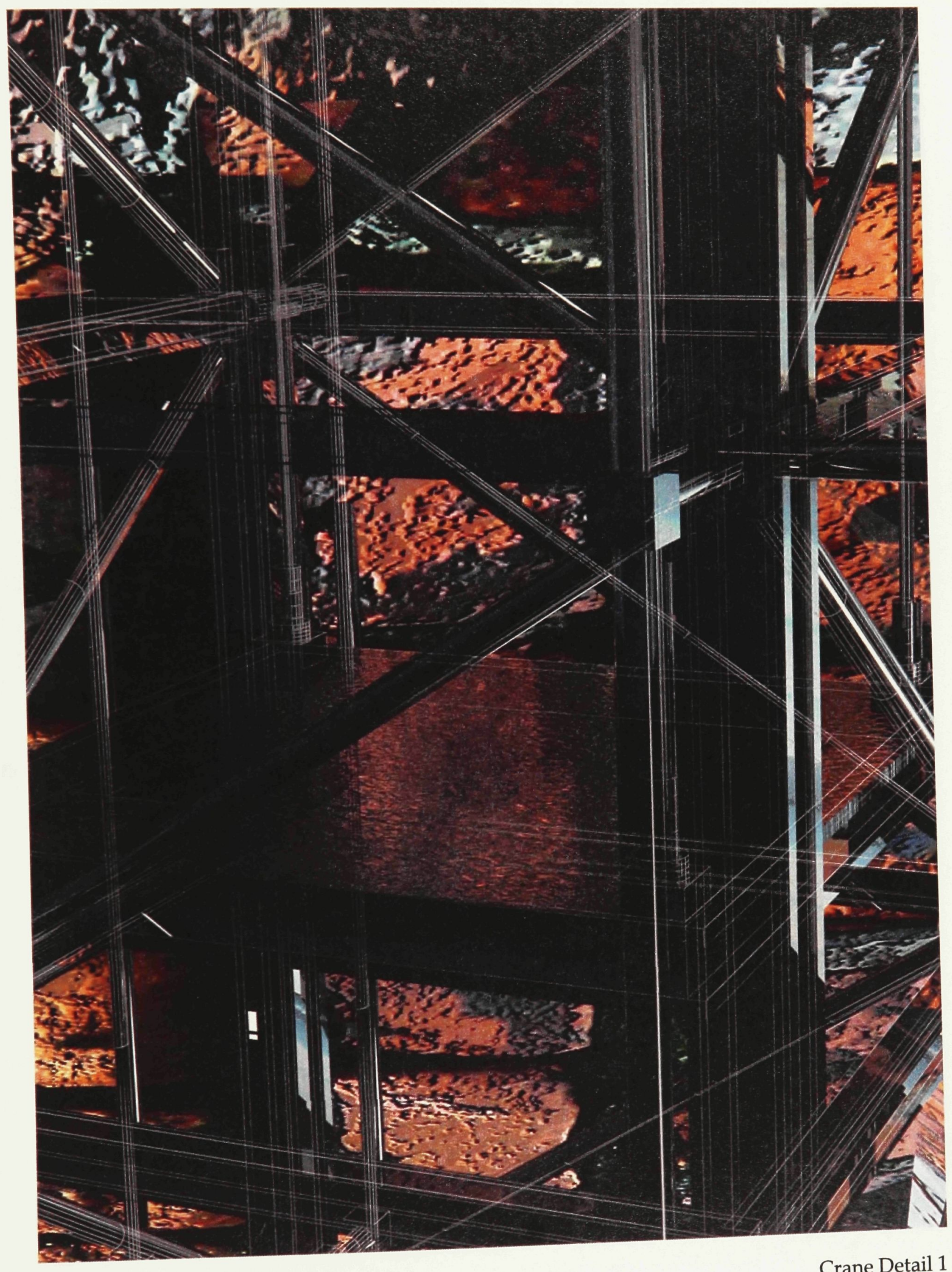




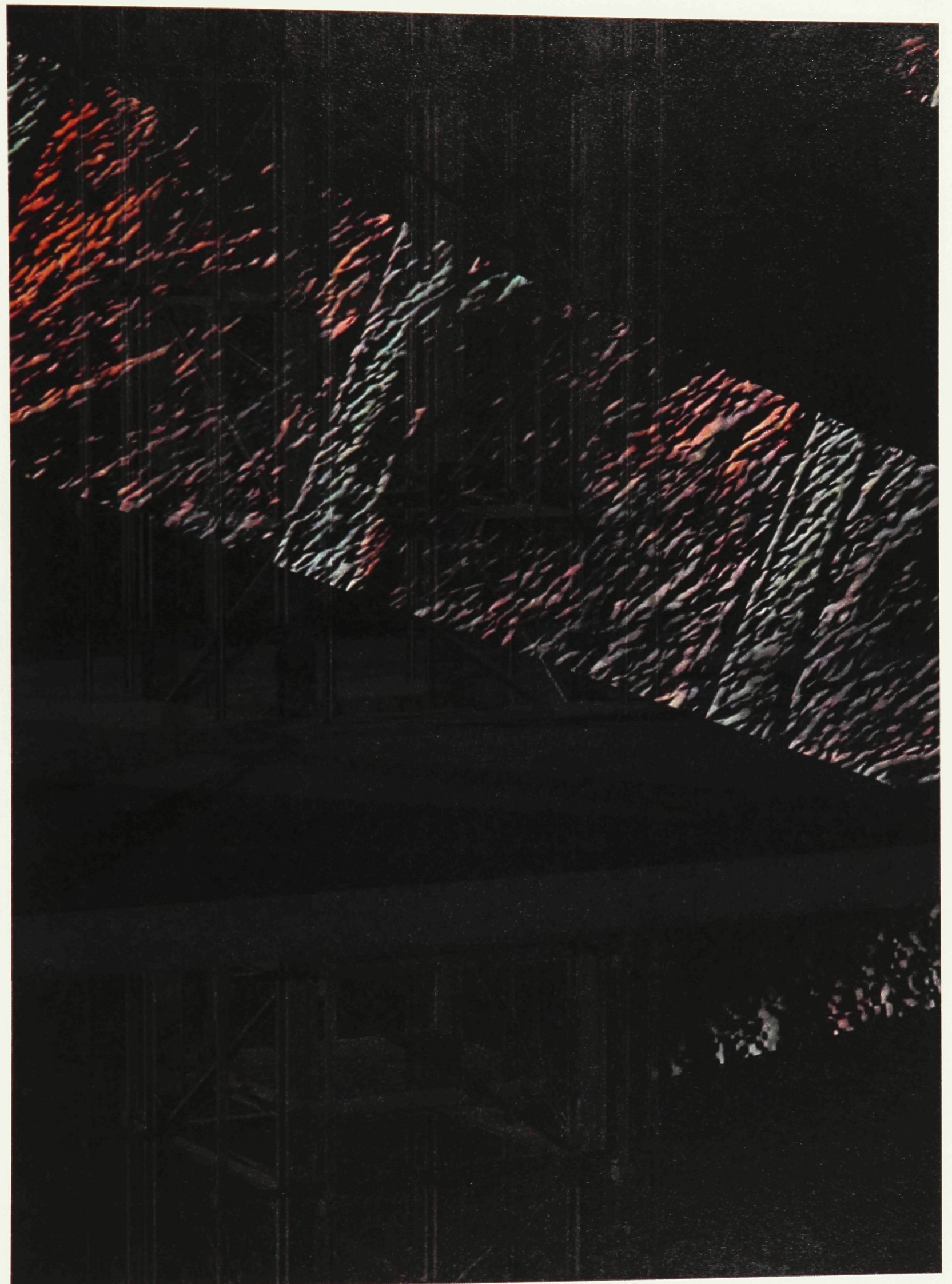

Crane Detail 2 3dStudio and Photoshop 


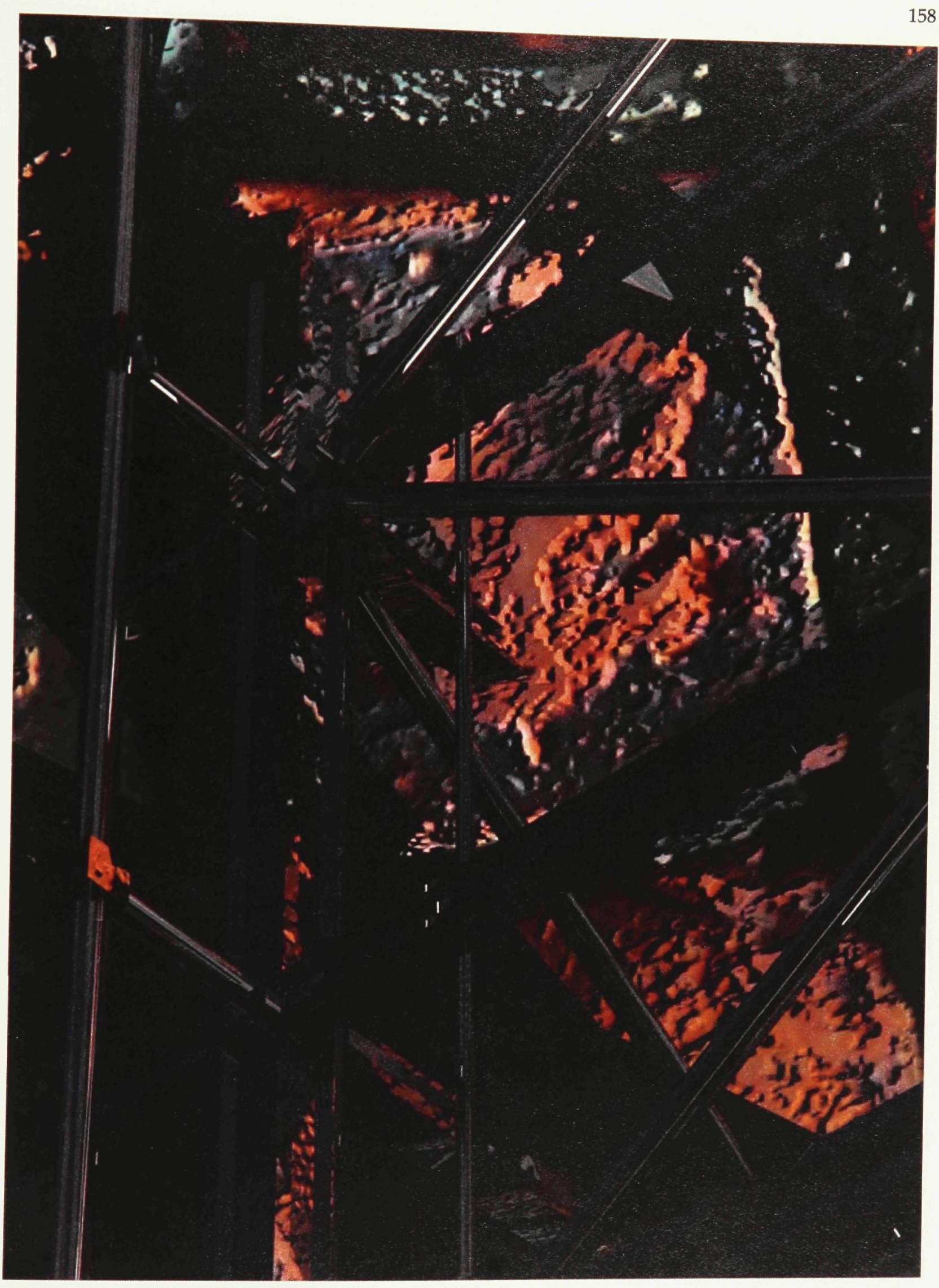

Crane Detail 3 3dStudio and Photoshop 


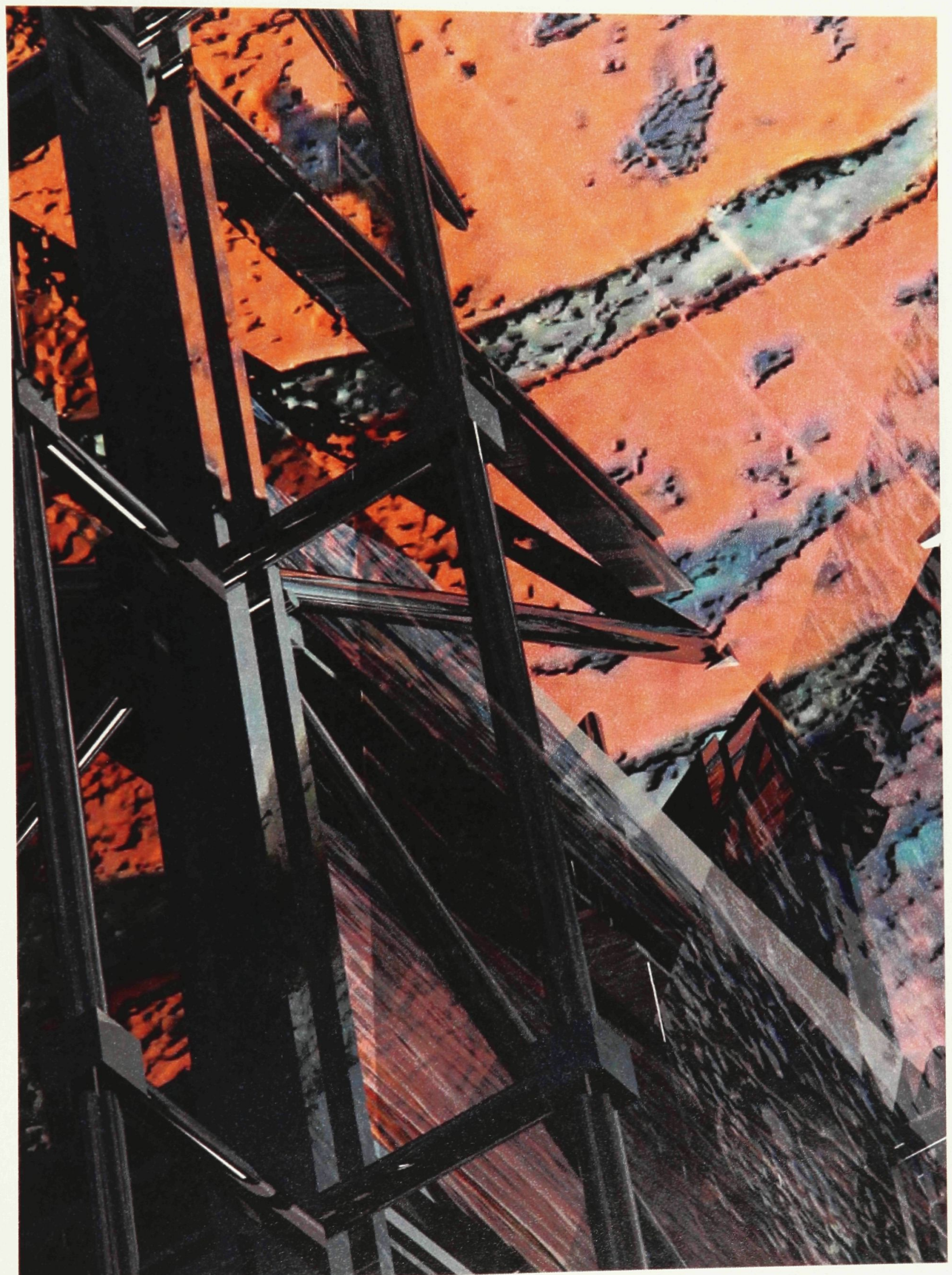

Crane Detail 4 3dStudio and Photoshop 


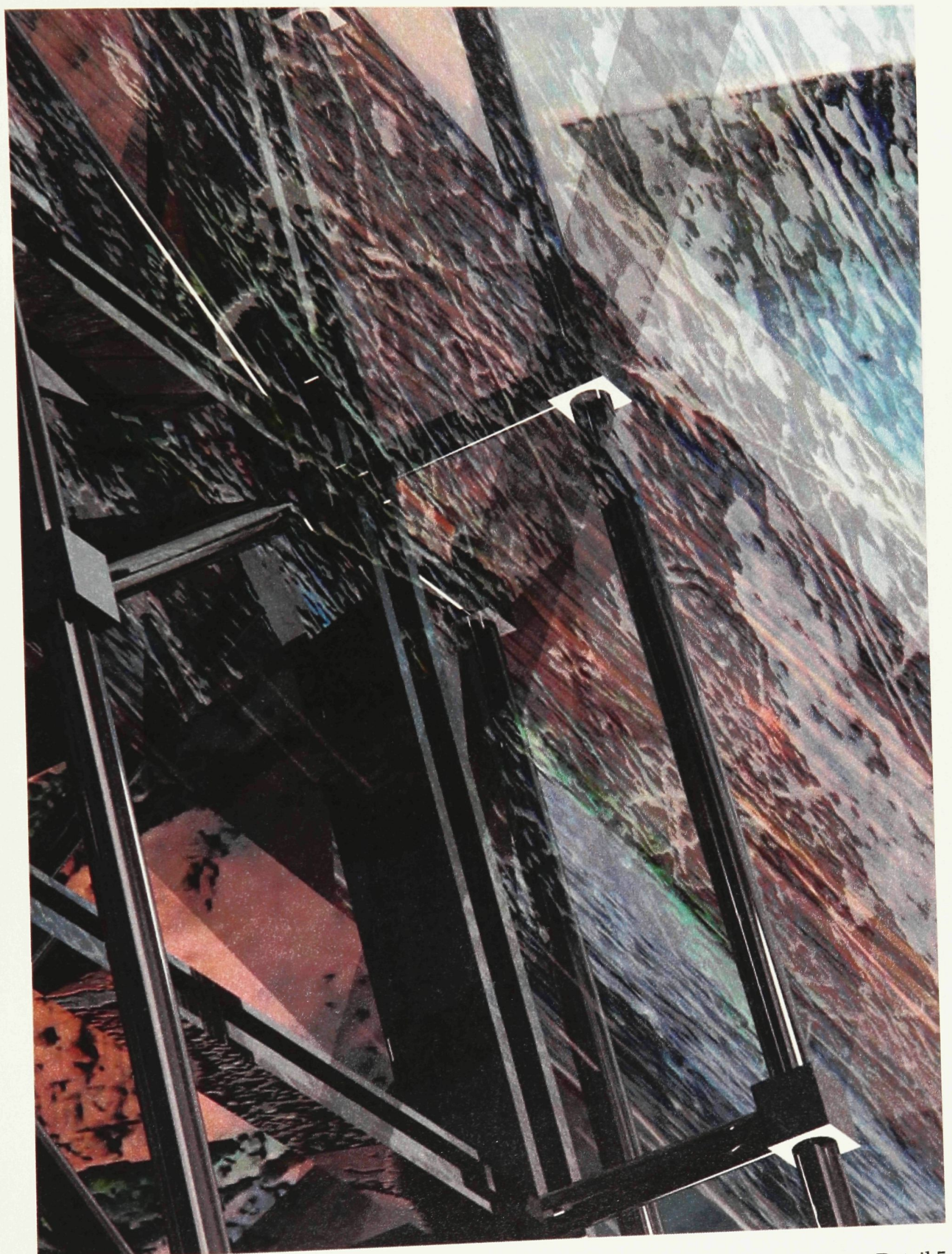

Crane Detail 5 